\title{
Current State of the Art of the Solid Rh-Based Catalyzed Hydroformylation of Short-Chain Olefins
}

\author{
Schirin Hanf ${ }^{1}\left(\mathbb{D}\right.$, Luis Alvarado Rupflin ${ }^{1}$, Roger Gläser ${ }^{2}\left(\mathbb{D}\right.$ and Stephan Andreas Schunk ${ }^{1,3, * \mathbb{C}}$ \\ 1 hte $\mathrm{GmbH}$, the high throughput experimentation company, Kurpfalzring 104, 69123 Heidelberg, Germany; \\ schirin.hanf@hte-company.de (S.H.); rupflin@gmail.com (L.A.R.) \\ 2 Institut für Technische Chemie, Fakultät für Chemie und Mineralogie, Universität Leipzig, Linnéstr. 3, \\ 04103 Leipzig, Germany; roger.glaeser@uni-leipzig.de \\ 3 BASF SE, Carl-Bosch Str. 38, 67056 Ludwigshafen, Germany \\ * Correspondence: Stephan.schunk@hte-company.de; Tel.: +49-6221-7497-111
}

Received: 22 April 2020; Accepted: 29 April 2020; Published: 6 May 2020

check for updates

\begin{abstract}
The hydroformylation of olefins is one of the most important homogeneously catalyzed processes in industry to produce bulk chemicals. Despite the high catalytic activities and selectivity's using rhodium-based homogeneous hydroformylation catalysts, catalyst recovery and recycling from the reaction mixture remain a challenging topic on a process level. Therefore, technical solutions involving alternate approaches with heterogeneous catalysts for the conversion of olefins into aldehydes have been considered and research activities have addressed the synthesis and development of heterogeneous rhodium-based hydroformylation catalysts. Different strategies were pursued by different groups of authors, such as the deposition of molecular rhodium complexes, metallic rhodium nanoparticles and single-atom catalysts on a solid support as well as rhodium complexes present in supported liquids. An overview of the recent developments made in the area of the heterogenization of homogeneous rhodium catalysts and their application in the hydroformylation of short-chain olefins is given. A special focus is laid on the mechanistic understanding of the heterogeneously catalyzed reactions at a molecular level in order to provide a guide for the future design of rhodium-based heterogeneous hydroformylation catalysts.
\end{abstract}

Keywords: heterogeneous catalysis; hydroformylation; short-chain olefins; heterogenized rhodium catalysts

\section{Introduction}

Since its discovery by Otto Roelen in 1938 [1,2], hydroformylation has become one of the most important homogeneously catalyzed processes to produce bulk chemicals, such as high-value aldehydes and alcohols [3]. Based on the initial findings of Roelen, up to now cobalt carbonyl complexes are still in use as catalysts for the hydroformylation of mid- and long-chain olefins [4]. One of the main advantages of cobalt catalysts is their robustness towards catalyst poisons in the feedstock. Most modern hydroformylation catalysts are applied to short-chain olefins $(<\mathrm{C} 5)$, however, which are comprised of far more active rhodium complexes, inspired by the Wilkinson catalyst $\left[\mathrm{RhCl}\left(\mathrm{PPh}_{3}\right)_{3}\right][5,6]$, with different types of phosphite and phosphine ligands [3]. Due to the presence of phosphorus containing ligands, the electronic and steric properties of catalysts can be tuned and a high level of understanding on a molecular level has been achieved [7-9]. Most importantly, industrial processes based on Rh hydroformylation catalysts, can be operated at much lower pressures in comparison to cobalt catalyzed hydroformylation reactions-a fact that has large implications on the economics of the process (Table 1) [10]. 
Table 1. Comparison of the industrial hydroformylation processes. TPPTS $=$ tri-(sodium-metasulfonatophenyl)-phosphine [10].

\begin{tabular}{ccccc}
\hline Catalyst & {$\left[\mathrm{Co}(\mathrm{CO})_{4} \mathbf{H}\right]$} & {$\left[\mathbf{C o}\left(\mathbf{P B u}_{3}\right)(\mathbf{C O})_{3} \mathbf{H}\right]$} & {$\left[\mathbf{R h}\left(\mathbf{P P h}_{3}\right)_{3}(\mathbf{C O}) \mathbf{H}\right]$} & {$\left[\mathbf{R h}(\mathrm{TPPTS})_{3}(\mathbf{C O}) \mathbf{H}\right]$} \\
\hline $\mathrm{T}[\mathrm{K}]$ & $383-457$ & $433-473$ & $358-388$ & $323-423$ \\
$\mathrm{p}[\mathrm{MPa}]$ & $20-35$ & $3-10$ & $1.5-2$ & $1-10$ \\
n:iso & 4 & 7.3 & 11.5 & 19 \\
Olefins & $\mathrm{C}_{2}-\mathrm{C}_{20}$ & Long-chain olefins & Small-chain olefins & Small-chain olefins \\
Process & Ruhrchemie BASF & Shell & Low Pressure Oxo & Ruhrchemie/Rhone \\
& Kuhlmann & & & Polenc \\
\hline
\end{tabular}

As mentioned before, ligand design allows a facile modification of the catalyst. The resulting catalyst properties regarding activity and selectivity behavior can be altered and adapted to process demands or demands of the specific chemistry involved [11]. Selectivity in the context of this review refers to side reactions, such as hydrogenation, isomerization and aldol condensation reactions, but most importantly to the regioselectivity, since during the hydroformylation of terminal olefins, linear $(n)$ and branched (iso) aldehydes can be obtained (Scheme 1). The aldehyde products that can be obtained through "oxo-chemistry" are valuable products for the synthesis of bulk chemicals, e.g., alcohols, esters and amines, and depending on the application, linear [12,13] or branched [14] aldehydes are more preferred. From this perspective the need of highly selective hydroformylation catalysts can we well understood. Most elegant solutions are catalyst systems that allow altering of the $n / i s o$ ratio depending on the reaction conditions and/or adjustable processes depending on the reaction conditions $[15,16]$.

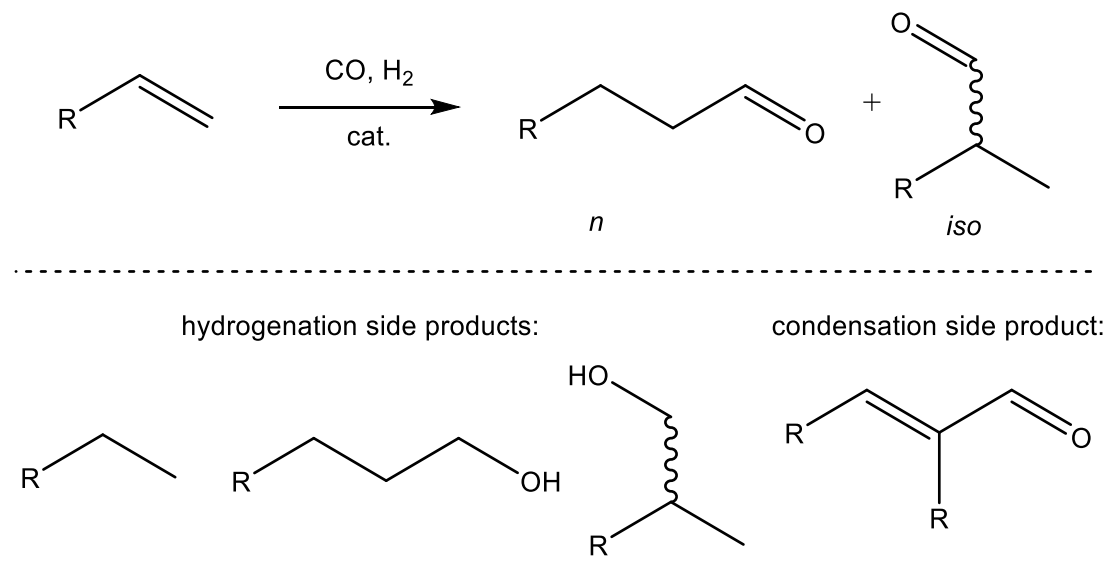

Scheme 1. Hydroformylation of an olefin leading to the formation of a $n$ and an iso aldehyde and the formation of hydrogenation and aldol condensation side products.

A major point in the context of selectivity, which is in our opinion often not discussed in the open literature, is the thermodynamic limitation of the hydroformylation reaction. As seen in Figure 1, which shows the equilibrium conversion of propylene to the corresponding aldehydes at a molar inlet composition $\mathrm{H}_{2} / \mathrm{CO} /$ propylene $=1: 1: 1$, hydroformylation is highly selective at low temperatures and selectivity can be improved for a given temperature by elevated pressures. Additionally, from the equilibrium curves it becomes obvious that iso-butanal is thermodynamically preferred over the $n$ isomer, with the $n /$ iso ratio being temperature dependent (Figure 2) [17]. Another point to mention in the context of selectivity is the fact that the most dominant side reaction, namely the hydrogenation of the olefin to the corresponding alkane, is thermodynamically preferred over the hydroformylation reaction, which explains the need for highly selective hydroformylation catalysts. 
a)

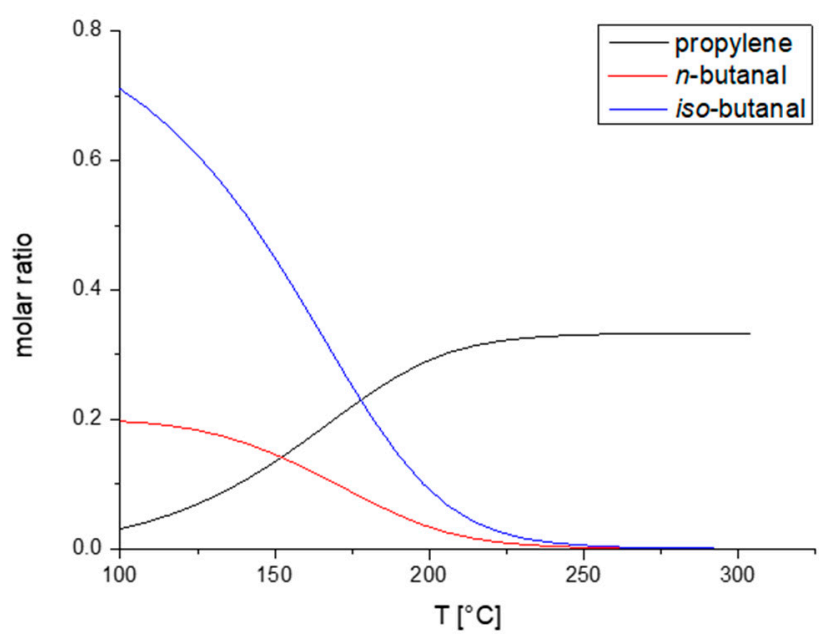

b)

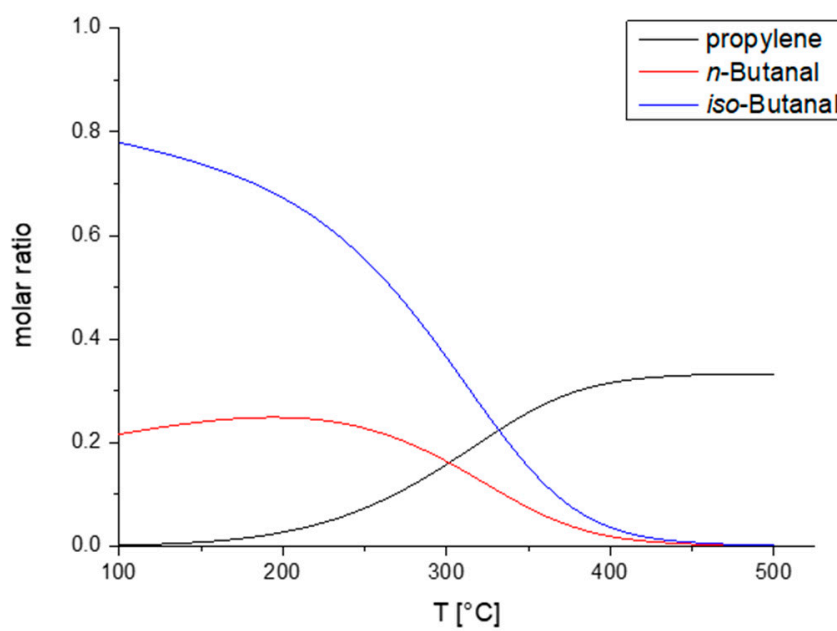

Figure 1. Hydroformylation of propylene at 1 bar (a) and 100 bar (b) with a molar inlet composition of $\mathrm{H}_{2} / \mathrm{CO} /$ propylene $=1: 1: 1$. Propylene equilibrium conversion and $n /$ iso distribution of butanal.

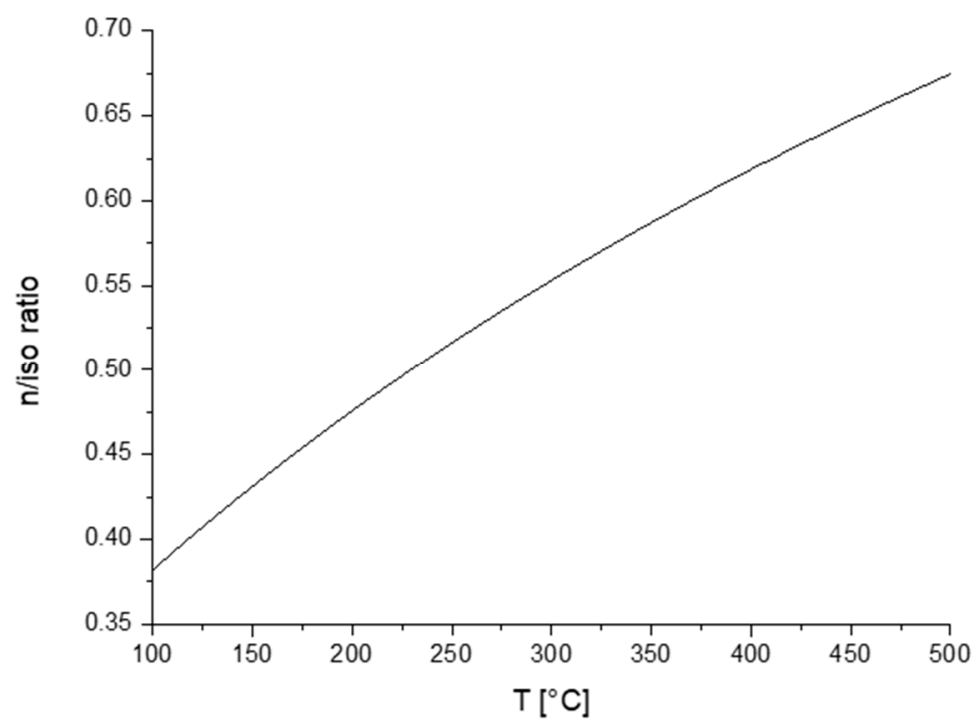

Figure 2. Calculated $n$-butanal/iso-butanal ratio at 100 bar with a molar inlet composition of $\mathrm{H}_{2} / \mathrm{CO} /$ propylene $=1: 1: 1$ depending on the reaction temperature. 
Although high chemoselectivity in the light of the hydroformylation reaction can already be achieved through the use of a variety of homogeneous hydroformylation catalysts, the technical hurdles involved with catalyst recovery and recycling of metal and ligand from the reaction mixture are a major hurdle in the technical implementation [18]. The term chemoselectivity refers hereby to the selectivity towards hydroformylation products. Since catalyst losses, especially precious metal losses, must be avoided even in the ppm range, technical solutions involving heterogeneous hydroformylation catalysis, with the catalyst being in the solid phase and the reactants and products in the gas or liquid phase, have attracted significant attention.

In this review we cover the progress made in the area of the heterogenization approaches in the field of rhodium catalysts with the aim of developing stable, active and selective hydroformylation catalysts from the 1970s up to now. An overview of different approaches for obtaining useful Rh-based materials is given and recent developments in their application are discussed to show the potentials and limitations of this not yet commercial process technology. Hereby, the focus of this article is on the hydroformylation of short-chain olefins in the gas phase. The advantage of this focus on gas-solid reactions lies in the fact that via proper experimental setup, condensed educts or products on the catalyst surface can be avoided. We assume that therefore, a clearer picture of the reaction mechanism and the underlying kinetics can be obtained, both of which are a major aspect discussed in this review.

\section{Mechanistic Considerations}

In order to control the chemo- and regio-selectivity of rhodium catalyzed hydroformylation reactions, a detailed mechanistic understanding is crucial. Therefore, we discuss the current state of the discourse in the well-studied field of homogeneous catalysis to gain a better understanding and abstract which factors may also play a role in heterogeneous hydroformylation reactions.

The generally accepted dissociative hydroformylation mechanism for the formation of the linear $n$-aldehydes using homogenous Rh based catalysts is shown in Figure 3 [19]. Through the loss of $\mathrm{CO}$ from the pre-catalyst complex $\left[\mathrm{HRh}(\mathrm{L})_{2}(\mathrm{CO})_{2}\right](\mathrm{L}=$ phosphine ligand or $\mathrm{CO})$, in-situ the electron-deficient 16-electron $\left[\mathrm{HRh}(\mathrm{L})_{2}(\mathrm{CO})\right]$ complex is formed. Whether mono- $\left[\mathrm{HRh}(\mathrm{L})(\mathrm{CO})_{2}\right]$ or disubstituted complexes $\left[\mathrm{HRh}(\mathrm{L})_{2}(\mathrm{CO})\right]$ are the catalytically active species depends strongly on the nature of the phosphine ligand and is still matter of discussion and ongoing research. However, kinetic modelling using $\mathrm{PPh}_{3}$ under industrial conditions, suggests that the dominating catalytically active species are monosubstituted by the phosphine ligand [20]. Olefin coordination occurs via TS-1 (TS = transition state), which is thermodynamically favored through decreasing basicity of the phosphine ligands [21]. This step is followed by hydrometallation towards the branched or the linear alkyl complex 4 . The formation of the alkyl complex is considered as the regioselectivity determining step, as the the $n /$ iso ratio is influenced by the steric and electronic properties of the catalyst and the substrate $[11,22]$. Since the carbon atom of the substrate coordinated to Rh has a partially negative charge, the electronic character of the organic groups bound to it either stabilize the branched or the linear isomer. Whereas $\mathrm{R}$ groups with $\pi$-accepting character, such as aryl and alkoxy groups, can stabilize the charge distribution better for the branched alkyl intermediates, $\sigma$ donating groups, such as alkyl groups, lead to the stabilization of the linear alkyl species [22]. The alkylation is followed by $\mathrm{CO}$ coordination and leads to the formation of the saturated complex [(Alkyl)Rh $\left.(\mathrm{L})_{2}(\mathrm{CO})_{2}\right](5)$, which is then acylated via TS-3 and results in the formation of 6 . Depending on the CO pressure, 6 can be converted into the resting state 7 , which is also considered as a dead end with respect to the catalytic reaction. However, 6 can also undergo oxidative addition of hydrogen to yield 8 . The reductive elimination via TS-5 leads to the product formation and the regeneration of the catalytically active complex 2.

The oxidation states of the rhodium center and the corresponding coordination geometries during the catalytic hydroformylation cycle are depicted in Scheme 2. During the catalytic cycle a shuffle between $\mathrm{Rh}^{\mathrm{I}}$ and $\mathrm{Rh}{ }^{\mathrm{III}}$ occurs and coordination numbers of 4 (square planar geometry), 5 (trigonal bipyramidal geometry) and 6 (octahedral geometry) have been determined. 


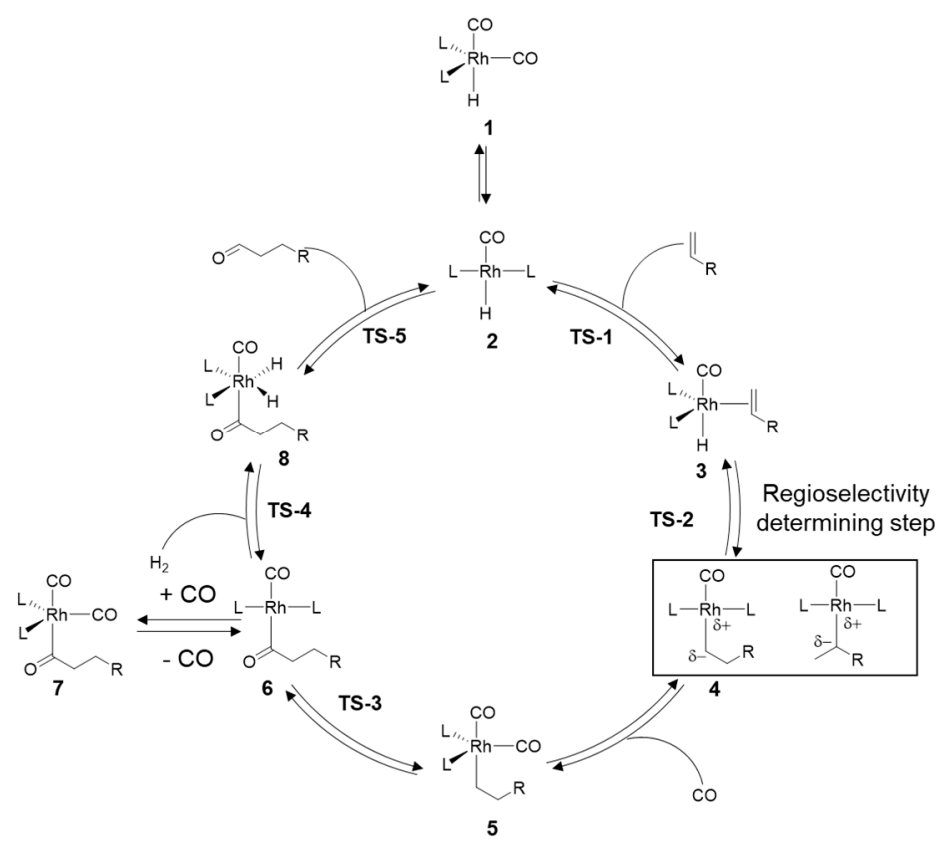

Figure 3. Generally accepted dissociative hydroformylation reaction mechanism for the formation of the linear $n$-aldehyde.
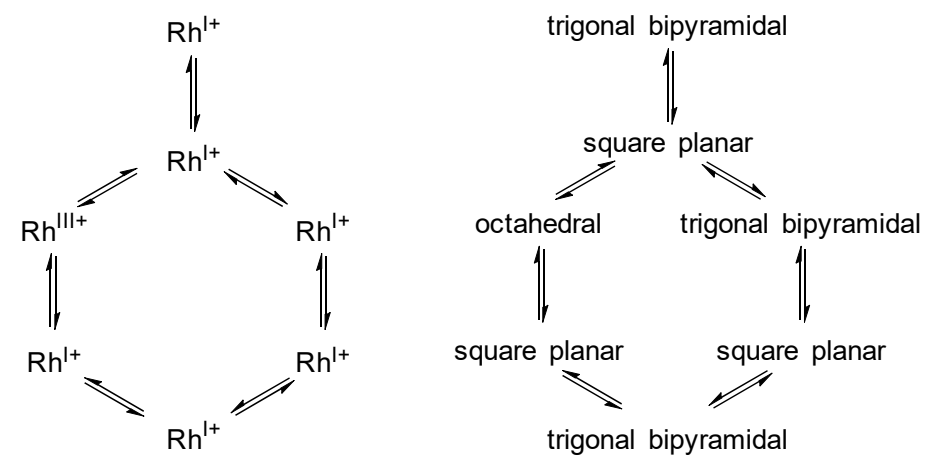

Scheme 2. Catalytic cycle of the hydroformylation and the corresponding rhodium oxidation states (left) and coordination geometries around the metal center (right).

In hydroformylation reactions generally two types of formal kinetics are topics of discussion. Whereas in "type-1" kinetics, $\mathbf{1}$ is regarded as the resting state and TS-1 or TS- $\mathbf{2}$ as the rate determining transition state, in "type-2" kinetics 6 is referred to as the resting state and TS-4 is assumed to be the rate determining transition state. For "type-1" kinetics a first order dependency of the reaction rate on the olefin concentration and an inverse first order dependency concerning the $\mathrm{CO}$ partial pressure are characteristic. In "type-2" kinetic reactions, there is a first order dependency on the hydrogen concentration [23].

Theoretical investigations of the hydroformylation of ethylene using $\left[\mathrm{HRh}(\mathrm{CO})_{3} \mathrm{~L}\right]\left(\mathrm{L}=\mathrm{P}(\mathrm{OMe})_{3}\right.$, $\mathrm{P}(\mathrm{OPh})_{3}, \mathrm{PMe}_{3}, \mathrm{PPh}_{3}$ or a $\mathrm{N}$-heterocyclic carbene) have shown the dependency of the rate determining step on the nature of the ligand coordinating the rhodium metal center (Figure 4). In agreement with experimental results, it could be verified via theoretical models that for electron donating ligands the rate determining step is the olefin coordination/insertion, whereas for electron withdrawing or good $\pi$-acceptor ligands the rate determining step was identified to be the hydrogenolysis. This is due to the dependency of the olefin insertion on the donor properties of the ligand. A high energy barrier was computed for $\sigma$-donating phosphines, whereas $\pi$-accepting ligands were found to have lower energy barriers for olefin insertion [24]. 


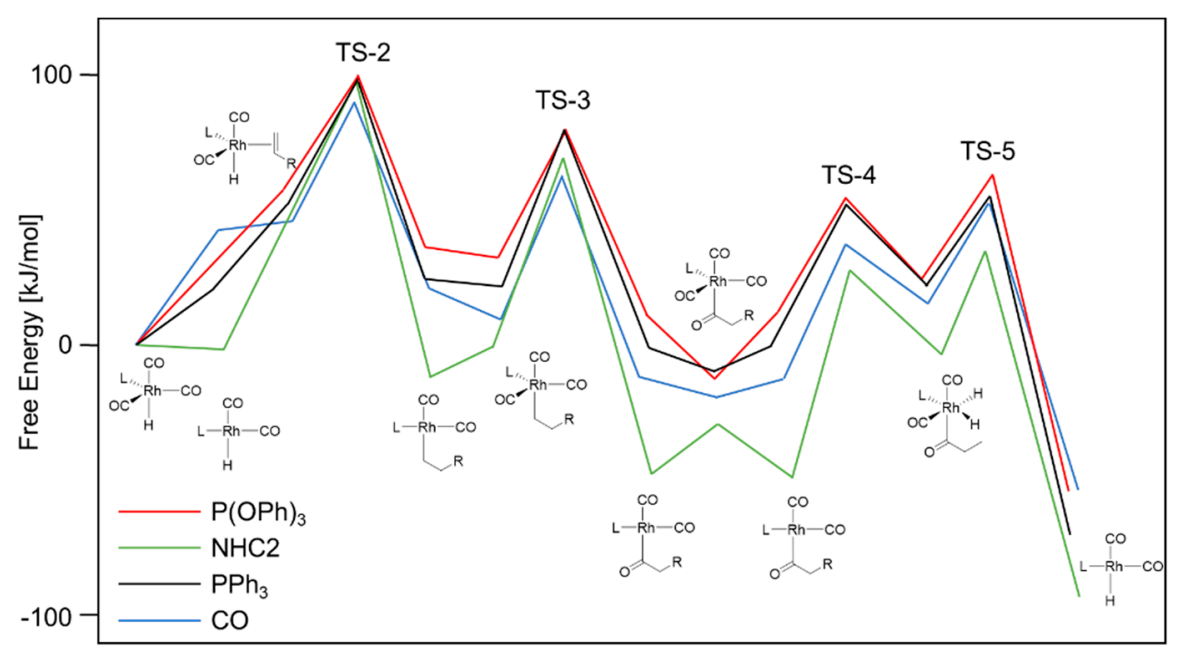

Figure 4. Free energy profile of hydroformylation of ethylene catalysed by $\left[\mathrm{HRh}(\mathrm{CO})_{3} \mathrm{~L}\right] . \mathrm{NHC2}=$ 1,3-dimethyl-2,3-dihydro-1H-imidazole. Graphic adapted from Sparta et al [24].

In contrast to the classical views on the formal hydroformylation kinetics and the determination of a single rate determining step, recent studies using a self-assembling 6-diphenylphosphinopyridone ligand by Gellrich et al. have shown, that not only one decisive step governs the hydroformylation reaction. Gellrich et al. could show that several intermediates and transition states control the apparent reaction rate and the selectivity. Moreover in the most extended scheme of the authors 24 species were reported to play a role, with CO being included as ligating species in five of them $[25,26]$. This complex interplay of kinetic and thermodynamic factors was also reported by Gleich and Hutter based on static and dynamic quantum-mechanical approaches [27]. It is therefore very challenging to postulate a generalized catalytic cycle and to exactly pinpoint the rate determining step, due to the fact that hydroformylation reactions are also extremely sensitive towards to the catalyst structure, the reactions conditions and the nature of the olefin substrate and finally also on a technical scale the impurity level of the technical process involved [28].

However, based on the literature several common crucial requirements for a homogeneous Rh hydroformylation catalyst can be summarized:

- The catalytically active species is an in-situ formed unsaturated 16e- Rh hydride complex

- At least one CO ligand must be present within the catalytically active Rh complex

- The coordination number around the Rh center alters between 4 and 6 within the catalytic cycle

- A change in oxidation state of the Rh center from +I to +III (and back to +I) occurs during the catalytic cycle

\section{Heterogenization of Rh Hydroformylation Catalysts}

With the aim to combine the activity and selectivity of molecular hydroformylation catalysts and the advantages in terms of catalyst stability and eased recovery, research has been directed towards heterogenized rhodium hydroformylation catalysts. We developed a scheme to group the different efforts made which is summarized in Figure 5. The attempts can be roughly divided into four categories, namely the deposition of molecular rhodium complexes, metallic rhodium nanoparticles and single-atom catalysts on a solid support as well as rhodium complexes present in supported liquids.

The first reports tackling the heterogenization of catalysts with respect to hydroformylation reactions included the deposition of molecular rhodium complexes, such as metal carbonyl complexes, on metal oxides as support materials. This approach has been reviewed perfectly by Lenarda et al. in 1996, showing the progresses made in this field and the challenges that have been encountered, such as the low catalytic activity of the materials and the leaching of $\mathrm{Rh}$, especially when applied in 
liquid phase catalysis [29]. In subsequent publications also the deposition of metallic nanoparticles and modified metallic nanoparticles on solid supports has been investigated. Although the supported metal nanoparticles do not show leaching of Rh only low activities and selectivity's have been achieved. In this context, also so-called "single-atom" catalysts and supported rhodium phosphides have attracted a great deal of attention in the hydroformylation community. A completely different approach reported has been pursued by the coverage and stabilization of molecular rhodium phosphite and phosphine complexes onto solid support materials via embedding in ionic liquids.

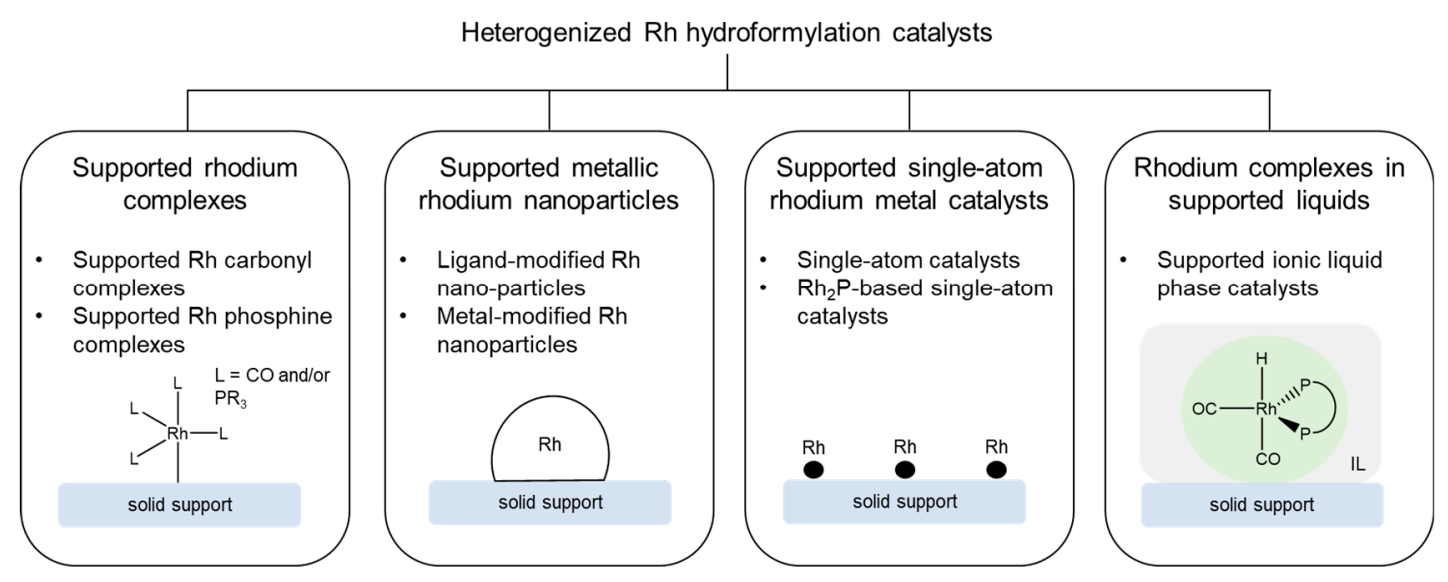

Figure 5. Different approaches for the synthesis of heterogenized rhodium-based hydroformylation catalysts.

In this review the recent advances in the heterogenization of homogeneous rhodium catalysts are presented with a focus is being laid on the four different approaches mentioned before (Figure 5). The current developments concerning porous organic ligand-supported catalysts will not be discussed in the context of this review [30,31].

\subsection{Supported Rhodium Complexes}

As mentioned before, early attempts in the heterogenization of hydroformylation catalysts were based on molecular metal complexes immobilized to a solid support system and an overview of the efforts made in this field was given by Neves et al. [32]. Suitable supports must exhibit a high chemical, thermal and mechanical stability as well as an appropriate surface area and/or fitting pore size in order to ensure efficient substrate diffusion and to avoid mass transport limitations.

In order to immobilize molecular rhodium complexes on a solid support different approaches can be utilized (Figure 6). Covalent/coordinative bonding is the most frequently pursued approach, since strong complex-support interactions are formed. Hereby the linkage can occur between the support and ligand, or the support and the rhodium center. In addition, both parts can be connected to a solid support [33]. Since the covalent/coordinate linkage requires a special functionalization of the ligand or the support, which is synthetically demanding, non-covalent approaches have attracted great deal of attention. In this context the immobilization via electrostatic interactions is a common and conceptually simple technique, in which the ionic catalytically active species is attached to anionic or cationic supports, such as ion exchange resins, inorganic clays and zeolites. A drawback of this method is the competition with other ionic species present in the reaction mixture, which lead to catalyst leaching. Another facile immobilization method is the adsorption of catalytically active species on a solid support. However, due to the weak van-der-Waals interactions, catalyst instability can be a problematic topic to be solved. Finally, metal complexes can be entrapped in the pores of a solid support. Using this approach, special attention must be paid towards the size of the metal complex and the substrate relative to the pores of the support, in order to achieve acceptable anchoring properties and still avoiding mass transport limitations [34]. 


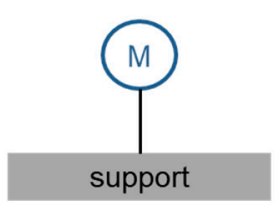

a) Covalent or coordinative bond

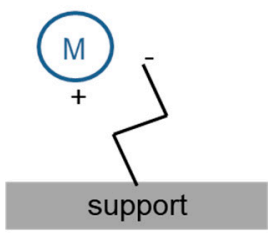

b) Electrostatic interaction

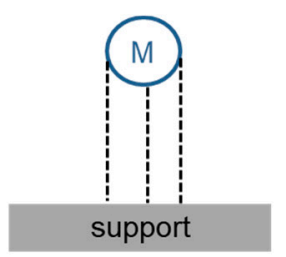

c) Adsorption

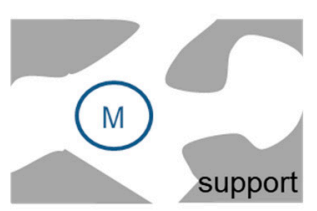

d) Entrapment

Figure 6. Strategies to introduce catalytically active transition metal complexes onto solid supports via (a) a covalent bond between an organic linker or a coordinative bond between the metal of the complex and the support, (b) electrostatic interactions, (c) adsorption or (d) entrapment of the metal complex in a porous material.

\subsubsection{Supported Rhodium Carbonyl Complexes}

In the past a number of groups have pursued the strategy of attachment of metal carbonyl complexes on solid support materials via impregnation or reactive deposition; good examples are known from the group of Ichikawa [35-37]. Such catalysts have been investigated the gas phase hydroformylation of ethylene and propylene, with catalysts derived from Rh and Co carbonyl complexes supported on metal oxides. It was shown that higher turnover frequencies (TOFs, throughout the review the turnover frequency is given in $\mathrm{mol}_{\text {aldehyde }} \cdot \mathrm{h}^{-1} \cdot \mathrm{mol}^{-1} \mathrm{Rh}$; hereby, the total rhodium amount within the catalysts is considered) were obtained for supported $\mathrm{Rh}$ carbonyl complexes, such as $\mathrm{ZnO}, \mathrm{MgO}$, $\mathrm{TiO}_{2}, \mathrm{La}_{2} \mathrm{O}_{3}$, compared to carbonyl complexes attached to $\mathrm{SiO}_{2}$ and $\mathrm{Al}_{2} \mathrm{O}_{3}$. While the specific rates for propylene hydroformylation could be achieved with $\left[\mathrm{Rh}_{4}(\mathrm{CO})_{12}\right] / \mathrm{ZnO}\left(\mathrm{w}_{\mathrm{Rh}}=0.28 \mathrm{wt} \%, \mathrm{~T}=431 \mathrm{~K}\right.$, $\left.\mathrm{p}=7.8 \mathrm{MPa}, \mathrm{C}_{3} \mathrm{H}_{6}: \mathrm{CO}: \mathrm{H}_{2}=9: 9: 10\right)$ where as high as $2.1 \mathrm{~h}^{-1}$ that, only a specific rate of formation of $0.04 \mathrm{~h}^{-1}$ could be achieved with the silica supported catalyst $\left[\mathrm{Rh}_{4}(\mathrm{CO})_{12}\right] / \mathrm{SiO}_{2}\left(\mathrm{w}_{\mathrm{Rh}}=2.24 \mathrm{wt} \%\right.$, $\mathrm{T}=428 \mathrm{~K}, \mathrm{p}=7.8 \mathrm{MPa}, \mathrm{C}_{3} \mathrm{H}_{6}: \mathrm{CO}: \mathrm{H}_{2}=9: 9: 10$ ). The authors explain this finding in the light of the acidity/basicity of the support materials. They propose a scheme that according to which the metal carbonyl complexes supported on silica or alumina lose their cluster structure and the low valent oxidation state due to strong interactions with the acidic surfaces of the supports [35]. Looking at the points of zero charges for the reported metal oxides [38], it can be debated whether this correlation of the catalytic activity with the acid/base properties of the support materials is self-evident.

Huang et al. investigated the catalytic activity of carbonyl complexes derived rhodium catalysts in hydroformylation and hydrogenation reactions on a very detailed level [39]. A key finding of the study was the dependency of the specific activity as function of rhodium dispersion. It could be shown that ethylene hydroformylation appears to be structure sensitive whereas ethylene hydrogenation is structure insensitive. This structural dependency and comprehensive IR spectroscopic studies led to the conclusion that $\mathrm{Rh}^{0}$ is active site for the hydroformylation reaction. In this context, Huang et al. also examined the rhodium interactions with the silica surface. Using IR spectroscopy, it could be shown that $\mathrm{Rh}$ is partially oxidized to $\mathrm{Rh}^{+}$by the acidic $\mathrm{OH}^{-}$groups of partially dehydroxylated silica (Equation (1). An obvious conclusion made is that the more dispersed the metal centers are, the easier the oxidation takes place. This can be explained by the fact, that the surface-particle interaction is restricted to their interface only and by the limited number of $\mathrm{OH}^{-}$groups around a $\mathrm{Rh}$ particle [39].

$$
2 \mathrm{Rh}^{0}+2 \mathrm{H}^{+} \rightarrow 2 \mathrm{Rh}^{+}+\mathrm{H}_{2}
$$

Of course, this finding appears contradictory to the assumption made that $\mathrm{Rh}^{0}$ is the catalytically active rhodium species. The authors argue that the rhodium centers are only partially oxidized and that under hydroformylation reaction conditions only $\mathrm{Rh}^{0}$-adsorbed $\mathrm{CO}$ can be monitored by IR spectroscopy. Studies by Basu et al. support this assumption, since the group delivered evidence for the inverse reaction of Equation (1) to take place if hydrogen is present. Therefore, hydrogen is thought to quench the surface-induced oxidation of $\mathrm{Rh}^{0}$ to $\mathrm{Rh}^{+}$[40]. 
As part of these investigations also the role of the $\mathrm{CO}$ coordination was elaborated and discussed. Whereas linear $\mathrm{CO}$ adsorbed on $\mathrm{Rh}$ was consumed during the formation of propanal from ethylene, the coordinated $\mathrm{CO}$ molecules in $\left[\mathrm{Rh}_{6}(\mathrm{CO})_{16}\right] / \mathrm{SiO}_{2}$ did not participate in $\mathrm{CO}$ insertion. Furthermore, analytical evidence points to the fact that the catalytic activity of the $\left[\mathrm{Rh}_{6}(\mathrm{CO})_{16}\right] / \mathrm{SiO}_{2}$ catalyst can be increased with a reduced number of coordinating $\mathrm{CO}$ molecules (induced by heat treatment under vacuum), which demonstrates the need for unsaturated Rh centers during the hydroformylation reaction [39]. This observation would be in complete agreement with the dissociative reaction mechanism in homogenously catalyzed hydroformylation reactions.

Besides the use of monometallic Rh carbonyl complexes as precursors for deposition, also bimetallic catalysts have been used and investigated. Ichikawa et al. for example examined the incorporation bimetallic Rh-Co cluster-derived catalysts on a NaY-zeolite support for the hydroformylation of ethylene and propylene. It was shown that that the $n /$ iso aldehyde ratio could be enhanced depending on the presence of cobalt; a possible explanation is given by the electron donating effect of the cobalt, which stabilizes the linear rhodium alkyl complex critical for the formation of the $n$-product 4 [35]. In the context of bimetallic catalysts, $\mathrm{Rh} / \mathrm{Fe}$ carbonyl complexes, such as $\left[\mathrm{NMe}_{2}\left[\mathrm{FeRh}{ }_{4}(\mathrm{CO})_{15}\right]\right.$, [TMBA] $\left[\mathrm{FeRh}_{5}(\mathrm{CO})_{16}\right]$ $\left(\mathrm{TMBA}=\right.$ trimethyl benzylammonium), $[\mathrm{TMBA}]_{2}\left[\mathrm{Fe}_{2} \mathrm{Rh}_{4}(\mathrm{CO})_{16}\right]$ and $\mathrm{Fe}_{3} \mathrm{Rh}_{2}(\mathrm{CO})_{14} \mathrm{C}$ have been in the center of interest as precursors for supported catalyst materials (NaY-Zeolite [36] and $\mathrm{SiO}_{2}$ [37] as supports) in the hydroformylation of propylene. It has been shown that catalysts prepared from [TMBA $]_{2}\left[\mathrm{Fe}_{2} \mathrm{Rh}_{4}(\mathrm{CO})_{16}\right]$ precursors impregnated on $\mathrm{SiO}_{2}$ exhibit a very high specific rate for aldehyde formation $\left(5.04 \mathrm{~h}^{-1}\right)$. In contrast, the tetranuclear rhodium precursor $\left[\mathrm{Rh}_{4}(\mathrm{CO})_{12}\right]$ supported on $\mathrm{SiO}_{2}$ shows only half the rate of $2.28 \mathrm{~h}^{-1}$ under the same reaction conditions $\left(\mathrm{w}_{\mathrm{Rh}}=0.5 \mathrm{wt} \%, \mathrm{~T}=437 \mathrm{~K}\right.$, $\mathrm{p}=1.0 \mathrm{MPa}, \mathrm{C}_{3} \mathrm{H}_{6}: \mathrm{CO}: \mathrm{H}_{2}=1: 1: 1, \mathrm{GHSV}=670 \mathrm{~h}^{-1}$ ). The higher specific rate of aldehyde formation was explained by the presence of the iron centers, or more precisely the presence of contiguous Rh-Fe units, on the catalyst surface. From IR-spectroscopic data, it could be concluded that the electropositive $\mathrm{Fe}^{3+}$ cations adjacent to atoms of noble metals such as $\mathrm{Rh}$, form bimetallic sites, e.g., $\mathrm{Rh}-\mathrm{Fe}^{3+}-\mathrm{O}$, which are claimed to enhance the migratory CO insertion into the Rh-alkyl bond [37].

Further investigations of the hydroformylation of ethylene and propylene with $\mathrm{SiO}_{2}$-supported bimetallic carbonyl complexes, e.g., $\left[\mathrm{RhCo}_{3}\left(\mathrm{CO}_{12}\right)\right],\left[\mathrm{Rh}_{2} \mathrm{Co}_{2}\left(\mathrm{CO}_{12}\right)\right]$ were carried out by Huang et al. [41,42]. [ $\left.\mathrm{RhCo}_{3}(\mathrm{CO})_{12}\right]$ deposited on $\mathrm{SiO}_{2}$ showed the highest catalytic activity in the hydroformylation of ethylene and propylene compared to monometallic carbonyl clusters, such as $\left[\mathrm{Co}_{2}(\mathrm{CO})_{8}\right]$ and $\left[\mathrm{Rh}_{4}(\mathrm{CO})_{12}\right]$. With the $\left[\mathrm{RhCo}_{3}(\mathrm{CO})_{12}\right]$ impregnated on $\mathrm{SiO}_{2}$ catalyst a specific rate of propylene hydroformylation of $396.0 \mathrm{~h}^{-1}\left(\mathrm{w}_{\mathrm{Rh}}=0.5 \mathrm{wt} \%, \mathrm{~T}=443 \mathrm{~K}, \mathrm{p}=0.1 \mathrm{MPa}, \mathrm{C}_{3} \mathrm{H}_{6}: \mathrm{CO}: \mathrm{H}_{2}=1: 1: 1\right)$ could be achieved whereas almost no activity was observed for $\left[\mathrm{Co}_{2}(\mathrm{CO})_{8}\right]$ and $\left[\mathrm{Rh}_{4}(\mathrm{CO})_{12}\right]$. From IR spectroscopic analyses it was suggested that the sub-carbonyl cluster, $\left[\mathrm{RhCo}_{3}(\mathrm{CO})_{12-x}\right]$, physiosorbed on the surface is the actual active catalyst, which is formed in-situ during the reaction [41]. Huang et al. further investigated the bimetallic $\mathrm{RhCo}_{3}$ cluster supported on $\mathrm{SiO}_{2}$ derived from $\left[\mathrm{Rh}_{4}(\mathrm{CO})_{12}\right]$ and $\left[\mathrm{Co}_{2}(\mathrm{CO})_{8}\right]$ in the hydroformylation of ethylene at atmospheric pressure and $423 \mathrm{~K}$. The bimetallic $\mathrm{RhCo}_{3}$ catalyst showed a higher catalytic activity than catalysts prepared from inorganic rhodium and cobalt salts or the monometallic Rh and Co catalysts themselves. These results show that an increase in activity can be attributed to a structurally defined bimetallic $\mathrm{RhCo}_{3}$ catalyst-entity and not only due to the synergistic effects of rhodium and cobalt sites [42], which is accordance with the observations made by Ichikawa et al. for the Rh-Fe bimetallic catalysts [37].

\subsubsection{Other Supported Rhodium Complexes}

Besides the use of rhodium carbonyl complexes, various other approaches using molecular rhodium complexes as precursors being anchored to solid supports are reported. De Munk et al., for example, anchored $\left[\mathrm{HRhCO}\left(\mathrm{PPh}_{3}\right)_{3}\right]$ complexes to the surface of polystyrene divinylbezene via phosphine and phosphonite ligands. The complex was chemically attached to the support via a molecular bond using chlorophosphonation and chloromethylation routes. The activity and regioselectivity towards $n$-butanal of the prepared catalyst could be enhanced by the additional 
supporting two to three equivalents of triphenylphosphine with respect to rhodium. The authors contribute this effect to the additional coordinating phosphine ligands, which alter the steric and electronic structure of the rhodium complex [43]. Similar work was carried out by Yoneda et al., who used a vinyl pyridine copolymer (VPC) crosslinked with divinylbenzene as support material. Here the catalysts were prepared by the simultaneous reaction of vinyl pyridine-divinylbenzene copolymers with rhodium acetate, the required phosphine ligand, the olefin reactant and the solvent. It was shown that with the VCP-supported material hydroformylation rates appear to be similar to homogeneous molecular catalyst systems, if excess $\mathrm{PPh}_{3}$ was present in the liquid phase of the molecular catalyst. The authors claim that the high excess triphenylphosphine is necessary for ligand coordination to occur on the catalyst surface. Unfortunately, high Rh leaching rates were detected for the system [44].

Bando et al. explored the catalytic activity of defined Rh dimer-entities attached to inorganic oxide supports in the hydroformylation of ethylene [45]. The Rh dimer trans-[( $\left.\left.\mathrm{RhCp}^{*} \mathrm{CH}_{3}\right)_{2}\left(\mathrm{CH}_{2}\right)_{2}\right]$ $\left(\mathrm{Cp}^{*}=\right.$ pentamethyl cyclopentadienyl) were attached to inorganic oxides such as $\mathrm{SiO}_{2}, \mathrm{Al}_{2} \mathrm{O}_{3}, \mathrm{TiO}_{2}$, and $\mathrm{MgO}$ via a covalent bonding. The rhodium complexes attached to silica system were found to be the most catalytically active catalyst systems and surface analyses have shown that the dimeric $\mathrm{Rh}$ structure is retained after the deposition to $\mathrm{SiO}_{2}$. It was shown that during the hydroformylation reaction a $\mathrm{Rh}-\mathrm{Rh}$ bond is alternately broken and formed. The anchoring reaction of the complex to the solid support is supposed to occur by the reaction of a methyl and a $\mathrm{Cp}^{*}$ ligand with the surface $\mathrm{OH}$ groups of the metal oxide, which leads to the formation of Rh-O bonds (Scheme 3). The strength of the Rh-O bonds was found to depend on the acid-base properties or rather the electronegativity of the support system and the reactivity of the systems was thought to be influenced by the Rh-O bond strength, the space between the oxygen linkage atoms and the electronic state of the $\mathrm{Rh}$ atoms [45].
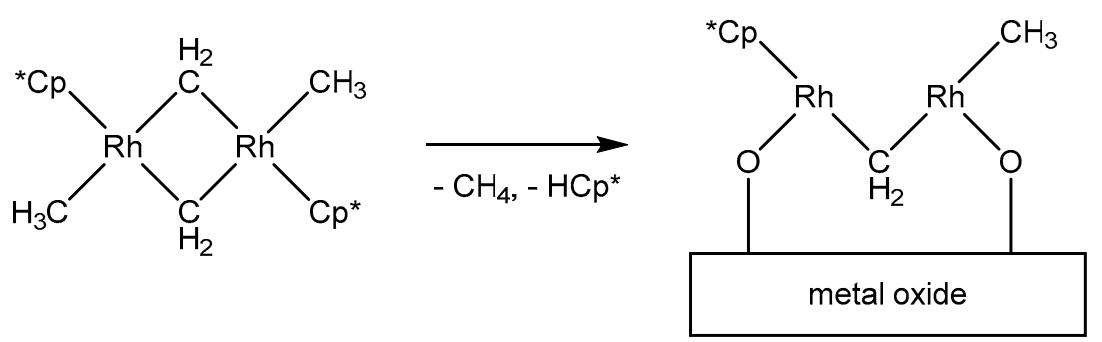

Scheme 3. The reaction of trans- $\left[\left(\mathrm{RhCp}^{*} \mathrm{CH}_{3}\right)_{2}\left(\mu-\mathrm{CH}_{2}\right)_{2}\right]$ dimers with a metal oxide, such as $\mathrm{SiO}_{2}, \mathrm{TiO}_{2}$ or $\mathrm{Al}_{2} \mathrm{O}_{3}$, under the loss of methane and cyclopentdadiene [45].

Table 2 gives a performance-oriented overview of the before-mentioned different supported rhodium catalysts, which were explored with regard to the gas-solid hydroformylation of short-chain olefins, such as ethylene and propylene.

For long-chain olefins also a range of mono- and bimetallic rhodium complexes supported on organic and inorganic materials, such as alumina, silica, magnesium silicate, zeolites or MOFs, have been investigated. Since the focus of this review is on the gas-solid hydroformylation of short-chain olefins, the results concerning longer olefins are only shortly mentioned in the following table for the sake of completeness (Table 3) [46-53].

\subsection{Supported Metallic Rhodium Nanoparticles}

Besides the immobilization of molecular Rh catalysts on solid supports, supported rhodium nanoparticles have been in the focus of interest as heterogeneous catalysts for hydroformylation reactions. The materials discussed in the open literature can be classified according to whether organic ligands (phosphine, phosphites or bi-phosphites) are present within the mixture (ligand-modified Rh nanoparticles) or if additional metals were added (metal-modified Rh nanoparticles) to enhance the catalytic activity. 
Table 2. Overview of different supported molecular rhodium complexes investigated in the gas phase hydroformylation of short olefins.

\begin{tabular}{|c|c|c|c|c|c|c|}
\hline Catalyst Precursor & Support & Substrate & $\begin{array}{c}\text { TOF }_{\text {bulk }} \\
{\left[h^{-1}\right]}\end{array}$ & $\begin{array}{c}\text { Sum-sel. }{ }^{\mathrm{a}} \\
{[\%]}\end{array}$ & $\begin{array}{c}n \text {-Regio-sel. } \\
{[\%]}\end{array}$ & Ref. \\
\hline \multirow{5}{*}[\mathrm{Rh}_{6}(\mathrm{CO})_{16}]{} & $\mathrm{MgO}$ & propylene & 0.720 & 78 & 32 & [35] \\
\hline & $\mathrm{TiO}_{2}$ & propylene & 0.154 & 86 & 62 & [35] \\
\hline & $\mathrm{La}_{2} \mathrm{O}_{3}$ & propylene & 0.038 & 50 & 75 & [35] \\
\hline & $\mathrm{ZnO}$ & $\begin{array}{l}\text { ethylene } \\
\text { propvlene }\end{array}$ & 3.60 & - & . & {$[35]$} \\
\hline & & & 1.23 & - & 70 & \\
\hline \multirow{8}{*}[\mathrm{Rh}_{4}(\mathrm{CO})_{12}]{} & $\mathrm{NaY}$ & $\begin{array}{l}\text { ethylene } \\
\text { propylene }\end{array}$ & $\begin{array}{l}1.32^{\mathrm{b}} \\
0.23^{\mathrm{c}}\end{array}$ & $\begin{array}{l}96 \\
92\end{array}$ & $\begin{array}{c}- \\
57\end{array}$ & $\begin{array}{l}{[36]} \\
{[36]}\end{array}$ \\
\hline & $\mathrm{TiO}_{2}$ & propylene & 0.41 & 70 & 56 & [35] \\
\hline & $\mathrm{La}_{2} \mathrm{O}_{3}$ & propylene & 0.77 & 45 & 68 & [35] \\
\hline & $\mathrm{SiO}_{2}$ & $\begin{array}{l}\text { ethylene } \\
\text { propylene }\end{array}$ & $\begin{array}{l}78^{b} \\
0.04\end{array}$ & $\begin{array}{l}66^{\mathrm{d}} \\
75\end{array}$ & $\begin{array}{c}- \\
63\end{array}$ & $\begin{array}{c}{[41]} \\
{[35,37,42]}\end{array}$ \\
\hline & & propylene & & & & [35] \\
\hline & $\mathrm{Al}_{2} \mathrm{O}_{3}$ & ethylene & 0 & - & - & [35] \\
\hline & & propylene & 9.79 & - & - & [35] \\
\hline & & & 2.05 & - & 58 & \\
\hline$\left[\mathrm{Fe}_{3} \mathrm{Rh}_{2}(\mathrm{CO})_{14} \mathrm{C}\right]$ & $\mathrm{SiO}_{2}$ & propylene & $5.04^{\mathrm{c}}$ & - & - & {$[37]$} \\
\hline \multirow{3}{*}[\mathrm{RhCo}_{3}(\mathrm{CO})_{12}]{} & $\mathrm{SiO}_{2}$ & $\begin{array}{l}\text { ethylene } \\
\text { propylene }\end{array}$ & $1152^{\mathrm{b}}$ & $80^{\mathrm{d}}$ & - & $\begin{array}{c}{[41,42]} \\
{[41]}\end{array}$ \\
\hline & $\mathrm{ZnO}$ & propylene & $396^{c}$ & $67^{\mathrm{e}}$ & - & [35] \\
\hline & & & 0.92 & - & 80 & \\
\hline \multirow{4}{*}[\mathrm{Rh}_{2}\mathrm{Co}_{2}(\mathrm{CO})_{12}]{} & \multirow{4}{*}{$\begin{array}{l}\mathrm{SiO}_{2} \\
\mathrm{ZnO}\end{array}$} & ethylene & & & & [41] \\
\hline & & propylene & $504^{\mathrm{b}}$ & $74^{\mathrm{d}}$ & - & [41] \\
\hline & & propy & $252^{c}$ & $80^{\mathrm{e}}$ & - & [35] \\
\hline & & & 1.34 & - & 70 & \\
\hline \multirow{2}{*}{$\begin{array}{c}{\left[\left(\mathrm{RhCp}^{*} \mathrm{CH}_{3}\right)_{2}\left(\mathrm{CH}_{2}\right)_{2}\right]} \\
\quad\left[\mathrm{HRhCO}\left(\mathrm{PPh}_{3}\right)\right]^{\mathrm{f}} \\
\end{array}$} & $\mathrm{SiO}_{2}$ & ethylene & 0.192 & 89 & - & [45] \\
\hline & VPC & propylene & 2700 & 100 & 60 & [44] \\
\hline
\end{tabular}

${ }^{a}$ Sum-selectivity towards hydroformylation. ${ }^{b}$ TOF calculated for $\mathrm{C}_{2} \mathrm{H}_{5} \mathrm{CHO}+\mathrm{C}_{3} \mathrm{H}_{7} \mathrm{OH}$. ${ }^{c}$ TOF calculated for $\mathrm{C}_{3} \mathrm{H}_{7} \mathrm{CHO}+\mathrm{C}_{4} \mathrm{H}_{9} \mathrm{OH}$. ${ }^{d}$ Selectivity calculated for $\mathrm{C}_{2} \mathrm{H}_{5} \mathrm{CHO}+n-\mathrm{C}_{3} \mathrm{H}_{7} \mathrm{OH}$. e Selectivity calculated for $\mathrm{C}_{3} \mathrm{H}_{7} \mathrm{CHO}+$ $n-\mathrm{C}_{4} \mathrm{H}_{9} \mathrm{OH} .{ }^{\mathrm{f}} \mathrm{PPh}_{3}$ was added.

Table 3. Overview of different supported molecular rhodium complexes investigated in the liquid phase hydroformylation of longer olefins. TPPTS $=3,3^{\prime}, 3^{\prime \prime}$-phosphanetriyltris(benzenesulfonic acid) trisodium salt, SPION = superparamagnetic iron oxide nanoparticles.

\begin{tabular}{ccccc}
\hline Catalyst Precursor & Support & Ligand & Substrate & Ref. \\
\hline & $\mathrm{SiO}_{2}$ & Amines & 1 -hexene & {$[47]$} \\
{$\left[\mathrm{Rh}_{2} \mathrm{Co}_{2}(\mathrm{CO})_{12}\right]$} & $\mathrm{Al}_{2} \mathrm{O}_{3}$ & Amines & 1 -hexene & {$[47]$} \\
& $\mathrm{MgO}_{\mathbf{S i O}}$ & - & 1 -hexene & {$[47]$} \\
& zeolites & - & 1 -hexene & {$[47]$} \\
{$[\mathrm{Rh}(\mathrm{acac})(\mathrm{cod})]$} & $\mathrm{MOF}$ & - & $\mathrm{C}_{6}-\mathrm{C}_{16}$ olefins & {$[48,49]$} \\
& $\mathrm{Hydrotalcite}$ & $\mathrm{TPPTS}$ & 1 -hexene & {$[50-52]$} \\
{$\left[\mathrm{HRh}(\mathrm{CO})\left(\mathrm{PPh}_{3}\right)_{3}\right]$} & $\mathrm{VPC}$ & $\mathrm{PPh}_{3}$ & octene & {$[44]$} \\
& $\mathrm{SPION}$ & $\mathrm{PPh}_{3}$ & styrene & {$[53]$} \\
\hline
\end{tabular}

Chuang and Pien pioneered the development of ligand- and metal-modified nanoparticles by investigating the hydroformylation of ethylene over a pure $\mathrm{Rh} / \mathrm{SiO}_{2}$ system $[54,55]$. The catalysts were prepared via an impregnation method, followed by calcination and reduction of the impregnated support. Prior to the hydroformylation tests the materials were: 1$)$ reduced in a $\mathrm{H}_{2}$ stream $\left(240{ }^{\circ} \mathrm{C}\right.$ in $\mathrm{H}_{2}$ for $1 \mathrm{~h}$ ) and 2 ) oxidized under air $\left(240^{\circ} \mathrm{C}\right.$, under air, $\left.1 \mathrm{~h}\right)$. XPS analyses of the materials have shown that the amount of $\mathrm{Rh}^{+}$species on the surface of the material, which was oxidized under air, is higher, than on the reduced material. Further results from $\mathrm{CO}$ absorption experiments showed 
that the oxidized sample coordinates the CO preferably linearly, while on the reduced sample more bridging $\mathrm{CO}$ could be observed. The different $\mathrm{CO}$ coordination behavior was attributed to the presence of differing rhodium species on the surface of the materials. Whereas $\mathrm{Rh}^{+}$species coordinate $\mathrm{CO}$ in a linear fashion, for $\mathrm{Rh}^{0}$ species a bridging $\mathrm{CO}$ coordination is preferred. The different rhodium species on the catalyst surface are discussed to have major influence on the catalytic activity; whereas the oxidized samples show a higher propanal formation rate compared to other samples, the reduced material exhibits a higher chemoselectivity for the formation of ethane [55].

Based on these results, Chuang et al. [54,55] formulated the following reaction mechanism for the hydroformylation of ethylene over the above mentioned materials: 1) through hydrogenation of $\mathrm{C}_{2} \mathrm{H}_{4}$ with an absorbed ${ }^{*} \mathrm{H}$ species an hydrogenated alkyl species is created, 2) $\mathrm{CO}$ insertion into the $\mathrm{C}-\mathrm{Rh}$ bond of an absorbed alkyl takes place, and 3) hydrogenation of the absorbed alkyl leads to the aldehyde formation. The CO insertion step is favored by the linearly coordinated $\mathrm{CO}$, which preferably forms on $\mathrm{Rh}^{+}$species on the surface (Figure 7).

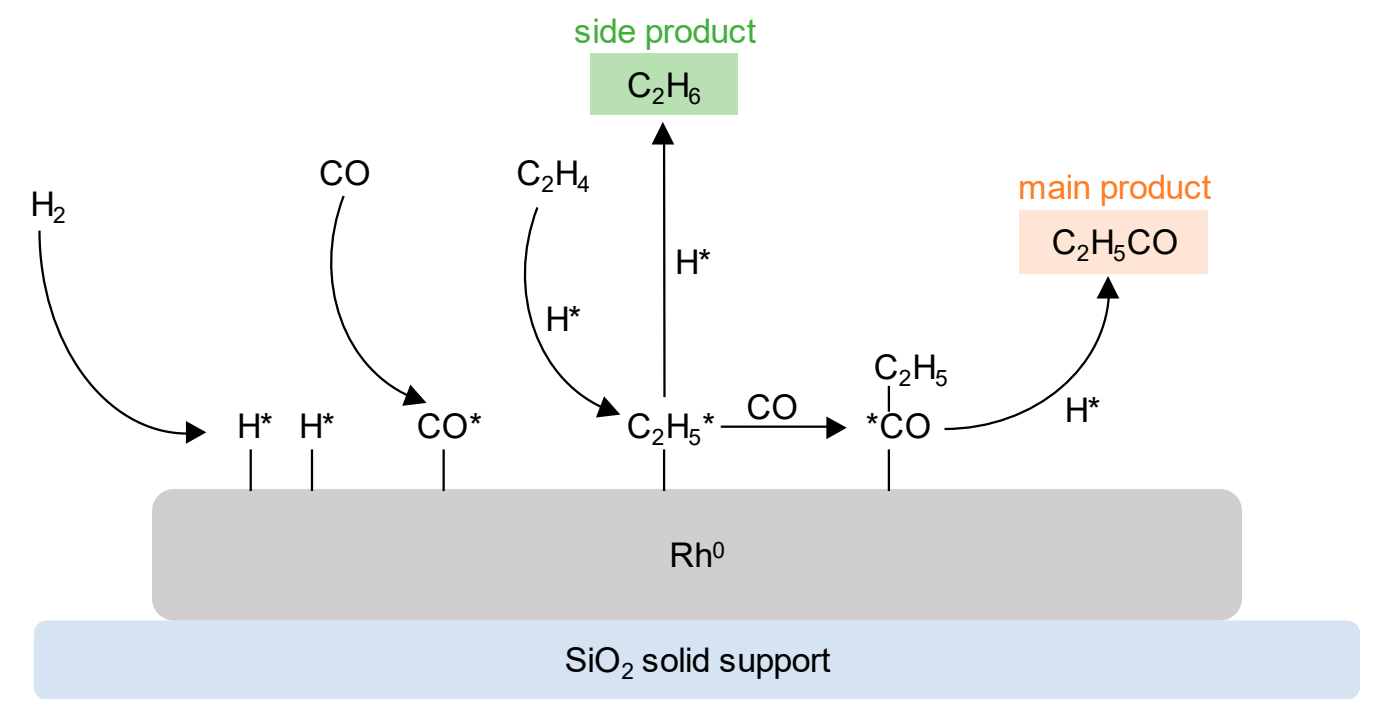

Figure 7. Schematic representation of the reaction pathway of the hydroformylation of ethylene with a $\mathrm{Rh} / \mathrm{SiO}_{2}$ catalyst material proposed by Chuang and Pien [55].

A comprehensive study of the structure-activity behavior of a $\mathrm{Rh} / \mathrm{SiO}_{2}$ system in the hydroformylation of ethylene was reported by McClure et al. and from the data it can be concluded that the $\mathrm{CO}$ insertion activity reaches an optimum for a $\mathrm{Rh}$ particle size of $\sim 2.5 \mathrm{~nm}$ (TOF $=0.4$ molecules $\left._{\mathrm{C} 3 \mathrm{H} 6 \mathrm{O}} \cdot \mathrm{site}^{-1} \cdot \mathrm{s}^{-1}, \mathrm{~T}=500 \mathrm{~K}, \mathrm{p}=0.05 \mathrm{MPa}, \mathrm{C}_{2} \mathrm{H}_{4}: \mathrm{CO}: \mathrm{H}_{2}=1: 1: 8\right)$. Kinetic and spectroscopic data suggested that the particle size affects the $\mathrm{CO}$ insertion step by two factors: 1) promotion of the $\mathrm{CO}$ insertion reaction on low coordinated Rh surface sites, and 2) small particles lead to a decrease in TOF, probably due to the formation of dispersed Rh carbonyl hydride species [56].

Besides silica supported rhodium nanoparticles, also graphite nanofibers have been used as support materials. The performance of these systems in the hydroformylation of ethylene was compared to silica-supported Rh catalysts, at a similar metal loading. Although the activity of the $\mathrm{Rh} / \mathrm{SiO}_{2}$ system was higher compared to the graphite nanofiber supported material $\left(\mathrm{T}=240{ }^{\circ} \mathrm{C}\right.$, $\mathrm{CO} / \mathrm{H}_{2} / \mathrm{C}_{2} \mathrm{H}_{4} / \mathrm{He}=1: 1: 1: 1$, flow rate $=120 \mathrm{~mL} \cdot \mathrm{min}^{-1}$, time $=2 \mathrm{~h}$, ethylene conversion graphite $=10 \%$, versus ethylene conversion $\mathrm{SiO}_{2}=20 \%$ ), the selectivity towards propanal was increased. It was shown that the graphite nanofiber material exhibits a higher selectivity of about $50 \%$ for the formation of propanal than the corresponding silica system with which only a selectivity of $6 \%$ towards the aldehyde could be achieved at identical reaction conditions $\left(\mathrm{T}=240{ }^{\circ} \mathrm{C}, \mathrm{CO} / \mathrm{H}_{2} / \mathrm{C}_{2} \mathrm{H}_{4} / \mathrm{He}=1: 1: 1: 1\right.$, flow rate $=120 \mathrm{~mL} \cdot \mathrm{min}^{-1}$ ). Based on an experimental study, in which the partial pressure was varied systematically, it was concluded that high partial pressures of $\mathrm{CO}$ and $\mathrm{C}_{2} \mathrm{H}_{4}$, and a concomitant low partial pressure of $\mathrm{H}_{2}$ gave the optimum performance of the Rh catalyst [57]. 


\subsubsection{Supported Ligand-Modified Rhodium Nanoparticles}

Yan et al. prepared rhodium nanoparticles on $\mathrm{SiO}_{2}$ by impregnation of the support with an aqueous solution of rhodium chloride using the incipient wetness method. Afterwards the samples were dried, calcined at $673 \mathrm{~K}$ in a quartz tube and finally reduced under an $\mathrm{H}_{2}$ atmosphere. The $\mathrm{Rh} / \mathrm{SiO}_{2}$ precursor was then treated with a $\mathrm{PPh}_{3}$ solution. Subsequent drying under vacuum lead to the formation of $\mathrm{PPh}_{3}-\mathrm{Rh} / \mathrm{SiO}_{2}$ (molar ratio $\mathrm{L}: \mathrm{Rh}=10: 1$ ) material, which was tested in the hydroformylation of propylene in a fixed bed reactor system $\left(\mathrm{T}=393 \mathrm{~K}, 4 \mathrm{~h}, \mathrm{p}=1 \mathrm{MPa}, \mathrm{H}_{2}: \mathrm{CO}: \mathrm{C}_{3} \mathrm{H}_{6}=1: 1: 1, \mathrm{GHSV}=2000 \mathrm{~h}^{-1}\right)$. The performance tests have shown that the $\mathrm{PPh}_{3}-\mathrm{Rh} / \mathrm{SiO}_{2}$ system is by far more reactive than the unmodified $\mathrm{Rh} / \mathrm{SiO}_{2}$ counterpart $\left(131 \mathrm{~h}^{-1}\right.$ vs. $\left.1.2 \mathrm{~h}^{-1}\right)$ [58]. The higher TOF values of the modified catalysts were attributed to the formation of $\left[\mathrm{HRh}(\mathrm{CO})_{2}\left(\mathrm{PPh}_{3}\right)_{2}\right]$ on the surface of the Rh nanoparticles after syngas treatment (Figure 8). Very similar observations were made for Rh carbonyl complexed on solid supports [39]. The assumption was confirmed by solid-state ${ }^{31} \mathrm{P}$ NMR and XPS measurements. Using FT IR techniques, the presence of three different carbonyl species could be shown, that correspond most likely to $\left[\mathrm{HRh}(\mathrm{CO})\left(\mathrm{PPh}_{3}\right)_{3}\right],\left[\mathrm{Rh}(\mathrm{CO})_{2}\left(\mathrm{PPh}_{3}\right)_{3}\right]_{2}$ and $\left[\mathrm{HRh}(\mathrm{CO})_{2}\left(\mathrm{PPh}_{3}\right)_{2}\right][58,59]$. The addition of $\mathrm{PPh}_{3}$ was shown to reduce the Rh leaching, which was monitored in an aqueous solution, since products were captured in an aqueous solution, significantly by direct attachment of the Rh nanoparticles to the support material and a strong bonding of the catalytically active Rh species via metal-metal bonds [59]. During the hydroformylation tests no deactivation of the catalyst was observed over a period of more than $1000 \mathrm{~h}$ under the provision that $\mathrm{PPh}_{3}$ was added at 300-350 $\mathrm{h}$ of time on stream [58].

Further studies concerning the hydroformylation of propylene using $\mathrm{PPh}_{3}$-modified $\mathrm{Rh}$ nanoparticles on $\mathrm{SiO}_{2}$ have shown similar apparent activation energies and pressure dependencies as homogeneous catalysts. A $100 \%$ selectivity towards $C_{4}$ aldehydes and a high $n /$ iso ratio of 14 could be achieved with this materials class under the best reaction conditions $\left(\mathrm{m}_{\text {catalyst }}=0.6 \mathrm{~g}, \mathrm{~T}=393 \mathrm{~K}\right.$, $\mathrm{p}=2 \mathrm{MPa}, \mathrm{PPh}_{3} / \mathrm{Rh}$ ratio of $15, \mathrm{H}_{2}: \mathrm{CO}: \mathrm{C}_{3} \mathrm{H}_{6}=1: 1: 1$, flow rate $=120 \mathrm{~mL} \cdot \mathrm{min}^{-1}$ ). Again, the catalytically active component was probably formed in-situ on the surface of the support and, since there is no evidence for interactions with the support surface such as formation of chemical bonds, is probably a $\mathrm{Rh}$ species dissolved in molten $\mathrm{PPh}_{3}$, such as $\left[\mathrm{HRh}(\mathrm{CO})_{\mathrm{n}}\left(\mathrm{PPh}_{3}\right)_{4-\mathrm{n}}\right]$. This assumption was supported by the similar formal kinetics observed in comparison with the kinetic behavior of molecular catalysts in a homogeneous medium [60].
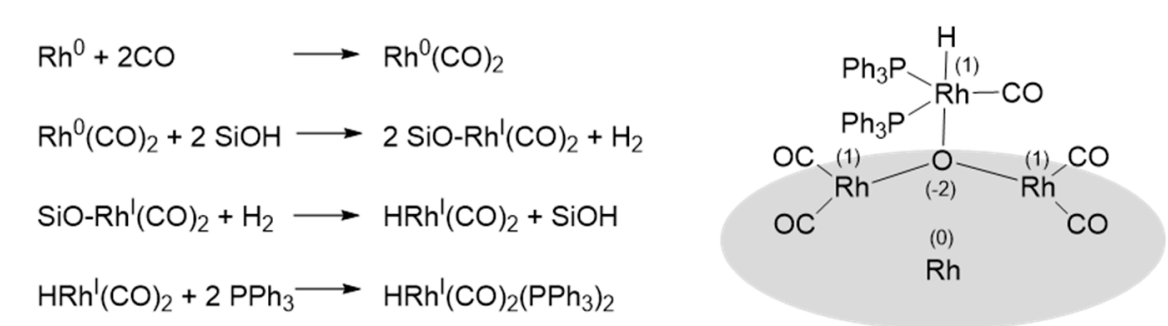

Figure 8. Proposed mechanism for the formation of homogenous catalysts on phosphine modified $\mathrm{Rh} / \mathrm{SiO}_{2}$ and proposed stabilization of the hydroformylation catalyst. Graphic adapted from Shylesh et al. [61].

Further investigations of the in-situ formation of a Wilkinson-type catalyst within phosphinemodified $\mathrm{Rh} / \mathrm{SiO}_{2}$ catalysts have focused on the ligand dependency of the hydroformylation of propylene. The selected ligands included triphenylphosphine, triphenylphosphite, fluorinated triphenylphosphine, methoxytriphenylphosphine, and the bidentate Xantphos. The catalytic results under identical conditions ( $\mathrm{w}_{\mathrm{Rh}}=0.2 \mathrm{wt} \%$ and a molar ligand-to-metal ratio of $\mathrm{L} / \mathrm{Rh}=15, \mathrm{~T}=393 \mathrm{~K}$, $\left.\mathrm{p}=20 \mathrm{MPa}, \mathrm{C}_{3} \mathrm{H}_{6} / \mathrm{H}_{2} / \mathrm{CO}=1: 1: 1\right)$ showed, that the Xantphos-modified $\mathrm{Rh} / \mathrm{SiO}_{2}$ catalysts exhibits the highest TOF values and the highest $n /$ iso ratio in the hydroformylation of propylene. The TOF value was doubled up to $78 \mathrm{~h}^{-1}$ in comparison with the TOF of the $\mathrm{PPh}_{3}$-modified catalyst $\left(35 \mathrm{~h}^{-1}\right)$ [61]. In accordance with other reporting's [58-60], the authors contributed the high catalytic activity of 
the system to the formation of $\mathrm{Rh}(\mathrm{I})(\mathrm{CO})_{2}$ species via an oxidative chemisorption process of $\mathrm{Rh}$ nanoparticles by $\mathrm{CO}$ and the subsequent ligation of phosphine ligands to the dicarbonyl species (Figure 8).

The higher catalytic activity of the bidentate Xantphos-modified $\mathrm{Rh} / \mathrm{SiO}_{2}$ system compared to the $\mathrm{PPh}_{3}$-modified $\mathrm{Rh} / \mathrm{SiO}_{2}$ system was related to the chelating ability of Xantphos, which yields a higher concentration of coordinated Rh species. Various possible Rh-containing species, which might be formed under hydroformylation reaction conditions, were proposed by the authors (Scheme 4) [61].

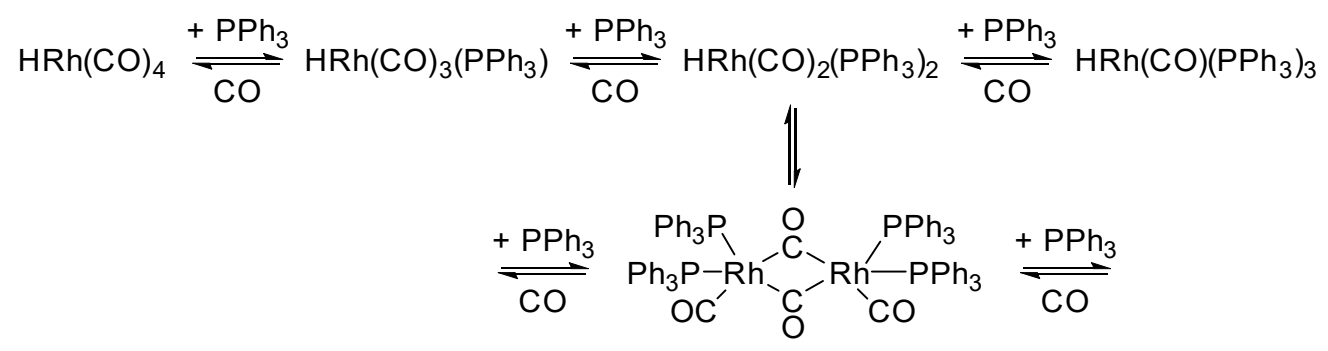

Scheme 4. Rhodium-containing species that might be formed under hydroformylation reaction conditions. Scheme adapted from Shylesh et al. [61].

In a comprehensive study by $\mathrm{Li}$ et al. $\mathrm{Rh} / \mathrm{SiO}_{2}$ catalysts were developed by attaching both the organic ligand and the metal directly on the surface of the support material. The tethered-ligand sets were synthesized by either mixing 2-(diphenylphosphino)ethyltriethoxysilane (DPPTS) or diphenylethylphosphine (DPEP) in a slurry with the before prepared $\mathrm{Rh} / \mathrm{SiO}_{2}$ material $\left(\mathrm{w}_{\mathrm{Rh}}=1 \mathrm{wt} \%\right)$. From thermogravimetric, NMR and FT-IR measurements it was concluded that both DPPTS or DPEP ligands and Rh were attached directly onto the support (Figure 9) [62]. According to the authors, the $\mathrm{Rh}$ species are bound by the Rh-O bonds and the metal-metal bonds [58].

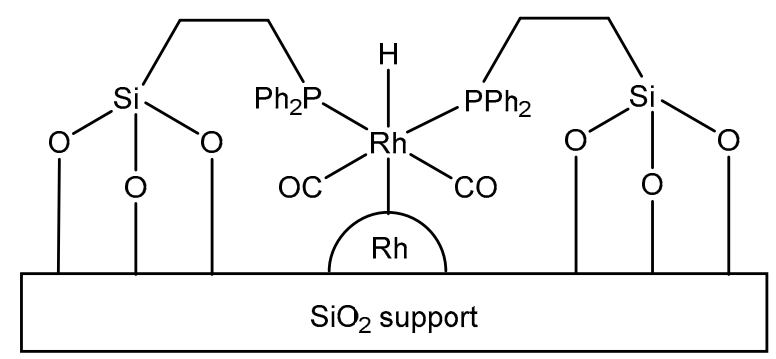

Figure 9. Scheme of a tethered ligand-modified $\mathrm{Rh} / \mathrm{SiO}_{2}$ catalyst. Graphic adapted from Li et al. [62].

The tethered ligand-based catalysts were tested in the hydroformylation of ethylene, where the DPPTS modified $\mathrm{Rh} / \mathrm{SiO}_{2}$ materials reached TOF values as high as $55 \mathrm{~h}^{-1}$. The material has proven to be stable for over $1000 \mathrm{~h}$, while the DPEP modified $\mathrm{Rh} / \mathrm{SiO}_{2}$ material quickly deactivates under the reaction conditions $\left(\mathrm{T}=393 \mathrm{~K}, \mathrm{p}=1.0 \mathrm{MPa}, \mathrm{C}_{2} \mathrm{H}_{4}: \mathrm{CO}: \mathrm{H}_{2}=1: 1: 1, \mathrm{GHSV}=2000 \mathrm{~h}^{-1}\right)$ [62]. Later on it was shown that the alkyl spacer lengths of the tethered-phosphine ligands influence the catalytic activity. Lengthening of the spacer lead to an enhanced activity, probably due to an improved flexibility and promotion of the formation of the active species [63].

Further the effect of doping with an $\mathrm{Al}^{3+}$ promoter on the catalytic activity of the DPPTS modified $\mathrm{Rh} / \mathrm{SiO}_{2}$ materials has been investigated. The $\mathrm{Al}^{3+}$ promoted $\mathrm{Rh} / \mathrm{SiO}_{2}$ catalyst was synthesized by co-impregnation of $\mathrm{SiO}_{2}$ with $\mathrm{RhCl}_{3} \cdot \mathrm{xH}_{2} \mathrm{O}$ and $\mathrm{Al}\left(\mathrm{NO}_{3}\right)_{3}$ and subsequent addition to the DPPTS ligand. The presence of $\mathrm{Al}^{3+}$ has a pronounced effect on the catalytic activity in the hydroformylation of ethylene. Whereas materials with a $\mathrm{Rh} / \mathrm{Al}$ molar ratio of 1 achieved the highest TOF values during the hydroformylation of ethylene $\left(\mathrm{TOF}_{\mathrm{AlRh}=1}=105 \mathrm{~h}^{-1}\right)$, catalysts with higher or lower $\mathrm{Rh} / \mathrm{Al}$ ratios showed lower TOF values $\left(\mathrm{TOF}_{\mathrm{AIRh}=0}=22 \mathrm{~h}^{-1}, \mathrm{TOF}_{\mathrm{AIRh}=0,2}=50 \mathrm{~h}^{-1}, \mathrm{TOF}_{\mathrm{AIRh}=3}=77 \mathrm{~h}^{-1}\right)$ under identical 
reaction conditions $\left(\mathrm{m}_{\text {catalyst }}=0.3 \mathrm{~g}, \mathrm{~T}=393 \mathrm{~K}, \mathrm{p}=1.0 \mathrm{MPa}, \mathrm{C}_{2} \mathrm{H}_{4}: \mathrm{CO}: \mathrm{H}_{2}=1: 1: 1, \mathrm{GHSV}=2000 \mathrm{~h}^{-1}\right.$, $\mathrm{P} / \mathrm{Rh}=2.2$ ). With a combination of analytical techniques, such as $\mathrm{N}_{2}$ sorption, TEM, pyridine adsorbed FT-IR, FT IR, $\mathrm{NH}_{3}$-TPD and solid-state NMR measurements, it could be shown that the Al-promoting inhibited the growth of metallic Rh particles, increased the dispersion and number of exposed $\mathrm{Rh}$ atoms and enhance the number of Bronsted as well as Lewis acid sites on the catalyst surface. Based on the results of solid-state ${ }^{31} \mathrm{P}$ NMR and ${ }^{27} \mathrm{Al}$ NMR spectroscopy, the authors attribute the enhanced catalytic activity of the catalyst to the electronic interaction of the aluminum cations with the ligand molecules causing a higher electron density at the phosphorus bridgehead [64].

Interestingly, triphenylphosphine was not only used as functional ligand for the synthesis of ligand-modified rhodium nanoparticles, but also as reducing agent to reduce graphene oxide. With this method a reduced graphene oxide supported rhodium-ligand complex catalysts could be obtained. This system was applied in the hydroformylation of long-chain olefins in liquid phase and will therefore not be further discussed [65].

\subsubsection{Supported Metal-Modified Rhodium Nanoparticles}

Beside the modification of rhodium nanoparticles with organic ligands, research has gone to explore metal- or metal oxide-modified Rh nanoparticles as hydroformylation catalysts. Already before, in the case of the supported molecular rhodium complexes, it has been shown that catalysts, containing two different metals, such as Rh-Fe or Rh-Co systems, can be superior over their monometallic counterparts in terms of their overall activity and chemoselectivity [37,46]. This concept has been transferred to rhodium nanoparticles and various elements have been employed as promotors, such as main group elements, alkali and transition metals.

Trunschke et al. investigated the hydroformylation of ethylene and propylene as well as the hydrogenation of aldehydes with Mo-promoted Rh catalysts supported on $\mathrm{SiO}_{2}$. The catalysts were prepared from the heteronuclear cluster $\left[\left(\mathrm{C}_{5} \mathrm{H}_{5}\right)_{3} \mathrm{RhMo}_{2}(\mathrm{CO})_{5}\right]$, which was deposited on silica by wet impregnation. The deposition of a cluster compound ensured the metallic components being in proximity. The addition of Mo increased the rate of hydroformylation but also the rate of the hydrogenation and no specific influence on the CO insertion reaction was observed [66]. These results suggest that the formation of the intermediate surface alkyl group on the Rh surface is the rate determining step in the hydroformylation, which corresponds to a "type-I" kinetic behavior.

Lenarda et al. examined the hydroformylation of ethylene and propylene over a rhodiumcontaining aluminum pillared smectite clay. The material was prepared by treatment of the commercially available $\mathrm{Na}^{+}$bentonite pillared with aluminum poly-oxocations and subsequent ion exchange with a $\mathrm{RhCl}_{3}$ solution. A clay material with $0.46 \mathrm{wt} \%$ of rhodium was obtained after thermal treatment and activation under syngas. The hydroformylation to hydrogenation ratio under the test conditions $\left(\mathrm{m}_{\text {catalyst }}=350 \mathrm{mg}, \mathrm{w}_{\mathrm{Rh}}=0.46 \mathrm{wt} \%, \mathrm{CO} / \mathrm{H}_{2} / \mathrm{C}_{2} \mathrm{H}_{4} / \mathrm{N}_{2}=5 / 15 / 5 / 75\right.$, flow rate $\left.=26 \mathrm{~mL} \cdot \mathrm{min}^{-1}\right)$, reached a maximum of $86 \%$ at $373 \mathrm{~K}$ and decreased with enhanced reaction temperature in the hydroformylation of ethylene. Propane, $n$ - and iso-butanal were the main products from the propylene hydroformylation. An overall decrease of one order of magnitude of reaction rate compared to ethylene is observed for both the hydroformylation and the hydrogenation of propylene. The value observed for linear to branched aldehyde regioselectivity at $398 \mathrm{~K}$ is $78.5 \%$ and decreases as the temperature increases [67].

Further, $\mathrm{Rh} / \mathrm{Al}$ and $\mathrm{Rh} / \mathrm{B}$ system were prepared by reducing rhodium trichloride supported on silica with lithium aluminum hydride or sodium borohydride at low temperatures [68-70]. It was shown that the nature of the catalyst strongly depends on the conditions of thermal pre-treatment. For the hydroformylation reactions performed, catalysts were treated thermally under argon at $543 \mathrm{~K}$ for $24 \mathrm{~h}$ and under syngas atmosphere $\left(\mathrm{CO} / \mathrm{H}_{2}=1\right.$, flow rate $\left.=20 \mathrm{~mL} \cdot \mathrm{min}^{-1}\right)$ for $24 \mathrm{~h}$ at $453 \mathrm{~K}$. The typical hydroformylation conditions applied were: mixture of $\mathrm{CO} / \mathrm{H}_{2} / \mathrm{C}_{2} \mathrm{H}_{4} / \mathrm{N}_{2}=1 / 1 / 1 / 15$ flowing at $26 \mathrm{~mL} \cdot \mathrm{min}^{-1}$, total pressure $1.0 \mathrm{MPa}$, space velocity $3100 \mathrm{~h}^{-1}$. The selectivity for the hydroformylation of $79 \%$ of propanal using the $\mathrm{Rh} / \mathrm{B} / \mathrm{SiO}_{2}$ material reached its maximum at $398 \mathrm{~K}$ with a $\mathrm{CO} / \mathrm{H}_{2}=2$ and was found to increase with increasing $\mathrm{CO}$ partial pressure and to decrease with increasing reaction 
temperature [70]. The $\mathrm{Al}$ promoted material was prepared in a similar manner and tested in the hydroformylation of propylene. The highest hydroformylation rates were achieved with a sample treated in air flow at $723 \mathrm{~K}$, then reduced in $\mathrm{H}_{2}$ at $623 \mathrm{~K}$ and finally treated in $\mathrm{CO} / \mathrm{H}_{2}$ flow at $453 \mathrm{~K}$ for $24 \mathrm{~h}$. The selectivity towards the sum of $\mathrm{C}_{4}$ aldehydes $(75 \%$ at $393 \mathrm{~K}$, and $16 \%$ at $453 \mathrm{~K}$ ) decreased with increasing reaction temperature while the regioselectivity of $62 \%$ towards linear aldehydes did not change with the reaction temperature [68].

In addition to these main group-promoted rhodium nanoparticles, also preparation of catalysts via the reduction of rhodium and cobalt salts on $\mathrm{SiO}_{2}$ with $\mathrm{NaBH}_{4}$ was investigated. The $\mathrm{Rh}-\mathrm{Co} / \mathrm{B}$ systems on silica were inactive for the hydroformylation of propylene under atmospheric pressure, what the authors attribute this fact to the obscuring of the active metal centers by large amounts of cobalt oxide. However, higher pressures lead to an enhanced activity, probably because inaccessible catalytic sites become liberated, presumably via cobalt carbonyl formation. A high selectivity towards hydroformylation products of $75 \%$ and regioselectivity towards linear aldehydes of $95 \%$ could be achieved at $1.0 \mathrm{MPa}$, with a $\mathrm{Rh} / \mathrm{Co} / \mathrm{B} / \mathrm{SiO}_{2}$ catalysts at $403 \mathrm{~K}$. As explanation for the high regioselectivity towards the $n$-aldehyde the authors proposed a model, in which a thick polyatomic and irregular cobalt oxide layer covers almost all the rhodium surface leaving only few windows available for the chemisorption of the reactant molecules. The constrained environment of the active sites probably hinders the formation of the bulkier branched isomer, which explains the regioselectivity [70].

In order to compare the activity of bimetallic and monometallic systems, Rh, Co and Rh-Co on $\mathrm{Al}_{2} \mathrm{O}_{3}$ were tested in the hydroformylation of ethylene in a temperature range from 448 to $498 \mathrm{~K}$ and pressures between 1-3 MPa. It was found that finely dispersed Rh particles were most active and selective (up to $45 \%$ to hydroformylation products) for the hydroformylation of ethylene to propanal and the subsequent hydrogenation product propanol. An explicit structure sensitivity in ethylene hydroformylation has been observed for Co based catalysts, with smaller Co particles being more active and selective [71].

The effect of different promotors on $\mathrm{SiO}_{2}$-supported $\mathrm{Rh}$ catalysts for the hydroformylation of ethylene and $\mathrm{CO}$ hydrogenation was also investigated by Hanaoka et al. (Figure 10). It was shown that in their experiments both hydroformylation of ethylene and $\mathrm{CO}$ hydrogenation occurred concurrently to produce propanal. $\mathrm{CO}$ hydrogenation to form $\mathrm{C}_{2}$-oxygenates and the ethylene hydroformylation have several steps in common, such as the $\mathrm{CO}$ insertion and metal-carbon bond hydrogenation. However, in the case of the $\mathrm{CO}$ hydrogenation the initial $\mathrm{CO}$ dissociation is required before the reaction can proceed [72].
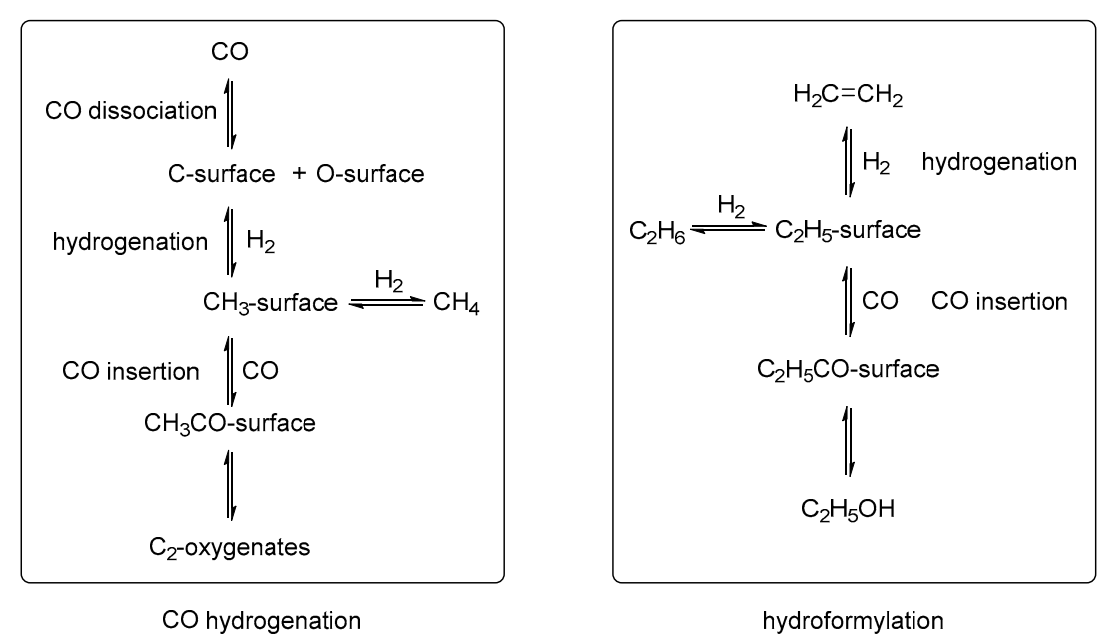

Figure 10. Schematic difference between CO hydrogenation and hydroformylation. Graphic adapted from Hanaoka et al. [72]. 
The desired hydroformylation could be enhanced over highly dispersed Rh particles with maximum activity observed at a particle diameter of $3.5 \mathrm{~nm}\left(\mathrm{TOF}=126 \mathrm{~h}^{-1}\right)$ at $180^{\circ} \mathrm{C}(\mathrm{p}=2.0 \mathrm{MPa}$, $\mathrm{C}_{2} \mathrm{H}_{4}: \mathrm{CO}: \mathrm{H}_{2}: \mathrm{Ar}=3: 4: 2: 1$, flow rate $\left.=100 \mathrm{~mL} \cdot \mathrm{min}^{-1}\right)$, whereas $\mathrm{CO}$ hydrogenation was favoured over large particles. The particle sizes were calculated from $\mathrm{Rh}$ dispersion measured by $\mathrm{H}_{2}$ chemisorption and XRD measurements. These experimental findings indicated that the hydroformylation is enhanced over highly dispersed $\mathrm{Rh} / \mathrm{SiO}_{2}$ catalysts and suggest that hydroformylation occurs preferably at the edge and corner Rh sites [72]. Site-dependent chemoselectivity and catalytic activity of certain catalysts has already been studies by various groups for other catalytic reactions using analytical techniques at the atomic resolution level as well as computational methods [73-77]. The addition of transition metal oxides, such as $\mathrm{MoO}_{3}, \mathrm{Sc}_{2} \mathrm{O}_{3}, \mathrm{TiO}_{2}, \mathrm{~V}_{2} \mathrm{O}_{5}$, and $\mathrm{Mn}_{2} \mathrm{O}_{3}$, which are expected to enhance $\mathrm{CO}$ dissociation only slowed down the hydroformylation process without any effect on the chemoselectivity. The addition of alkali metals reduces generally the catalytic activity but leads to increased chemoselectivity of the reaction towards hydroformylation products. The chemoselectivity of the catalysts towards propanal decreased in the order: $\mathrm{Li}>\mathrm{Na}>\mathrm{K}>\mathrm{Cs}$, which correlates well with the electronegativity of the alkali metal cations [72].

The influence of cationic alkali promoters on catalyst systems similar to the ones descried above was also investigated by Sordelli et al. The catalysts were prepared by co-impregnation of $\mathrm{RhCl}_{3} \cdot 3 \mathrm{H}_{2} \mathrm{O}$ and the corresponding alkali metal chloride salt in a 1:1 ratio. Under the conditions of the reaction of the hydroformylation of propylene, small Rh metal particles are formed, with a mean diameter of $3.2 \mathrm{~nm}$ obtained from HR TEM measurements. As discussed before [72], the activity of the different materials reflects the trend of the polarizing power, which can also be associated with the size of the cation and the corresponding electronegativity, of the cation within Group 1. The lower the polarizing effect of the metal, the smaller is the promoting effect for the hydroformylation reaction. The presence of $\mathrm{Li}$, in a molar ratio of $1: 1$, promoted mainly the hydroformylation reaction and the $n$-aldehyde formation rate on the Li-containing sample was six times higher than the non-promoted counterpart $\left(\mathrm{TOF}_{\mathrm{Rh} / \mathrm{Li}}=462 \mathrm{~h}^{-1}\right.$ vs. $\left.\mathrm{TOF}_{\mathrm{Rh}}=69.6 \mathrm{~h}^{-1}\right)$ and also the selectivity was higher for the Li promoted material (59\% vs. $42 \%)$ under identical test conditions $\left(\mathrm{w}_{\mathrm{Rh}}=2.0 \mathrm{wt} \%, \mathrm{~T}=413 \mathrm{~K}, \mathrm{p}=0.1 \mathrm{MPa}\right.$, $\mathrm{C}_{3} \mathrm{H}_{6}: \mathrm{CO}: \mathrm{H}_{2}=0.5: 1: 1$, flow rate $=15 \mathrm{~mL} \cdot \mathrm{min}^{-1}$ ). From these observations in can be concluded that $\mathrm{Li}$ enhances the selectivity towards aldehydes but does not suppress the hydrogenation reaction. An excess of promoting metal caused a decrease of the total activity, as shown from a sample with a $\mathrm{Li} / \mathrm{Rh}$ ratio $=5$, which was completely inactive towards the hydroformylation. On the opposite, the addition of Cs resulted in a deactivation of both the hydrogenation and hydroformylation activity. The hydroformylation rate of the alkali promoted catalysts has the following order: $\mathrm{Li}>\mathrm{Na}>\mathrm{K}>\mathrm{Rb}>>$ Cs. Sordelli et al. suggested that the alkali metal promoter cations are present as "patches" of oxide at the surface of the rhodium particles, where the hydroformylation process occurs at the metal/oxide interface [78].

\subsection{Supported Single-Atom Rhodium Metal Catalysts}

\subsubsection{Supported Single-Atom Catalysts}

After Zhang et al. pioneering work on single-atom catalysts (SACs, $\mathrm{Pt} 1 / \mathrm{FeO}_{\mathrm{x}}$ ) for carbon monoxide oxidation [79], various types of SACs have been employed in catalytic reactions and have shown remarkable activity and selectivity. In this context the term "single-atom catalyst" was first reported and the concept was then further developed in the following years [80,81]. Only very recently, comprehensive reviews about SACs and their applications were given by Chen et al. [82] and Liu. [83].

The term single-atom catalyst is used to describe materials, which contain isolated, highly dispersed single-atoms on a solid support. These isolated and individual atoms enhance the metals atomic efficiency and provide uniform active sites, which is not a typical feature for conventionally prepared heterogeneous catalysts. The reported performance of SACs can be attributed to the unique features of single-atoms on a solid support in comparison with bulk or even nanomaterials (Figure 11) [84]. 


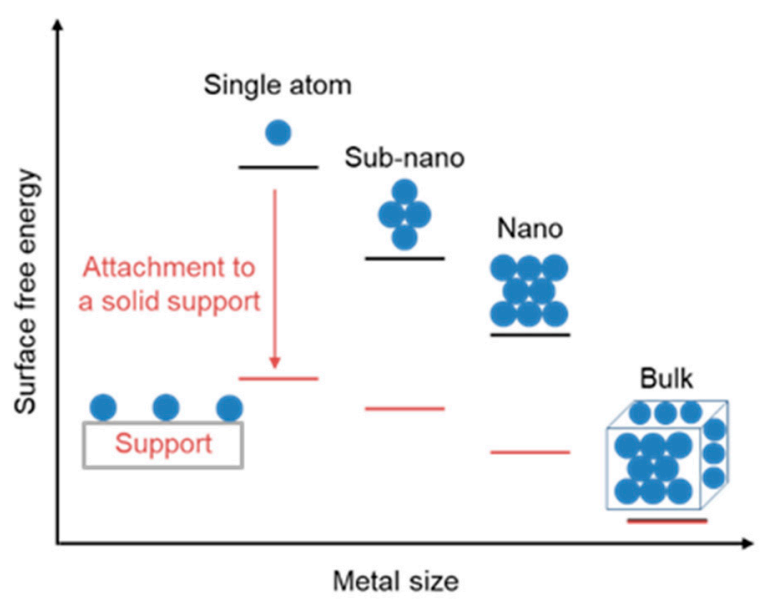

Figure 11. Relationship between the surface free energy and metal size when going from a single atom to a bulk material and the energy reduction by the attachment to a solid support. The solid support can hereby be a metal oxide or sulfide as well as a carbon-based material. Graphic adapted from Yang et al. [84].

The high surface free energy is said to be responsible for the catalytic properties, but also results in the instability of the supported single-atoms, which can lead to aggregation and the formation of nanoparticles, especially under harsh preparation and reaction conditions [85]. To address this key problem, metal loadings are typically kept low, or approaches to enhance the metal-support interactions, such as the utilization of defects in metal oxide supports $\left(\mathrm{FeO}_{\mathrm{x}}, \mathrm{CeO}_{2}\right.$ and $\left.\mathrm{TiO}_{2}\right)$, are utilized [86]. Another strategy to enhance the metal-support interactions is the introduction of additives or dopants to create nonoxygen binding motifs, such as $\mathrm{M}-\mathrm{N}_{\mathrm{x}}$ or $\mathrm{M}-\mathrm{S}_{\mathrm{x}}$ [87]. This leads to an enhanced stability of doped SACs [88], and also allows altering of the electronic properties of the single-metal atom.

Since SACs have the potential to combine the advantages of homogeneous catalysts (define active sites) and heterogeneous catalysts (catalysts recovery) within one system and are therefore being considered as bridge between homogeneous and heterogeneous catalysts, they also have attracted a great deal of attention in the development of novel heterogeneous hydroformylation catalysts.

Lang et al. for example reported the hydroformylation of different olefins using a Rh SAC supported on $\mathrm{ZnO}$ nanowires. HAADF-STEM (high-angle annular dark-field scanning transmission electron microscopy) and infrared CO chemisorption experiments showed the presence of isolated Rh atoms on the solid support and XPS and XANES spectra indicated the metallic electronic state of rhodium. From this it could be assumed that the $\mathrm{Rh}$ atoms occupy the $\mathrm{O}$ vacancies of $\mathrm{ZnO}$, thus, electron transfer from $\mathrm{Zn}$ to $\mathrm{Rh}$ is enabled. This leads to a strong interaction between rhodium and the support material and explains the excellent recyclability in liquid phase reactions. For all substrates, such as styrene, hexene and propylene an excellent chemoselectivity in the hydroformylation reaction could be achieved, and no hydrogenation product was observed. In the case of propylene, a selectivity of $99 \%$ and TON of 15000 was reported under mild conditions $\left(\mathrm{w}_{\mathrm{Rh}}=0.006 \mathrm{wt} \%, \mathrm{~T}=100^{\circ} \mathrm{C}, \mathrm{p}=0.8 \mathrm{MPaCO}\right.$, $0.8 \mathrm{MPa}_{2}$ ). Under similar reaction conditions the homogeneous Wilkinson catalysts achieved TONs of 37000 . In the case of the hydroformylation of styrene or styrene derivates the Rh SAC catalysts was superior over two orders of magnitude over the Wilkinson catalyst [89].

Almost concurrently, Wang et al. reported a CoO-supported Rh single-atom catalyst. It was found that an increase in Rh mass loading leads to the formation of aggregated metallic rhodium clusters on the support. In the reaction of the hydroformylation of propylene, a regioselectivity of $94.4 \%$ towards $n$-butanal and TOF of $2065 \mathrm{~h}^{-1}$ could be achieved using the $0.2 \% \mathrm{Rh} / \mathrm{CoO}$ catalyst. Mechanistic studies indicated that a structural rearrangement of the Rh single atoms occurred during the catalytic process. Surprisingly, by XPS spectroscopy it was found that the Rh atoms on $\mathrm{CoO}$ were present in the +3 oxidation state and not in the +1 oxidation state which is commonly found in homogenous 
counterparts. The authors state that this higher valence state might be an essential factor for the high selective of the Rh-based SAC catalyst towards linear aldehyde [90].

\subsubsection{Supported $\mathrm{Rh}_{2} \mathrm{P}$-Based Catalysts}

In the context of supported rhodium-containing hydroformylation catalysts, transition metal phosphides are also discussed as alternative candidate materials. These heterogeneous catalysts [91-94] show high activities not only in hydrotreating reactions, such as the hydrodesulphurization [95-99] hydrodeoxygenation $[91,100]$ or hydrodenitrogenation $[91,101]$ but also in CO activation reactions, such as hydroformylation reactions [102-104]. Moreover, rhodium phosphides have also been employed as electrocatalyst for water splitting [105].

Among the platinum group metal phosphides, rhodium phosphides have been the most investigated compounds in the field of heterogeneous catalysis, with five different phosphides $\left(\mathrm{Rh}_{2} \mathrm{P}, \mathrm{Rh}_{3} \mathrm{P}_{2}, \mathrm{Rh}_{4} \mathrm{P}_{3}, \mathrm{RhP}_{2}, \mathrm{RhP}_{3}\right.$, Table 4$)$ being reported in the literature. Hereby, only the metal rich $\mathrm{Rh}_{2} \mathrm{P}$ has been identified as suitable catalyst for hydrotreating reactions [103].

Table 4. Structure, space group and bravais lattice of the five different rhodium phosphides. Right: solid-state structure of $\mathrm{Rh}_{2} \mathrm{P} . \mathrm{Rh}=$ grey, $\mathrm{P}=$ red.

\begin{tabular}{|c|c|c|c|c|c|}
\hline Phase & Space Group & Bravais Lattice & Structure & Ref. & Unit Cell of $R_{2} P$ \\
\hline $\mathrm{Rh}_{2} \mathrm{P}$ & $F m \overline{3} m$ & Cubic & Anti-CaF 2 & [106] & \\
\hline $\mathrm{Rh}_{3} \mathrm{P}$ & $\mathrm{P} \overline{4} m 2$ & Cubic & Anti-PbFCl & [107] & \\
\hline $\mathrm{Rh}_{4} \mathrm{P}_{3}$ & Pnma & Orthorhombic & $\mathrm{Rn}_{4} \mathrm{P}_{3}$ & [108] & \\
\hline $\mathrm{RhP}_{2}$ & $P 2_{1} / c$ & Monoclinic & $\mathrm{CoSb}_{2}$ & [109] & \\
\hline $\mathrm{RhP}_{3}$ & $\operatorname{Im} \overline{3}$ & Cubic & $\mathrm{CoAs}_{3}$ & [110] & \\
\hline
\end{tabular}

Whereas the $\mathrm{Rh}_{3} \mathrm{P}_{2}$ structure comprises phosphorus atoms coordinating to tetrahedrons and square pyramids, in the $\mathrm{Rh}_{4} \mathrm{P}_{3}$ structure the phosphorus atoms are only coordinated to square pyramids. The $\mathrm{RhP}_{2}$ phosphide crystallizes in the $\mathrm{CoSb}_{2}$ structure and the metal-rich phosphide $\mathrm{Rh}_{2} \mathrm{P}$ in the anti- $\mathrm{CaF}_{2}$ structure (Table 4, right). In general, it has been found that with increasing metal to phosphorus ratio the metallic properties of the phosphide increase [111]. This also becomes obvious from the band structure and density of state diagram of $\mathrm{Rh}_{2} \mathrm{P}$ (Figure 12) [112].

Already in 1971 Muetterties and Sauer prepared a broad range of different metal phosphides, including rhodium phosphide, supported on $\mathrm{Al}_{2} \mathrm{O}_{3}$ and tested them as catalysts in hydrogenation, isomerization and hydroformylation reactions of olefins. The catalysts were prepared by a slurry impregnation of the alumina support in a metal precursor containing solution. The treatment of the supported precursor in a $\mathrm{PH}_{3}$ stream for $2 \mathrm{~h}$ at a temperature between 250 and $300{ }^{\circ} \mathrm{C}$ lead to the formation of the corresponding transition metal phosphides. Although some materials were active as hydrogenation catalysts, attempts to perform the hydroformylation of propylene with metal phosphides were unsuccessful at $150{ }^{\circ} \mathrm{C}, 3.5 \mathrm{MPa}$ and an olefin: $\mathrm{H}_{2}: \mathrm{CO}(1: 1: 1)$ feed mixture, which the authors attribute to the low density of coordination sites [113].

The successful application of $\mathrm{Rh}_{2} \mathrm{P}$ as a catalyst for the hydroformylation of short-chain olefins was reported by Rupflin et al. [102,103]. The catalysts were prepared from $\mathrm{SiO}_{2}, \mathrm{Rh}\left(\mathrm{NO}_{3}\right)_{3}$ and phosphoric acid via the incipient wetness impregnation method to obtain supported phosphate precursors, which were then converted into phase pure $\mathrm{Rh}_{2} \mathrm{P}$ on $\mathrm{SiO}_{2}$ under reductive thermal treatment $\left(250-900{ }^{\circ} \mathrm{C}\right)$. The formation of phase pure $\mathrm{Rh}_{2} \mathrm{P}$ was confirmed by PXRD, TEM and HR TEM measurements. It has been shown that the reductive thermal treatment strongly influences the hydroformylation activity of the catalyst, with the catalyst reduced at the highest temperature $\left(900^{\circ} \mathrm{C}\right)$ being the most active and selective material for the hydroformylation of ethylene and propylene and the formation of the 
aldehyde. The best hydroformylation results were achieved at low $\mathrm{H}_{2}: \mathrm{CO}$ ratios $\left(\mathrm{T}=170-240{ }^{\circ} \mathrm{C}\right.$, $\mathrm{p}=5.0 \mathrm{MPa}, 10 \% \mathrm{C}_{2} \mathrm{H}_{4}, 10 \% \mathrm{H}_{2}, 70 \% \mathrm{CO}, 10 \% \mathrm{Ar}$, GHSV $=2773 \mathrm{~h}^{-1}$ ). A high CO partial pressure was necessary to suppress the olefin hydrogenation as side reaction. In the case of the hydroformylation of propylene with $\mathrm{Rh}_{2} \mathrm{P}$ supported on $\mathrm{SiO}_{2}$ a selectivity of over $90 \%$ towards butanal and an $n /$ iso ratio of 2.4 could be achieved. By adding water to the feed an increase of the selectivity towards the aldehyde could be observed and the formation of hydrogenation and aldol condensation products could be reduced. Up to $200{ }^{\circ} \mathrm{C}$, the formation of ethane and condensation products could even be completely suppressed during the hydroformylation of ethylene. Simultaneously, no activity of the catalyst in the water-gas shift reaction was observed. The authors attributed the selectivity enhancing effect of water to the blocking of unselective surface sites that are mainly active in the hydrogenation of the olefin by $\mathrm{H}_{2} \mathrm{O}$ molecules [103].
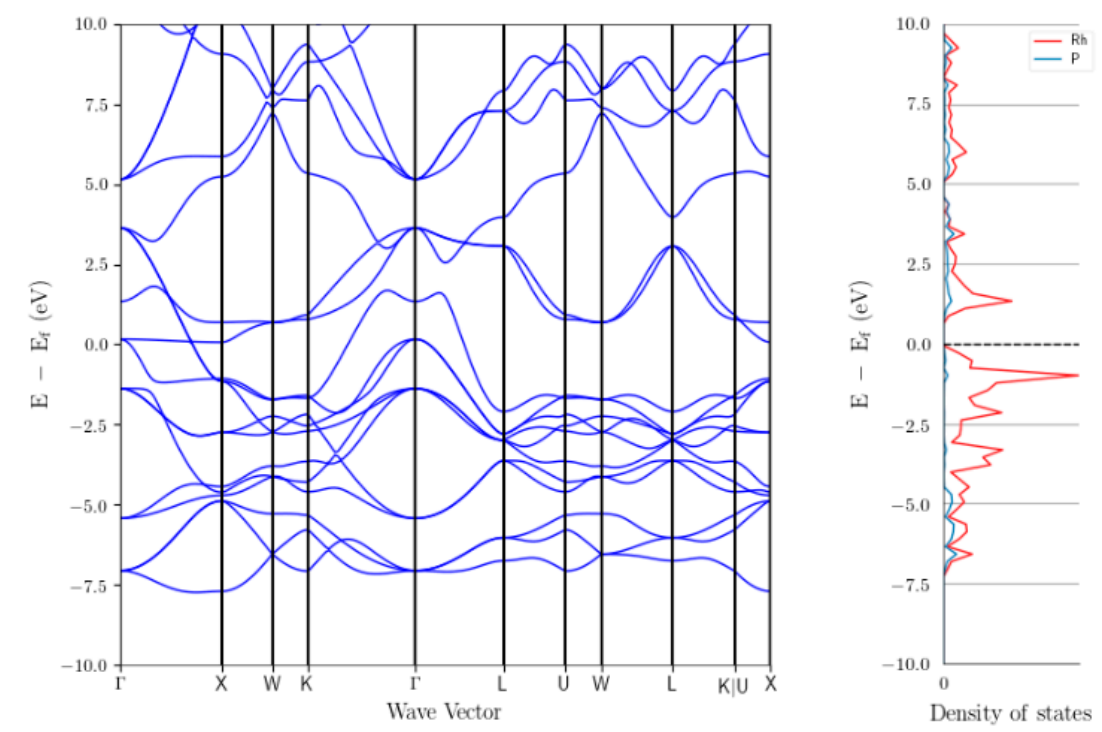

Figure 12. Band structure and density of states of $\mathrm{Rh}_{2} \mathrm{P}$, showing the metallic character of the phosphide. Graphic adapted from Perrson [112].

\subsubsection{Investigation of The Surface Properties of $\mathrm{Rh}_{2} \mathrm{P}$-Based Catalysts}

Based on the findings of Schunk and Rupflin et al., we are discussing the catalytic activity of rhodium phosphide $\mathrm{Rh}_{2} \mathrm{P}$ in the hydroformylation of olefins on a mechanistic level. Therefore, a detailed analysis of the surface constitution of the $\mathrm{Rh}_{2} \mathrm{P}$ catalysts is of importance.

As mentioned before, the reduction temperature of the phosphide has a major influence on the catalytic activity, with the catalyst being reduced at $900{ }^{\circ} \mathrm{C}$ showing the best performance in the hydroformylation of ethylene and propylene. To further investigate this finding, the dispersion of the phosphides, reduced at different temperatures, were evaluated via $\mathrm{CO}$ chemisorption measurements. As shown in Figure 13 (left) the dispersion only drops from 16\% to $11 \%$ despite increasing the reduction temperature from 250 to $900{ }^{\circ} \mathrm{C}$ [114].

The influence of the reduction temperature was also investigated using XPS measurements. It could be shown that the sample being reduced at $900{ }^{\circ} \mathrm{C}$ exhibits the highest Rh:P ratio, as depicted in Figure 13 (right). The more pronounced metallic character of the surface gives evidence for rhodium being the surface terminating species, with Rh adopting a non-zero $\delta^{+}$valence state, which is caused by the electron donation towards the phosphine atoms [114].

The fact that $\mathrm{Rh}$ is surface terminating is a crucial point for the mechanistic understanding and was also verified by IR spectroscopic measurements of the catalysts after $\mathrm{CO}$ adsorption experiments, which did not show the formation of any $\mathrm{P}=\mathrm{C}=\mathrm{O}$ surface species. The IR spectra of the catalysts reduced at 500 and $900{ }^{\circ} \mathrm{C}$ showed the occurrence of $\mathrm{Rh}-\mathrm{CO}$ bands. Whereas the $500{ }^{\circ} \mathrm{C}$ catalyst exhibits signals around $2000 \mathrm{~cm}^{-1}$ that correspond to both linearly and bridging $\mathrm{CO}$ atoms, as shown 
by Chuang [55] and Yan [58,59], the $900{ }^{\circ} \mathrm{C}$ catalyst showed one single signal at $2070 \mathrm{~cm}^{-1}$, which is assigned to $\mathrm{CO}$ groups that coordinate $\mathrm{Rh}$ in a linear fashion. Since Chuang and Pien reported that linear $\mathrm{CO}$ coordination is beneficial for hydroformylation reactions; the higher activity and selectivity observed for catalysts reduced at the highest temperature can therefore be explained $[54,55]$. The absence of bridging CO molecules also rules out the existence of Rh cluster compounds [103].
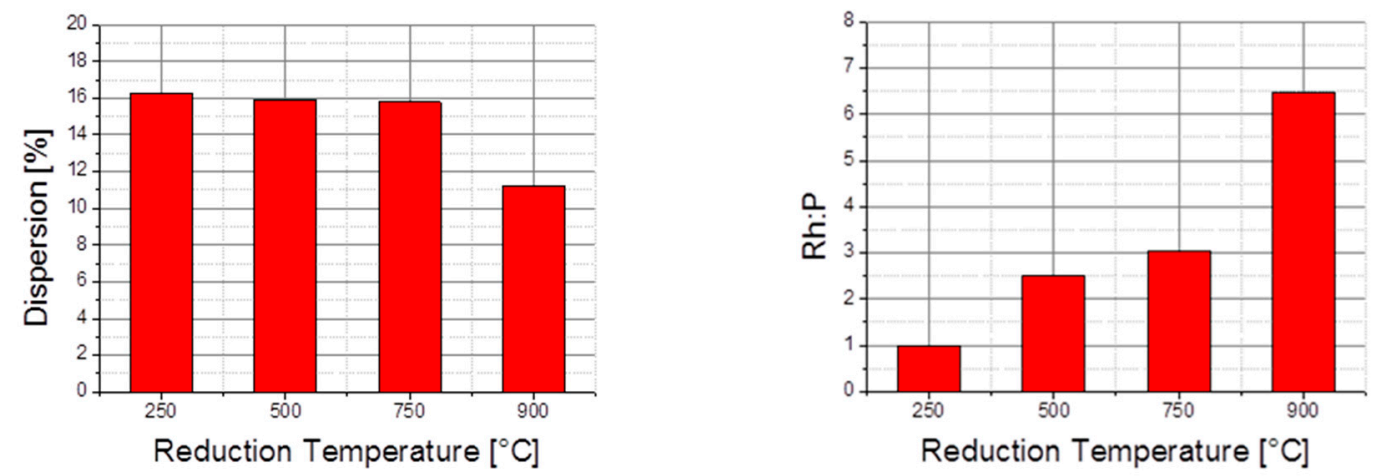

Figure 13. (Left) Dispersion obtained from CO chemisorption and (right) molar Rh:P ratio obtained from XPS measurements (Rh 3d spectra, P 2p spectra), both depending on the reduction temperature. Graphics adapted from Rupflin [114].

Based on these findings, the authors suggested that $\mathrm{Rh}_{2} \mathrm{P}$, in the form of highly crystallinesupported nanoparticles, feature surface sites that are different from the metallic anti-CaF 2 structured bulk of the phosphide, in which each Rh is surrounded by four P centers in a tetrahedral fashion. In contrast, at the surface of the phosphide the bonding situation has most likely similarities to phosphine or phosphite rhodium complexes applied in homogeneous catalysis. To further elucidate this assumption, cuts through the cubic phase of the prototype are examined. As shown in Figure 14, cuts through the cubic phase, even along high indices surfaces, always result in a separation of the rhodium sites and phosphorus. This leads to the conclusion that the surface of highly crystalline $\mathrm{Rh}_{2} \mathrm{P}$ nanoparticles can be defined as single-atom catalysts with frustrated single catalytic sites $[103,104]$. If cuts through the surface are made, surface terminations can easily be found where $\mathrm{Rh}$ is coordinated by three $\mathrm{P}$ atoms. Through the elevated sintering temperatures and the thereof resulting high crystallinity of the nanoparticles, an enhanced number of step sites, in which each Rh is only surrounded by two phosphorus centers and therefore coordinatively unsaturated, can be assumed to be present [77]. The importance of undercoordinated Rh sites present in Rh nanoparticles on oxide supports for the hydroformylation of olefins was already mentioned by McClure et al. [56].

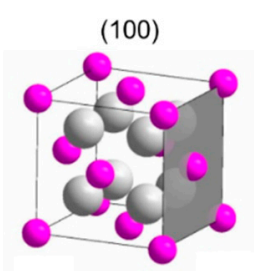

(110)

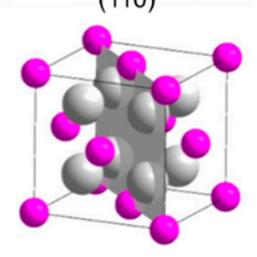

(010)

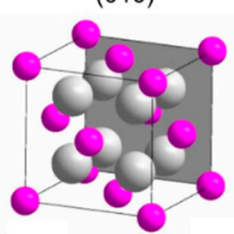

(101)

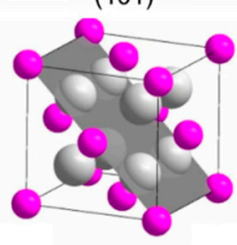

(001)

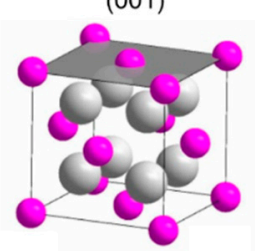

(011)

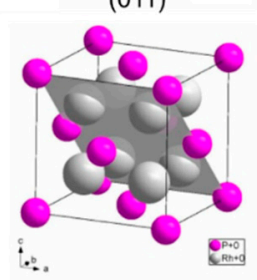

Figure 14. Low and high index cuts through the cubic structure of $\mathrm{Rh}_{2} \mathrm{P}$ do always deliver surface segments, where rhodium is separated by phosphorus. 
Hypothesis for a reaction mechanism for the hydroformylation of short-chain olefins over supported $\mathrm{Rh}_{2} \mathrm{P}$ nanoparticles

- Based on the experimental and analytical data mentioned before, we extracted the following characteristic features of $\mathrm{Rh}_{2} \mathrm{P}$ catalysts, which are crucial for the hypothetic hydroformylation reaction mechanism shown in Figure 15.

- Surface of $\mathrm{Rh}_{2} \mathrm{P}$ is $\mathrm{Rh}$ terminated

- Site separation of Rh and P occurs

- Undercoordinated Rh sites are present, which are similar to Rh phosphine complexes

- $\mathrm{Rh}_{2} \mathrm{P}$ reduced at $900{ }^{\circ} \mathrm{C}$ coordinates $\mathrm{CO}$ in a linear fashion via $\mathrm{Rh}$

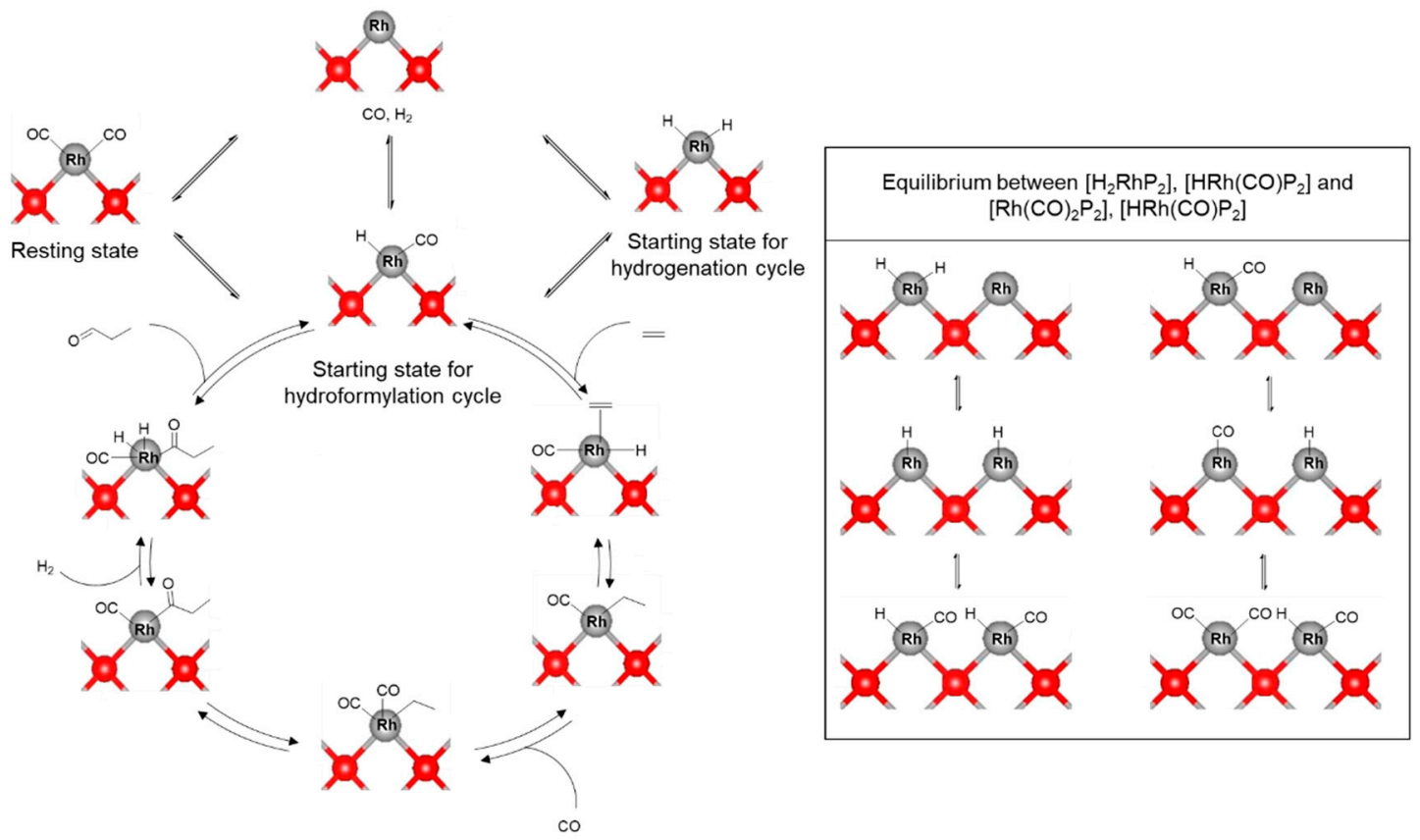

Figure 15. Proposed reaction mechanism for the hydroformylation of ethylene using a $\mathrm{Rh}_{2} \mathrm{P}$-based single-atom catalysts. The proposed mechanism is based on the experimental studies by Rupflin et al. [103].

As mentioned before, the surface sites on $\mathrm{Rh}_{2} \mathrm{P}$ have similarities to the environment in molecular rhodium phosphine or phosphite complexes and the high crystallinity of the nanoparticles points towards the fact that each Rh center at the surface is coordinated to two phosphorus centers. We therefore assume that a reaction mechanism in line with the basic assumptions accepted in the field of homogeneous catalysis is plausible. Under syngas treatment the Rh centers at the surface can then either undergo oxidative addition of $\mathrm{H}_{2}$ to form an active hydrogenation catalyst $\left[\mathrm{H}_{2} \mathrm{RhP}_{2}\right]$ or coordination of a two CO molecules can occur to form $\left[\mathrm{Rh}(\mathrm{CO})_{2} \mathrm{P}_{2}\right]$ which represents a resting state and is not active in the hydroformylation of an olefin. Further, the coordination of one CO molecule and addition of an hydride can occur, which leads to the formation of an active hydroformylation catalyst $\left[\mathrm{HRh}(\mathrm{CO}) \mathrm{P}_{2}\right]$. Depending on the feed gas composition a statistical distribution of the three species $\left[\mathrm{H}_{2} \mathrm{RhP}_{2}\right],\left[\mathrm{Rh}(\mathrm{CO})_{2} \mathrm{P}_{2}\right]$ and $\left[\mathrm{HRh}(\mathrm{CO}) \mathrm{P}_{2}\right]$ can be assumed. This explains also the hydroformylation activity enhancing effect of the high $\mathrm{CO}$ partial pressure. Logically, higher coordinated species might also be present. Assuming that each rhodium centre can adopt oxidation states between 0 and +1 , four different Rh complexes can be formed with a coordination number of 5 and also with a coordination number of 6 . However, higher coordinated Rh species are less relevant to the catalytically active hydrogenation or hydroformylation species considered here. Whereas the distribution of three relevant species in our case might only be the result of statistical distribution, in homogeneous catalysis further 
effects, such as solvents effects, the different gas solubilities in various solvents, the different diffusion coefficients of the gases as well as the different solubilities of the Rh species have to be taken into consideration $[115,116]$.

Since $\mathrm{Rh}-\mathrm{CO}$ bonds are quite labile, there is most likely an equilibrium between $\left[\mathrm{H}_{2} \mathrm{RhP}_{2}\right]$, $\left[\mathrm{HRh}(\mathrm{CO}) \mathrm{P}_{2}\right]$ and $\left[\mathrm{Rh}(\mathrm{CO})_{2} \mathrm{P}_{2}\right]$, as shown in Figure 15 (right), which is enabled through a hydrogen spillover to neighboring $\mathrm{Rh}$ sites. After the formation of the catalytically active $\left[\mathrm{HRh}(\mathrm{CO}) \mathrm{P}_{2}\right]$ hydroformylation catalyst, the coordination of the olefin occurs, to form a $\pi$-complex, which is followed by migratory insertion of the $\mathrm{H}$ into the $\mathrm{Rh}-\mathrm{C}$ bond. Subsequently, $\mathrm{CO}$ coordination leads to the acyl-complex, which after oxidative addition of hydrogen and reductive elimination of the aldehyde, can be converted into the active hydroformylation catalyst.

\subsubsection{Potential Role of Water in The Reaction}

As Rupflin et al. stated before, the role of water in suppressing olefin hydrogenation can probably be attributed to the blocking of surface sites, that are mainly active in the hydrogenation [103]. This is plausible since the nature of the chemical substrate bond that is activated during the catalytic reaction has an enormous influence on the surface atom arrangement of the catalyst that provides the lowest action energy. These particle-dependent reactivity changes in heterogeneous catalytic systems have extensively been studies by Murzin [76] and van Santen [77]. It has been shown that reactions that involve activation of $\pi$-bonds, as in CO, can be distinguished from reactions that involve $\sigma$ bonds, such as $\mathrm{H}_{2}$ dissociation. More precisely, whereas the activation of molecular $\pi$-bonds requires catalytic centers, which consist of several metal atoms and step-edge sites, hydrogenation reactions are typically particle-size independent [77]. Since through the addition of water to the stream, the chemoselectivity of towards the aldehyde products can be enhanced and the unwanted hydrogenation can be suppressed, it is plausible to assume that water preferably blocks the terrace Rh sites. However, studies by Bazhenov et al. have shown that water adsorption of Rh and Pt nanoparticles is also preferred over unsaturated edge and corner sites of the particle, which is in contradiction with our assumption [117]. Therefore, another explanation for the chemoselectivity enhancing effect and the suppression of the formation of condensation products through the addition of water, might be a facilitated product elimination. This can seamlessly be explained by the formation of hydrogen bonds between the carbonyl oxygen atom of the acyl complex and water, which renders the carbonyl carbon atom more electropositive and therefore more active for the nucleophilic attack of the hydride (Figure 16).

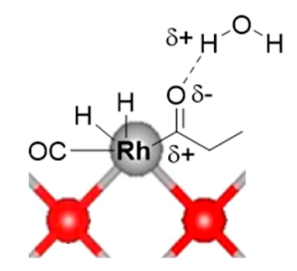

Figure 16. Potential role of water in the formation of the aldehyde. Thought hydrogen bonds the electron density at the carbonyl carbon atom is reduced and therefore the nucleophilic attack of the hydride is facilitated.

\subsection{Rhodium Complexes in Supported Liquids}

An alternative approach in the heterogenization of Rh based catalysts, deals with the anchoring of molecular rhodium complexes to solid supports via a mediating liquid. In this context, ionic liquids (IL), which can be defined as organic salts being present as liquids below $100^{\circ} \mathrm{C}$ [118], and subsequently supported ionic liquid phase (SILP) catalysts have been investigated. ILs can be constituted of a wide range of organic cations, such as imidazolium, pyridinium or morpholinium among others as well as of inorganic or organic anions like halogenides, perfluorinated borates and phosphates, and carboxylates etc. Such SILP catalysts combine the advantages of homogeneous (high activity and 
selectivity) and heterogeneous catalysts (manageable catalysts recycling) and several reviews point out the successful catalytic application of SILPs [119-123]. De Vos and co-workers have, for example, given a great overview of SILP applications in hydroformylation, metathesis, carbonylation, hydrogenation, hydroamination, $\mathrm{C}-\mathrm{C}$ coupling and various enantioselective reactions [122].

In a SILP catalyst, the ligand, such as the sulfonated Xantphos phosphine ligand (Sulphoxantphos, Figure 17), and the transition metal precursor, for example rhodium carbonyl complexes, are dissolved in an ionic liquid, which is impregnated on a support material (Figure 17). In an ideal system, a thin film of the catalyst/ionic liquid solution can be immobilized on a highly porous material via physisorption, tethering or covalent anchoring of ionic liquid fragments. The film thickness, which can be very well-controlled by physical vapor deposition, is a crucial point to consider, since during the catalytic reaction the reactants have to reach the active metal species through the film surface and the product has to diffuse back and pass through the surface [123].

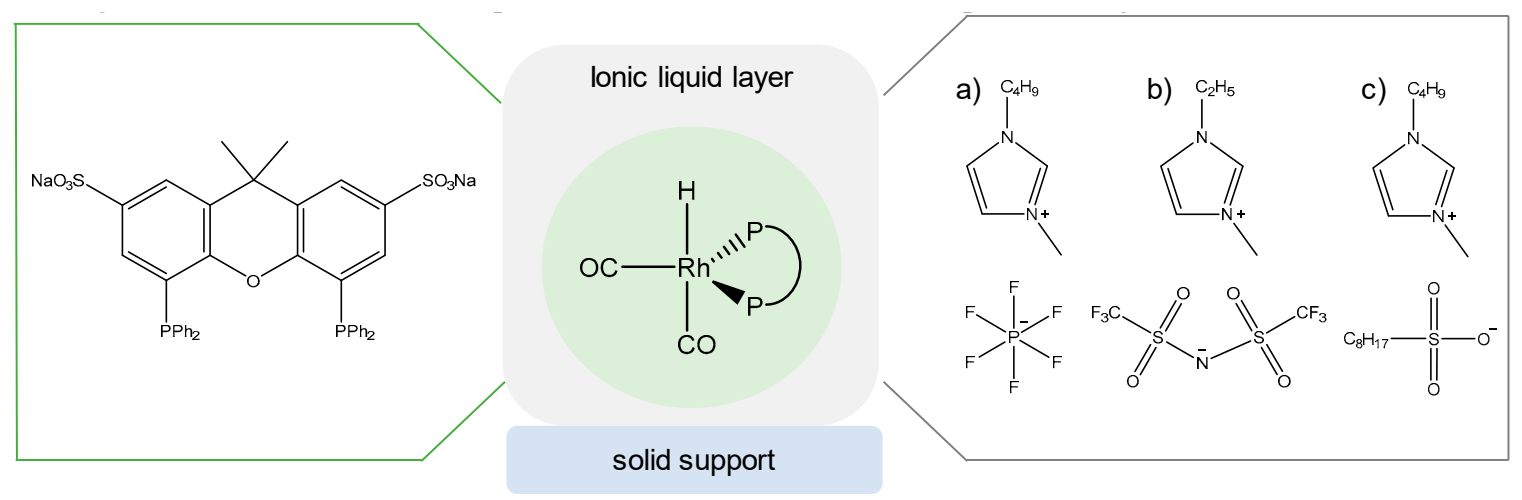

Figure 17. Schematic presentation of SILP catalyst, containing a rhodium carbonyl Sulphoxantphos complex. Different ionic liquids used for the preparation of SILP catalyst are shown: (a) 1-butyl-3-methylimidazol-3-ium hexafluorophosphat [BMIM][PF 6$]$, (b) 1-ethyl-3- methylimidazolium bis(trifluoromethylsulfonyl)amide [EMIM] $\left[\mathrm{NTf}_{2}\right]$ and (c) 1-n-butyl-3-methylimidazolium n-octylsulfate $[\mathrm{BMIM}]\left[\mathrm{OctSO}_{4}\right]$.

Riisager et al. first reported the gas phase hydroformylation of propylene with a SILP catalyst consisting of 1-butyl-3-methylimidazol-3-ium hexafluorophosphat [BMIM] $\left[\mathrm{PF}_{6}\right]$ or the halogen-free 1-n-butyl-3-methylimidazolium $n$-octylsulfate [BMIM] $\left[\mathrm{OctSO}_{4}\right]$ as an ionic liquid supported on $\mathrm{SiO}_{2}$ in a fixed bed reactor. $\left[\mathrm{Rh}(\mathrm{CO})_{2}(\mathrm{acac})\right]$ was used in combination with the Sulphoxantphos ligand. The materials prepared from [BMIM] $\left[\mathrm{PF}_{6}\right]$ exhibited TOFs of up to $37 \mathrm{~h}^{-1}$ and regioselectivity's for the $n$-aldehyde of up to $96 \%$ under propylene hydroformylation conditions $\left(\mathrm{w}_{\mathrm{Rh}}=0.2 \mathrm{wt} \%, \mathrm{~T}=373 \mathrm{~K}\right.$, $\mathrm{p}=1.0 \mathrm{MPa}, \mathrm{C}_{3} \mathrm{H}_{6}: \mathrm{CO}: \mathrm{H}_{2}=1: 1: 1, \mathrm{GHSV}=7000 \mathrm{~h}^{-1}$, performing the experiments at a propylene conversion of $X \approx 1 \%$ ). The effect of the variation of the [BMIM] ionic liquid anions from $\left[\mathrm{PF}_{6}\right]$ to $\left[\mathrm{OctSO}_{4}\right]$ on the catalytic performance of the catalysts was not significant, and both catalysts show similar activity and selectivity values under identical conditions [124]. The Rh-Sulphoxantphos /[BMIM] $\left[\mathrm{OctSO}_{4}\right]$ system has a fair long-term stability evaluated from data of $60 \mathrm{~h}$ on stream under hydroformylation conditions [125].

Kinetic studies of the Rh-Sulphoxantphos/[BMIM][OctSO $\left.]_{4}\right] / \mathrm{SiO}_{2}$ SILP catalyst in the hydroformylation of propylene in a fixed bed reactor have shown that TOF values of up to $500 \mathrm{~h}^{-1}$ under the best reaction conditions ( $\mathrm{n}_{\text {Rhodium }}=8.17 \cdot 10^{-5} \mathrm{~mol}, \mathrm{~T}=413 \mathrm{~K}, \mathrm{p}=1.0 \mathrm{MPa}, \mathrm{p}_{\mathrm{C} 3 \mathrm{H} 6}=0.32 \mathrm{MPa}$, $\mathrm{H}_{2}: \mathrm{CO}=1: 1, \tau=0.9 \mathrm{~s}$ ) could be achieved. The regioselectivity toward $n$-butanal was shown to be $87 \%$. Nevertheless, an activity loss of approximately $17 \%$ of the catalyst occurred within $180 \mathrm{~h}$ on stream, which was attributed to the formation and absorption of high-boiling side products through aldol condensation within the ionic liquid. Extraction of the side products with cyclohexane and characterization of the species by gas chromatography confirmed the formation of 2-butanol, 2-ethyl-hexanal and 2-ethyl-hexanol, which could also alternatively be removed by evacuation of the 
reactor. This enabled a full restorage of the catalyst activity. From these data an apparent activation energy for the hydroformylation of propylene was estimated to be $63 \mathrm{~kJ} \cdot \mathrm{mol}^{-1}$, which is in the range of the activation energies obtained with molecular hydroformylation catalysts. This comparison, and the fact that Rh-SILP catalyst perform very similar compared to homogeneous catalysts regarding variations in the syngas composition, provides additional evidence that the Rh-SILP catalyst are present as a homogeneous catalyst in the ionic film immobilized on silica [126].

The effect of temperature on the kinetics of the hydroformylation of propylene using SILP catalysts (Rh-Sulphoxantphos/[BMIM] $\left[\mathrm{OctSO}_{4}\right]$ on $\mathrm{SiO}_{2}$ ) were studied by Hanna et al. It was found that elevated temperatures have profound effects on the regioselectivity and the nature of the rate-determining step as seen in the field of homogenous catalysts. At low temperatures the RDS is the olefin insertion into a $\mathrm{Rh}-\mathrm{H}$ bond, whereas at higher temperatures the oxidative addition of $\mathrm{H}_{2}$ becomes rate determining. The variation of the RDS was explained by looking at the elementary reaction steps with the largest Gibbs free energy of activation. The enthalpic energy barrier for olefin insertion is greater than for the oxidative addition step, which causes the olefin insertion to be the RDS at low temperature. At high temperature, however, the enhanced entropy loss leads to the oxidative addition being the RDS of the hydroformylation reaction [127].

Characterization techniques, such as in-situ FT IR, solid-state ${ }^{31} \mathrm{P}$ and ${ }^{29} \mathrm{Si}$ MAS NMR of the SILP catalyst (Rh-Sulphoxantphos/[BMIM] $\left[\mathrm{OctSO}_{4}\right]$ on $\mathrm{SiO}_{2}$ ) have suggested that the active form of the catalyst consists of $\left[\mathrm{HRh}(\mathrm{CO})_{2}\right.$ (Sulphoxantphos)] complexes stabilized through interactions of the sulfonate groups of the ligand with silanol groups of the support (Figure 18) [128].

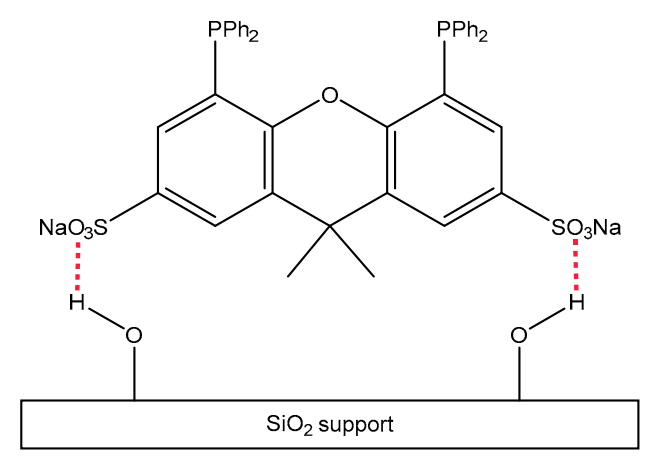

Figure 18. Interaction of the Sulphoxantphos ligand with surface silanol groups of the $\mathrm{SiO}_{2}$ support via hydrogen bonds [128].

This assumption was supported by the findings of Riisager et al. since a color change was observed from light red to yellow during the catalytic reaction, which is an indicator for the formation of the [HRh $(\mathrm{CO})_{2}$ (Sulphoxantphos)] complex $[124,125]$. The pre-treatment of $\mathrm{SiO}_{2}$ at temperatures above $373 \mathrm{~K}$ decreased the surface density of the silanol groups and increased the acidity of these groups. Consequently, the Sulphoxantphos-support interaction was enhanced, which led to a reduced electron density of the phosphorous lone pairs and consequently a weakened Rh-P coordinative bond. This causes the catalytic activity of the SILP catalyst to drop [125,128].

Haumann et al. extended the application of Rh-containing SILP catalyst to the hydroformylation of 1-butene. A rhodium Sulfoxantphos complex was dissolved in $[\mathrm{BMIM}]\left[\mathrm{OctSO}_{4}\right]$ and this solution was supported on silica. A kinetic study in a fixed bed reactor revealed that SILP catalysts are highly active, selective and long-term stable for $120 \mathrm{~h}$ on stream in the hydroformylation of butene. The most active SILP catalyst ( $\mathrm{w}_{\mathrm{Rh}}=0.3 \mathrm{wt} \%, \mathrm{~L} / \mathrm{Rh}=10, \mathrm{IL}$ loading $=0.1$ (IL volume/support pore volume), supported on $\mathrm{SiO}_{2}$ ) achieved TOF values of up to $563.5 \mathrm{~h}^{-1}$ with a pentanal chemoselectivity of $97.1 \%$ under following reaction conditions: $\mathrm{p}=1.0 \mathrm{MPa}$, $\mathrm{p}_{1 \text {-butene }}=0.24 \mathrm{MPa}, \mathrm{H}_{2}: \mathrm{CO}=1: 1, \tau=17 \mathrm{~s}$. The first order dependency with respect to rhodium indicated that the reaction was not limited by mass transport effects. The hydrogen partial pressure was found to have a positive effect on the reaction rate, whereas the carbon monoxide partial pressure had a slightly negative one [129]. The results from the 
fixed bed reactor were later on compared to a gradient-free gas-phase loop reactor (Berty type) using the same SILP catalyst (Rh-Sulphoxantphos/[BMIM][OctSO $\left.\mathrm{S}_{4}\right]$ on $\left.\mathrm{SiO}_{2}\right)$ [130]. The apparent activation energy has been determined between $80^{\circ} \mathrm{C}$ and $110^{\circ} \mathrm{C}$ at low conversions $(10 \%)$ and was found to be $64.1 \mathrm{~kJ} \cdot \mathrm{mol}^{-1}$. This value matched the results obtained from the fixed bed reactor studies under similar conditions and is large enough to assume that the SILP catalyst operates under no mass transport diffusion at the conditions applied [126,129]. Stability tests of the catalyst have shown that no ligand degradation took place after $120 \mathrm{~h}$ time on stream [130].

Jakuttis et al. further expanded the application of SILP catalysts for the hydroformylation of a mixture of $\mathrm{C}_{4}$ olefins. The effect of the ligand is studied by preparing and testing SILP catalysts with two different ligands: the well-studied Sulphoxanthphos ligand (Figure 17) and a complex diphosphite ligand (Figure 19). 1-Ethyl-3-methylimidazolium bis(trifluoro-methylsulfonyl)amide ([EMIM][NTf $\left.{ }_{2}\right]$ ) was used as ionic liquid and $\mathrm{SiO}_{2}$ as support material $\left[\mathrm{w}_{\mathrm{Rh}}=0.2 \mathrm{wt} \%, \mathrm{~L} / \mathrm{Rh}=10\right.$, IL loading $=0.1$ (IL volume/support pore volume)]. With the diphosphite SILP catalyst a chemoselectivity of more than $99 \%$ towards $n$-pentanal in the hydroformylation of a simulated industrial $\mathrm{C}_{4}$ mixture $\left(\mathrm{m}_{\text {catalyst }}=3 \mathrm{~g}\right.$, $\mathrm{p}=1.0 \mathrm{MPa}, \mathrm{p}_{\mathrm{C} 4}=0.2 \mathrm{MPa}, \mathrm{H}_{2}: \mathrm{CO}=1$, flow rate $=13.8 \mathrm{~mL} \cdot \mathrm{min}^{-1}, 500 \mathrm{ppm}$ of $\mathrm{H}_{2} \mathrm{O}$ ) could be achieved. The high regioselectivity indicated that the diphosphite SILP catalyst is a very active isomerization catalyst that selectively catalyzes the hydroformylation of 1-butene. No reaction with 2-butenes or the large amounts of isobutene present occurred [131].

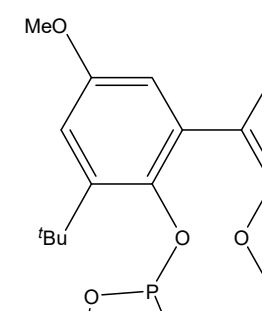

Figure 19. Sophisticated diphosphite ligand applied by Jakuttis et al. for the preparation of a SILP-catalysts used in the highly selective hydroformylation of a mixed $\mathrm{C}_{4}$ olefin mixture [131].

Weiß et al. reported the application of nitrogen doped carbon materials as support for SILP catalysts (Rh-Xantphos, [EMIM][NTf $\left.{ }_{2}\right]$ ) for the hydroformylation of ethylene. Whereas the catalytic activity of SILP catalysts dispersed on commercially available activated carbon was very low, the incorporation of nitrogen functionalities into the surface lead to an enhanced catalytic activity and the suppression of aldol condensation product formation. The nitrogen doped material was obtained by oxidation of the original carbon support followed by functionalization using urea or ammonia [132].

Table 5 gives an overview of the before mentioned rhodium complexes in supported ionic liquids, which were applied in gas liquid hydroformylation.

Table 5. Overview of performance data for rhodium based SILP catalysts employed in the hydroformylation reaction of short-chain olefins. TPPTS-Cs1 = tri(m-sulfonyl)triphenyl phosphine tricesium salt.

\begin{tabular}{|c|c|c|c|c|c|c|c|}
\hline Support & Ionic Liquid & Ligand & Substrate & TOF $\left(h^{-1}\right)$ & $\begin{array}{c}\text { Sum-sel. } \\
(\%)\end{array}$ & $\begin{array}{c}n \text {-Regio-sel. } \\
(\%)\end{array}$ & Ref. \\
\hline $\mathrm{SiO}_{2}$ & {$[\mathrm{BMIM}]\left[\mathrm{OctSO}_{4}\right]$} & TPPTS-Cs & ethylene & 800 & 90 & - & [133] \\
\hline \multirow[t]{2}{*}{$\mathrm{SiO}_{2}$} & {$[\mathrm{BMIM}]\left[\mathrm{OctSO}_{4}\right]$} & Sulpho- & propylene & $60-500$ & - & $88-96$ & [124-128] \\
\hline & & xantphos & butylene & 564 & - & 91 & \\
\hline $\mathrm{SiO}_{2}$ & {$[\mathrm{EMIM}]\left[\mathrm{NTf}_{2}\right]$} & $\begin{array}{l}\text { Sulpho- } \\
\text { xantphos } \\
\text { Diphos- } \\
\text { phite }\end{array}$ & C4-mixture & 3600 & - & 99 & [130] \\
\hline N-doped carbon & {$[\mathrm{EMIM}]\left[\mathrm{NTf}_{2}\right]$} & Xantphos & ethylene & 650 & 95 & - & [131] \\
\hline
\end{tabular}




\subsection{Comparison of The Different Heterogeneous Hydroformylation Rh Catalysts with Regard to Performance}

In Table 6 a comparison of the heterogenized Rh-based catalysts from the scientific and patent literature all with $\mathrm{SiO}_{2}$ as solid supports in the hydroformylation of propylene is shown. One candidate out of each section in this review was selected to pinpoint the performance differences.

Table 6. Comparison of performance data for heterogeneous rhodium-based catalysts on $\mathrm{SiO}_{2}$ mentioned in this review in the hydroformylation of propylene.

\begin{tabular}{|c|c|c|c|c|c|}
\hline $\begin{array}{l}\text { Section } \\
\text { Catalyst }\end{array}$ & $\begin{array}{c}\text { Section } 3.1 \\
{\left[\mathrm{Rh}_{4}(\mathrm{CO})_{12}\right]}\end{array}$ & $\begin{array}{c}\text { Section } 3.2 \\
\text { Rh }\end{array}$ & $\begin{array}{c}\text { Section } 3.2 \\
\mathrm{PPh}_{3}-\mathrm{Rh}\end{array}$ & $\begin{array}{c}\text { Section } 3.3 \\
\mathbf{R h}_{\mathbf{2}} \mathbf{P}^{\mathbf{b}}\end{array}$ & $\begin{array}{c}\text { Section } 3.4 \\
\text { Rh SILP }^{c}\end{array}$ \\
\hline $\mathrm{Rh}[\mathrm{wt} \%]$ & 2.24 & 1.0 & 1.0 & 5.07 & 0.2 \\
\hline $\mathrm{C}_{3} \mathrm{H}_{6}[\%]$ & 32 & 33.33 & 33.33 & 10 & 32 \\
\hline $\mathrm{CO}[\%]$ & 32 & 33.33 & 33.33 & 50 & 34 \\
\hline $\mathrm{H}_{2}[\%]$ & 36 & 33.33 & 33.33 & 10 & 34 \\
\hline $\mathrm{H}_{2} \mathrm{O}[\%]$ & - & - & - & 20 & - \\
\hline Ar [\%] & - & - & - & 10 & - \\
\hline $\mathrm{p}$ [MPa] & 0.07 & 1 & 1.0 & 2.0 & 1.0 \\
\hline $\mathrm{T}[\mathrm{K}]$ & 428 & 393 & 393 & 503 & 413 \\
\hline GHSV & - & 2000 & 2000 & 3000 & 462 \\
\hline Sum-sel. ${ }^{\mathrm{a}}[\%]$ & 75 & - & 100 & 87 & 88 \\
\hline Conv. [\%] & - & 0.12 & 27.1 & 7.3 & 28.1 \\
\hline $\mathrm{TOF}_{\text {bulk }}\left[\mathrm{h}^{-1}\right]$ & 0.04 & 1.2 & 131 & 3.5 & 500 \\
\hline $\mathrm{TOF}_{\text {surf }}\left[\mathrm{h}^{-1}\right]$ & - & - & - & 31.8 & - \\
\hline Ref. & [35] & [58] & [58] & [114] & [126] \\
\hline
\end{tabular}

${ }^{a}$ Sum-selectivity towards hydroformylation. ${ }^{b}$ Rhodiumphosphide catalyst was reduced at $1173 \mathrm{~K} \cdot{ }^{\mathrm{c}}$ Ionic liquid $=$ 1-butyl-3-methylimidazoliumoctylsulfat $(50 \mathrm{wt} \%)$, ligand = TPPS, L:Rh = 5 .

The highest turnover frequencies of $500 \mathrm{~h}^{-1}$ could be achieved using a Rh SILP catalyst, reported by Riisager et al. [126], whereas the second highest TOF of $131 \mathrm{~h}^{-1}$ was reported for the ligand-modified $\mathrm{Rh}$ nanoparticles $\left(\mathrm{PPh}_{3}-\mathrm{Rh}\right)$ [58]. With the rhodium phosphide on $\mathrm{SiO}_{2}$ a bulk TOF of $3.5 \mathrm{~h}^{-1}$ could be achieved, which corresponds to a surface normalized TOF of $31.8 \mathrm{~h}^{-1}$. The number of surface-active Rh centers was in this case determined from CO absorption measurements [114]. Wit rhodium nanoparticles on $\mathrm{SiO}_{2}$ a TOF of $1.2 \mathrm{~h}^{-1}$ was obtained in the hydroformylation of propylene [58]. whereas the rhodium carbonyl clusters $\mathrm{Rh}_{4}(\mathrm{CO})_{12}$ deposited on $\mathrm{SiO}_{2}$ only exhibited a TOF of $0.04 \mathrm{~h}^{-1}$ [35]. Despite the very high TOF values that could be achieved using Rh SILP catalysts, one major disadvantage is the formation of condensation products. Up to now no technical measures have been found to avoid this side-product channel, causing severe deactivation of the SILP catalyst.

A broader overview of the performance and selectivity of the before mentioned solid Rh-based catalysts is given in Figures 20 and 21, Tables A1 and A2. From Figure 20, which shows the sum-selectivity towards hydroformylation versus the logarithm of the TOF, it becomes obvious that the catalysts can roughly be grouped into four categories. The supported rhodium carbonyl complexes (category I) show a quite low catalytic activity with arbitrarily normalized sum-selectivity's of $100 \%$, whereas the supported $\mathrm{Rh}_{2} \mathrm{P}$-based catalyst is a candidate, which offers a very good compromise between catalytic activity and selectivity (category II). Higher TOFs can be achieved using Rh-Co based supported catalysts as well as lithium-modified Rh nanoparticles (category III). However, these catalysts only show sum-selectivity's between $65 \%$ and $80 \%$ towards butanal. The highest sum-selectivity's as well as a good catalytic performance can be achieved using Rh-based catalysts in the presence of organic, more precisely phosphine, ligands (category IV), such as Xantphos- $\mathrm{Rh} / \mathrm{SiO}_{2}$, $\mathrm{PPh}_{3}-\mathrm{Rh} / \mathrm{SiO}_{2}$ and $\left[\mathrm{HRhCO}\left(\mathrm{PPh}_{3}\right)\right] / \mathrm{VPC}$.

A similar effect can be observed for the $n /$ iso ratio of butanal depending on the TOF. As seen before, the presence of phosphine ligands is found to lead to an enhanced regioselectivity towards $n$-butanal and therefore to an increased $n / i$ so ratio. However, not only phosphine ligands may have a positive effect on the regioselectivity in the hydroformylation of propylene, but also the coordinating 
oxygen atoms, as seen in the case of the single-atom catalyst $\mathrm{Rh} / \mathrm{CoO}$ (category I). Apart from the ligand nature, in all of these cases a $\mathrm{Rh}$ oxidation state greater than $0\left(\mathrm{Rh}^{\delta+}, 0<\delta\right)$ seems to play an important role in improving the activity and selectivity of olefin hydroformylation. This finding is in accordance with the mechanistic considerations in the area of homogeneous catalysis and shows that heterogenized Rh-based catalysts have the potential to bridge the gap between homogeneous and heterogeneous catalysis. Rh-based catalysts without the presence of phosphine ligands tend to show a lower regioselectivity (category II). However, $\mathrm{Rh}_{2} \mathrm{P} / \mathrm{SiO}_{2}, \mathrm{Li}-\mathrm{Rh} / \mathrm{SiO}_{2}$ and $\left[\mathrm{HRh}(\mathrm{CO})\left(\mathrm{PPh}_{3}\right)\right] / \mathrm{VPC}$, marked in grey in Figure 21, exhibit similar TOF values to highly active and selective category I catalysts. Hereby it must be mentioned that the TOF for the $\mathrm{Rh}_{2} \mathrm{P}$-based catalyst is calculated based on the accessible surface $\mathrm{Rh}$ atoms determined by $\mathrm{CO}$ adsorption.
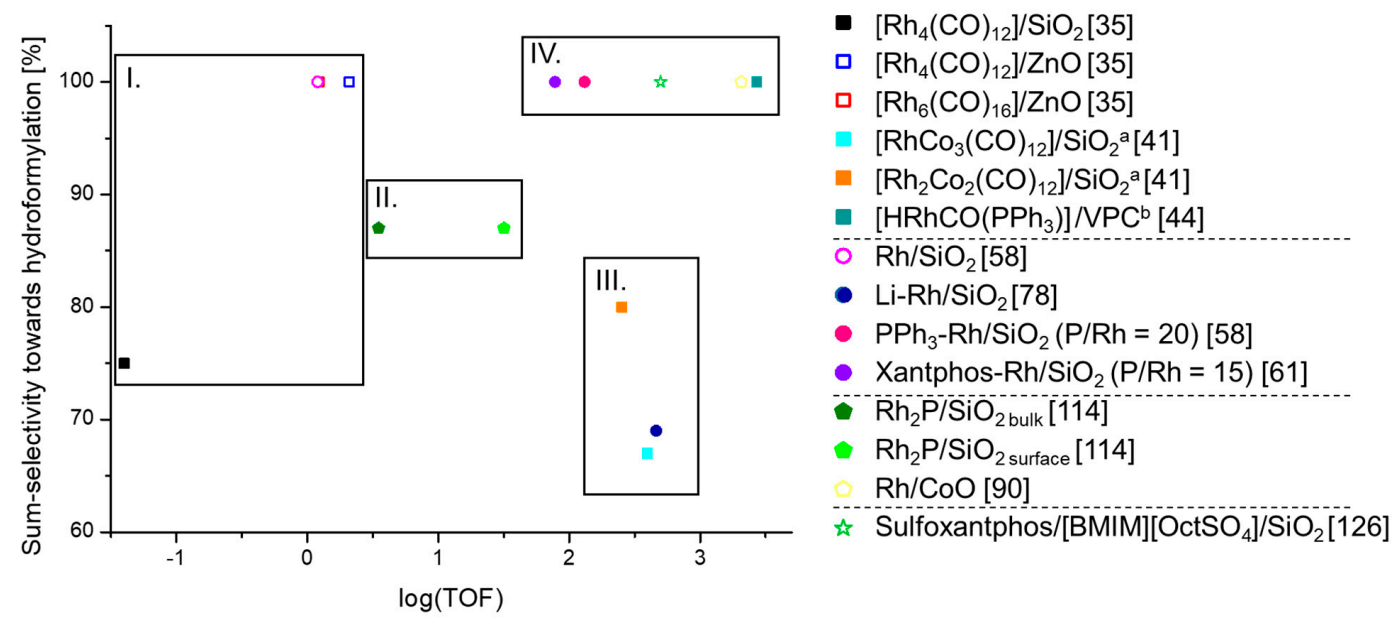

Figure 20. Sum-selectivity towards the hydroformylation product butanal depending on log (TOF). Filled symbols are sum-selectivity values directly taken from the corresponding literature, whereas empty symbols are normalized to $100 \%$ because of the lack of data in the literature. ${ }^{\text {a }} \mathrm{TOF}$ calculated for $\mathrm{C}_{3} \mathrm{H}_{7} \mathrm{CHO}+\mathrm{C}_{4} \mathrm{H}_{9} \mathrm{OH}$ and sum-selectivity calculated for $\mathrm{C}_{3} \mathrm{H}_{7} \mathrm{CHO}+\mathrm{n}-\mathrm{C}_{4} \mathrm{H}_{9} \mathrm{OH},{ }^{b} \mathrm{PPh}_{3}$ was added.

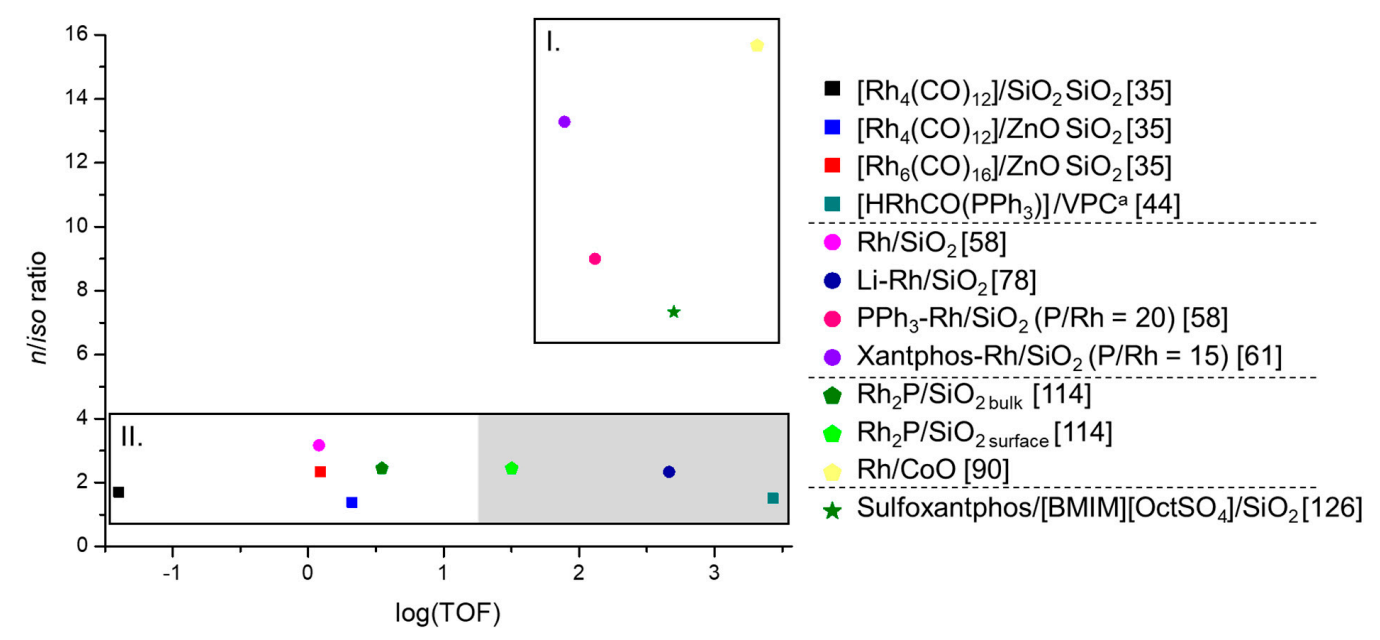

Figure 21. $n$-iso ratio of butanal depending on $\log (\mathrm{TOF}) .{ }^{\mathrm{a}} \mathrm{PPh}_{3}$ was added.

\section{Conclusions}

Over the last 40 years, various studies on different material classes concerning the catalytic hydroformylation of olefins using heterogenized catalysts have been published. The main driving force for this ongoing research has been the need for highly active and selective catalysts with an easily manageable catalyst recovery in order to avoid losses of precious metals and potentially expensive ligand materials. 
In this review we have discussed four different systematic material approaches for the heterogenization of hydroformylation catalysts. Firstly, the deposition of molecular rhodium complexes, such as carbonyl complexes, on various support materials was described. As additional ligands mainly phosphine and phosphite ligands have been utilized in the past. Additionally, a large amount of research efforts has been invested to develop various nanoparticle-based materials. In order to enhance the activity and selectivity of catalysts ligand- and metal-modified nanoparticles have been explored. Most recently, single-atom catalysts have been employed in the hydroformylation of short-chain olefins. A very interesting material in this context is the supported rhodium phosphide $\mathrm{Rh}_{2} \mathrm{P}$ on $\mathrm{SiO}_{2}$. Furthermore, rhodium complexes in supported liquids have been investigated and show high catalytic activities. As part of this review we gave a broad overview of the performance of different catalysts and compared sum-selectivity's as well as $n /$ iso ratios of the hydroformylation of propylene depending on the catalytic activity. This will give a solid basis for the performance evaluation and classification of novel heterogenized Rh-based catalysts in comparison with already existing materials.

Overall, we can state that the kinetic and mechanistic evaluation using heterogenized Rh-based catalysts in the field of hydroformylation is a very demanding topic. However, recently much insight into this came from the progresses made in the field of sophisticated computational methods and the enhanced availability of computing power. Also, the development of spectroscopic and X-ray based techniques as well as electron microscopy enables a detailed catalyst characterization on an atomic level even under reaction conditions. We emphasized the importance of the interplay of various analytic techniques for the in-depth investigation of the hydroformylation reaction mechanism using the $\mathrm{Rh}_{2} \mathrm{P}$-based catalyst.

Despite the challenges encountered in the determination of the reaction mechanism and the catalytically active species, there are common issues that have been discussed in the literature. For example, the solid support and the interaction of the support with the Rh metal species deposited on it has a huge influence on the catalytic performance. In this context, also the oxidation of $\operatorname{Rh}(0)$ to $\mathrm{Rh}(\mathrm{I})$ by the solid support has been described in various publications. However, there is still no clear answer for all of the materials reported to the question of whether $\mathrm{Rh}(0)$ or $\mathrm{Rh}(\mathrm{I})$ is responsible for the catalytic activity towards the hydroformylation of short-chain olefins. Our catalytic performance and selectivity evaluation of various Rh-based catalysts has shown that the surrounding atoms of the Rh centers definitely play a major role in this context and that a Rh oxidation state greater than 0 seems to have an activity and selectivity enhancing effect in the hydroformylation of propylene. Another point to mention is the fact that the $\mathrm{CO}$ adsorption mode on the catalytically surface is a crucial point to consider when discussing activity and selectivity behavior of the materials. A common general finding has been shown that linear bound $\mathrm{CO}$ appears to be more reactive in hydroformylation reactions that other surface coordination geometries, such as gem-dicarbonyl species or bridging $\mathrm{CO}$ molecules for example.

We believe that in the next years the field of heterogeneous hydroformylation catalysis will grow further and attract attention not only in an academic environment but also in an industrial context. Since the synthetic toolbox for the heterogenization of rhodium-based catalysts is very extensive and continuously expands, through the use of different Rh precursors, additional ligands or coordinating matrices, as well as the application of various liquid and solid support materials, new directions for the development of novel catalysts are opened. In this context advanced analytic techniques and computational methods will be of major importance and may provide further insights as well as additional options. We hope that this review gave an overview of the available synthetic strategies and enhances the understanding of heterogeneous hydroformylation catalysis also on an atomic level. At this point we would like to emphasize the importance of a detailed mechanistic and kinetic knowledge of the hydroformylation catalysts is for the future tailor-made development of more advanced catalysts.

Author Contributions: First draft: L.A.R., Proof first draft: S.A.S. and R.G., Methodology: S.A.S. and S.H., Second draft: S.A.S. and S.H., Finalization: S.A.S. and R.G. All authors have read and agreed to the published version of the manuscript. 
Funding: Funding through BASF SE and hte GmbH is gratefully acknowledged.

Acknowledgments: We thank Rainer Papp (BASF SE) for his constant support during the writing process of this review.

Conflicts of Interest: The authors declare no conflict of interest

\section{Appendix A}

Table A1. Overview of the heterogenized rhodium-based catalysts mentioned in this review in the hydroformylation of propylene.

\begin{tabular}{|c|c|c|c|c|c|c|}
\hline $\begin{array}{l}\text { Section } \\
\text { Catalyst }\end{array}$ & {$\left[\mathrm{Rh}_{4}(\mathrm{CO})_{12}\right]$} & {$\left[\mathrm{Rh}_{4}(\mathrm{CO})_{12}\right]$} & {$\left[\mathrm{Rh}_{6}(\mathrm{CO})_{16}\right]$} & $\begin{array}{l}\text { Section } 3.1 \\
{\left[\mathrm{RhCo}_{3}(\mathrm{CO})_{12}\right]}\end{array}$ & {$\left[\mathrm{Rh}_{2} \mathrm{Co}_{2}(\mathrm{CO})_{12}\right]$} & {$\left[\mathrm{HRhCO}\left(\mathrm{PPh}_{3}\right)\right]^{\mathrm{C}}$} \\
\hline $\mathrm{Rh}[\mathrm{wt} \%]$ & 2.24 & 0.3 & 0.3 & - & - & - \\
\hline Support & $\mathrm{SiO}_{2}$ & $\mathrm{ZnO}$ & $\mathrm{ZnO}$ & $\mathrm{SiO}_{2}$ & $\mathrm{SiO}_{2}$ & VPC \\
\hline $\mathrm{C}_{3} \mathrm{H}_{6}[\%]$ & 32 & 32 & 32 & 33.33 & 33.33 & 33.33 \\
\hline $\mathrm{CO}[\%]$ & 32 & 32 & 32 & 33.33 & 33.33 & 33.33 \\
\hline $\mathrm{H}_{2}[\%]$ & 36 & 36 & 36 & 33.33 & 33.33 & 33.33 \\
\hline $\mathrm{H}_{2} \mathrm{O}[\%]$ & - & - & - & - & - & - \\
\hline $\operatorname{Ar}[\%]$ & - & - & - & - & - & - \\
\hline $\mathrm{p}$ [MPa] & 0.07 & 0.07 & 0.07 & 0.1 & 0.1 & 2.9 \\
\hline $\mathrm{T}[\mathrm{K}]$ & 428 & 423 & 423 & 443 & 443 & 393 \\
\hline GHSV & - & - & - & - & - & - \\
\hline Sum-sel. ${ }^{\mathrm{a}}[\%]$ & 75 & - & - & $67^{\mathrm{b}}$ & $80^{\mathrm{b}}$ & 100 \\
\hline Conv. [\%] & - & - & - & 12.6 & 6.9 & - \\
\hline n/iso ratio & 1.7 & 1.4 & 2.33 & - & - & 1.5 \\
\hline $\mathrm{TOF}_{\text {bulk }}\left[\mathrm{h}^{-1}\right]$ & 0.04 & 2.1 & 1.23 & $396^{\mathrm{b}}$ & $252^{\mathrm{b}}$ & 2700 \\
\hline $\operatorname{TOF}_{\text {surf }}\left[\mathrm{h}^{-1}\right]$ & - & - & - & - & - & - \\
\hline Ref. & [35] & [35] & [35] & [41] & [41] & [44] \\
\hline
\end{tabular}

${ }^{a}$ Sum-selectivity towards hydroformylation. ${ }^{b}$ TOF calculated for $\mathrm{C}_{3} \mathrm{H}_{7} \mathrm{CHO}+\mathrm{C}_{4} \mathrm{H}_{9} \mathrm{OH}$ and sum-selectivity calculated for $\mathrm{C}_{3} \mathrm{H}_{7} \mathrm{CHO}+n-\mathrm{C}_{4} \mathrm{H}_{9} \mathrm{OH}$. ${ }^{c} \mathrm{PPh}_{3}$ was added.

Table A2. Overview of the heterogenized rhodium-based catalysts mentioned in this review in the hydroformylation of propylene.

\begin{tabular}{|c|c|c|c|c|c|c|c|}
\hline \multirow{2}{*}{$\begin{array}{l}\text { Section } \\
\text { Catalyst }\end{array}$} & \multicolumn{4}{|c|}{ Section 3.2} & \multicolumn{2}{|c|}{ Section 3.3} & \multirow{2}{*}{$\begin{array}{l}\text { Section } 3.4 \\
\text { Rh SILPb }\end{array}$} \\
\hline & $\mathbf{R h}$ & Li-Rh & $\mathrm{PPh}_{3}-\mathrm{Rh}$ & Xantphos-Rh & $\mathrm{Rh}_{2} \mathrm{P}^{\mathrm{a}}$ & Rh SAC & \\
\hline $\operatorname{Rh}[w t \%]$ & 1.0 & 2 & 1.0 & 0.2 & 5.07 & 0.2 & 0.5 \\
\hline Support & $\mathrm{SiO}_{2}$ & $\mathrm{SiO}_{2}$ & $\mathrm{SiO}_{2}$ & $\mathrm{SiO}_{2}$ & $\mathrm{SiO}_{2}$ & $\mathrm{CoO}$ & $\mathrm{SiO}_{2}$ \\
\hline $\mathrm{C}_{3} \mathrm{H}_{6}[\%]$ & 33.33 & 20 & 33.33 & 33.33 & 10 & 6 & 24 \\
\hline $\mathrm{CO}[\%]$ & 33.33 & 40 & 33.33 & 33.33 & 50 & 47 & 38 \\
\hline $\mathrm{H}_{2}[\%]$ & 33.33 & 40 & 33.33 & 33.33 & 10 & 47 & 38 \\
\hline $\mathrm{H}_{2} \mathrm{O}[\%]$ & - & - & - & - & 20 & - & - \\
\hline $\operatorname{Ar}[\%]$ & - & - & - & - & 10 & - & - \\
\hline $\mathrm{p}$ [MPa] & 1 & 0.1 & 1.0 & 0.2 & 2.0 & 1.66 & 1.32 \\
\hline $\mathrm{T}[\mathrm{K}]$ & 393 & $413 \mathrm{~K}$ & 393 & 398 & 503 & 373 & 413 \\
\hline GHSV & 2000 & - & 2000 & - & 3000 & - & - \\
\hline Sum-sel. ${ }^{\mathrm{a}}[\%]$ & - & 59 & 100 & 100 & 87 & - & - \\
\hline Conv. $[\%]$ & 0.12 & 0.85 & 27.1 & $<1$ & 7.3 & 94.6 & 28.1 \\
\hline$n /$ iso ratio & 3.17 & 2.33 & 9 & 13.29 & 2.45 & 15.67 & 7.13 \\
\hline $\mathrm{TOF}_{\text {bulk }}\left[\mathrm{h}^{-1}\right]$ & 1.2 & 462 & 131 & 78 & 3.5 & 2065 & 500 \\
\hline $\mathrm{TOF}_{\text {surf }}\left[\mathrm{h}^{-1}\right]$ & - & - & - & - & 31.8 & - & - \\
\hline Ref. & [58] & [78] & [58] & [61] & [114] & [90] & [126] \\
\hline
\end{tabular}

a Sum-selectivity towards hydroformylation. ${ }^{\mathrm{b}}$ Ionic liquid = 1-butyl-3-methylimidazoliumoctylsulfat, ligand $=$ Sulphoxantphos.

\section{References}

1. Roelen, O. Verfahren zur Herstellung von Sauerstoffhaltigen Verbindungen. DE Patent 849548, 20 September 1938.

2. Roelen, O. Production of Oxygenated Carbon Compounds. U.S. Patent 2327066, 17 August 1943.

3. Franke, R.; Selent, D.; Börner, A. Applied hydroformylation. Chem. Rev. 2012, 112, 5675-5732. [CrossRef] 
4. Pospech, J.; Fleischer, I.; Franke, R.; Buchholz, S.; Beller, M. Alternative metals for homogeneous catalyzed hydroformylation reactions. Angew. Chem. Int. Ed. 2013, 52, 2852-2872. [CrossRef] [PubMed]

5. Evans, D.; Osborn, J.A.; Wilkinson, G. Hydroformylation of alkenes by use of rhodium complex catalysts. J. Chem. Soc. A 1968, 3, 3133-3142. [CrossRef]

6. Brown, C.K.; Wilkinson, G. Homogeneous hydroformylation of alkenes with hydridocarbonyltris(triphenylphosphine)rhodium(I) as catalyst. J. Chem. Soc. A 1970, 2753-2764. [CrossRef]

7. Tolman, C.A. Phosphorus ligand exchange equilibriums on zerovalent nickel. Dominant role for steric effects. J. Am. Chem. Soc. 1970, 92, 2953-2956. [CrossRef]

8. Tolman, C.A. Steric effects of phosphorus ligands in organometallic chemistry and homogeneous catalysis. Chem. Rev. 1977, 77, 313-348. [CrossRef]

9. Durand, D.J.; Fey, N. Computational Ligand Descriptors for Catalyst Design. Chem. Rev. 2019, 119, 6561-6594. [CrossRef] [PubMed]

10. Wiese, K.-D.; Obst, D. Catalytic Carbonylation Reactions; Beller, M., Ed.; Springer: Berlin/Heidelberg, Germany, 2006.

11. Jiao, Y.; Torne, M.S.; Gracia, J.; Niemantsverdriet, J.H.; van Leeuwen, P.W. Ligand effects in rhodium-catalyzed hydroformylation with bisphosphines: Steric or electronic. Catal. Sci. Technol. 2017, 7, 1404-1414. [CrossRef]

12. Takahashi, K.; Yamashita, M.; Nozaki, K. Tandem Hydroformylation/Hydrogenation of Alkenes to Normal Alcohols Using Rh/Ru Dual Catalyst or Ru Single Component Catalyst. J. Am. Chem. Soc. 2012, 134, 18746-18757. [CrossRef]

13. Fleischer, I.; Dyballa, K.M.; Jennerjahn, R.; Jackstell, R.; Franke, R.; Spannenberg, A.; Beller, M. From olefins to alcohols: Efficient and regioselective ruthenium-catalyzed domino hydroformylation/ reduction sequence. Angew. Chem. Int. Ed. 2013, 52, 2949-2953. [CrossRef]

14. Agbossou, F.; Carpentier, J.; Mortreux, F. Asymmetric hydroformylation. Chem. Rev. 1995, 95, $2485-2506$. [CrossRef]

15. Shaharun, M.S.; Mukhtar, H.; Dutta, B.K. Selectivity of Rhodium-catalyzed Hydroformylation of 1-Octene in a Thermomorphic Solvent System. J. Appl. Sci. 2011, 11, 1157-1163. [CrossRef]

16. Caiazzoa, A.; Settambolob, R.; Pontornoa, L.; Lazzaron, R. Chemoselectivity in the rhodium-catalyzed hydroformylation of 4-vinylpyridine: Crucial role of phosphine ligand in promoting carbonylation instead of hydrogenation. J. Organomet. Chem. 2000, 599, 298-303. [CrossRef]

17. Wiberg, K.B.; Crocker, L.S.; Morgan, M.K. Thermochemical studies of carbonyl compounds. 5. Enthalpies of reduction of carbonyl groups. J. Am. Chem. Soc. 1991, 113, 3447-3450.

18. Gorbunov, D.N.; Volkov, A.V.; Kardasheva, Y.S.; Maksimov, A.L.; Karakhanov, E.A. Hydroformylation in petroleum chemistry and organic synthesis: Implementation of the process and solving the problem of recycling homogeneous catalysts. Pet. Chem. 2015, 55, 587-603. [CrossRef]

19. Evans, D.; Yagupsky, G.; Wilkinson, G. The reaction of hydridocarbonyltris(triphenylphosphine)rhodium with carbon monoxide, and of the reaction products, hydridodicarbonylbis(triphenylphosphine)rhodium and dimeric species, with hydrogen. J. Chem. Soc. A 1968, 2660-2665. [CrossRef]

20. Kiss, G.; Mozeleski, E.J.; Nadler, K.C.; Van Driessche, E.; DeRoover, C. Hydroformylation of ethene with triphenylphosphine modified rhodium catalyst: Kinetic and mechanistic studies. J. Mol. Catal. A 1999, 138, 155-176. [CrossRef]

21. Kégl, T. Computational aspects of hydroformylation. RSC Adv. 2015, 5, 4304-4327. [CrossRef]

22. Lazzaroni, R.; Settambolo, R.; Alagona, G.; Ghio, C. Investigation of alkyl metal intermediate formation in the rhodium-catalyzed hydroformylation: Experimental and theoretical approaches. Coord. Chem. Rev. 2010, 254, 696-706. [CrossRef]

23. Rush, L.E.; Pringle, P.G.; Harvey, J.N. Computational kinetics of cobalt-catalyzed alkene hydroformylation. Angew. Chem. Int. Ed. 2014, 53, 8672-8676. [CrossRef]

24. Sparta, M.; Børve, K.J.; Jensen, V.R. Activity of Rhodium-Catalyzed Hydroformylation: Added Insight and Predictions from Theory. J. Am. Chem. Soc. 2007, 129, 8487-8499. [CrossRef] [PubMed]

25. Gellrich, U.; Koslowski, T.; Breit, B. Full kinetic analysis of a rhodium-catalyzed hydroformylation: Beyond the rate-limiting step picture. Catal. Sci. Technol. 2015, 5, 129-133. [CrossRef]

26. Gellrich, U.; Seiche, W.; Keller, M.; Breit, B. Mechanistic Insights into a Supramolecular Self-Assembling Catalyst System: Evidence for Hydrogen Bonding during Rhodium-Catalyzed Hydroformylation. Angew. Chem. Int. Ed. 2012, 51, 11033-11038. [CrossRef] [PubMed] 
27. Gleich, D.; Hutter, J. Computational Approaches to Activity in Rhodium-Catalysed Hydroformylation. Chem. Eur. J. 2004, 10, 2435-2444. [CrossRef] [PubMed]

28. van Leeuwen, P.W.M.N.; Casey, C.P.; Whiteker, G.T. Rhodium Catalyzed Hydroformylation; van Leeuwen, P.W.M.N., Ed.; Academic Publishers: Dordrecht, The Netherlands, 2000.

29. Lenarda, M.; Storaro, L.; Ganzerla, R. Hydroformylation of simple olefins catalyzed by metals and clusters supported on unfunctionalized inorganic carriers. J. Mol. Catal. A 1996, 111, 203-237. [CrossRef]

30. Sun, Q.; Dai, Z.; Liu, X.; Sheng, N.; Deng, F.; Meng, X.; Xiao, F.-S. Highly Efficient Heterogeneous Hydroformylation over Rh-Metalated Porous Organic Polymers: Synergistic Effect of High Ligand Concentration and Flexible Framework. J. Am. Chem. Soc. 2015, 137, 5204-5209. [CrossRef]

31. Sun, Q.; Jiang, M.; Shen, Z.; Jin, Y.; Pan, S.; Wang, L.; Meng, X.; Chen, W.; Ding, Y.; Lib, J.; et al. Porous organic ligands (POLs) for synthesizing highly efficient heterogeneous catalysts. Chem. Commun. 2014, 50, 11844-11847. [CrossRef]

32. Neves, Â.C.B.; Calvete, M.J.F.; Pinho e Melo, T.M.V.; Pereira, D.M.M. Immobilized Catalysts for Hydroformylation Reactions: A Versatile Tool for Aldehyde Synthesis. Eur. J. Org. Chem. 2012, 2012, 6309-6320. [CrossRef]

33. Li, C.; Wang, W.; Yan, L.; Ding, Y. A mini review on strategies for heterogenization of rhodium-based hydroformylation catalysts. Front. Chem. Sci. Eng. 2018, 12, 113-123. [CrossRef]

34. Wang, Z.; Ding, K.; Uozumi, Y. Handbook of Asymmetric Heterogenous Catalysis; Ding, K., Uozumi, Y., Eds.; WILEY-VCH: Weinheim, Germany, 2008.

35. Ichikawa, M. Catalytic Hydroformylation of Olefins Over the Rhodium, Bimetallic Rh-Co, and Cobalt Carbonyl Clusters Supported with Some Metal-Oxides. J. Catal. 1979, 59, 67-78. [CrossRef]

36. Fukuoka, A.; Rao, L.-F.; Kosugi, N.; Kuroda, H.; Ichikawa, M. Selective hydroformylation of ethene and propene catalysed on nay zeolite-entrapped $\mathrm{Rh}_{6}$ and bimetallic $\mathrm{RhFe}$ clusters and their structural characterization by extended x-ray absorption fine structure and fourier transform infrared spectroscopy. Appl. Catal. 1989, 50, 295-301. [CrossRef]

37. Ichikawa, M.; Rao, L.-F.; Kimura, T.; Fukuoka, A. Heterogenized bimetallic clusters: Their structures and bifunctional catalysis. J. Mol. Catal. 1990, 62, 1-35. [CrossRef]

38. Kosmulski, M. Isoelectric points and points of zero charge of metal (hydr)oxides: 50 years after Parks' review. Adv. Colloid Interfac. Sci. 2016, 238, 1-61. [CrossRef] [PubMed]

39. Huang, L.; Xu, Y.; Guo, W.; Liu, A.; Li, D.; Guo, X. Study on catalysis by carbonyl cluster-derived $\mathrm{SiO}_{2}$-supported rhodium for ethene hydroformylation. Catal. Lett. 1995, 32, 61-81. [CrossRef]

40. Basu, P.; Panayotov, D.; Yates, J.T. Rhodium-carbon monoxide surface chemistry: The involvement of surface hydroxyl groups on alumina and silica supports. J. Am. Chem. Soc. 1988, 110, 2074-2081. [CrossRef]

41. Huang, L.; Xu, Y.; Piao, G.; Liu, A.; Zhang, W. Enhancement of olefin hydroformylation related to supported bimetallic Rh-Co clusters. Catal. Lett. 1994, 23, 87-95. [CrossRef]

42. Huang, L. Formation of bimetallic $\mathrm{RhCo}_{3}$ clusters from monometallic carbonyl clusters on $\mathrm{SiO}_{2}$ as probed by hydroformylation. J. Mol. Catal. A 1997, 125, 47-52. [CrossRef]

43. de Munk, N.A.; Verbruggen, M.W.; de Leur, J.E.; Scholten, J.J.F. Gas Phase Hydroformylation of Propene with Porous Resin Anchored Rhodium Complexes. Part II. The Catalytic Performance. J. Mol. Catal. 1981, 11, 331-342. [CrossRef]

44. Yoneda, N.; Nakagawa, Y.; Mimami, T. Hydroformylation catalyzed by immobilized rhodium complex to polymer support. Catal. Today 1997, 36, 357-364. [CrossRef]

45. Bando, K.K.; Asakura, K.; Arakawa, H.; Isobe, K.; Iwasawa, Y. Surface Structures and Catalytic Hydroformylation Activities of Rh Dimers Attached on Various Inorganic Oxide Supports. J. Phys. Chem. 1996, 100, 13636-13645. [CrossRef]

46. Alvila, L.; Pakkanen, T.A.; Pakkanen, T.T.; Krause, O. Catalytic hydroformylation of 1-hexene over $\mathrm{Co}_{2} \mathrm{Rh}_{2}(\mathrm{CO})_{12}$ supported on inorganic carrier materials. J. Mol. Catal. 1992, 75, 333-345. [CrossRef]

47. Van Vu, T.; Kosslick, H.; Schulz, A.; Harloff, J.; Paetzold, E.; Schneider, M.; Radnik, J.; Steinfeldt, N.; Fulda, G.; Kragl, U. Selective hydroformylation of olefins over the rhodium supported large porous metal-organic framework MIL-101. Appl. Catal. A 2013, 468, 410-417. [CrossRef]

48. Van Vu, T.; Kosslick, H.; Schulz, A.; Harloff, J.; Paetzold, E.; Lund, H.; Kragl, U.; Schneider, M.; Fulda, G. Influence of the textural properties of Rh/MOF-5 on the catalytic properties in the hydroformylation of olefins. Microporous Mesoporous Mater. 2012, 154, 100-106. 
49. Sharma, S.K.; Parikh, P.A.; Jasra, R.V. Hydroformylation of alkenes using heterogeneous catalyst prepared by intercalation of HRh(CO)(TPPTS) ${ }_{3}$ complex in hydrotalcite. J. Mol. Catal. A. 2010, 316, 153-162. [CrossRef]

50. Sudheesh, N.; Sharma, S.K.; Shukla, R.S.; Jasra, R.V. HRh(CO) $\left(\mathrm{PPh}_{3}\right)_{3}$ encapsulated mesopores of hexagonal mesoporous silica (HMS) acting as nanophase reactors for effective catalytic hydroformylation of olefins. J. Mol. Catal. A 2008, 296, 61-70. [CrossRef]

51. Sudheesh, N.; Sharma, S.K.; Shukla, R.S.; Jasra, R.V. Investigations on the kinetics of hydroformylation of 1-hexene using $\mathrm{HRh}(\mathrm{CO})\left(\mathrm{PPh}_{3}\right)_{3}$ encapsulated hexagonal mesoporous silica as a heterogeneous catalyst. J. Mol. Catal. A 2010, 316, 23-29. [CrossRef]

52. Duanmu, C.; Wu, L.; Gu, J.; Xu, X.; Feng, L.; Gu, X. Magnetic nanoparticle supported triphenylphosphine ligand for the Rh-catalyzed hydroformylation reaction. Catal. Commun. 2014, 48, 45-49. [CrossRef]

53. Gorbunov, D.; Safronova, D.; Kardasheva, Y.; Maximov, A.; Rosenberg, E.; Karakhanov, E. New Heterogeneous Rh-Containing Catalysts Immobilized on a Hybrid Organic-Inorganic Surface for Hydroformylation of Unsaturated Compounds. ACS Appl. Mater. Interfaces 2018, 10, 26566-26575. [CrossRef]

54. Chuang, S.S.C.; Pien, S.-I. Infrared spectroscopic studies of ethene hydroformylation on $\mathrm{Rh} / \mathrm{SiO}_{2}$ : An investigation of the relationships between homogeneous and heterogeneous hydroformylation. J. Mol. Catal. 1989, 55, 12-22. [CrossRef]

55. Chuang, S.C.; Pien, S.-I. Infrared Study of the CO Insertion Reaction on Reduced, Oxidized, and Sulfided $\mathrm{Rh} / \mathrm{SiO}_{2}$ Catalysts. J. Catal. 1992, 135, 618-634. [CrossRef]

56. McClure, S.M.; Lundwall, M.J.; Goodman, D.W. Planar oxide supported rhodium nanoparticles as model catalysts. Proc. Natl. Acad. Sci. USA 2011, 108, 931-936. [CrossRef] [PubMed]

57. Gao, R.; Tan, C.D.; Baker, R.T.K. Ethene hydroformylation on graphite nanofiber supported rhodium catalysts. Catal. Today 2001, 65, 19-29. [CrossRef]

58. Yan, L.; Ding, Y.J.; Zhu, H.J.; Xiong, J.M.; Wang, T.; Pan, Z.D.; Lin, L.W. Ligand modified real heterogeneous catalysts for fixed-bed hydroformylation of propene. J. Mol. Catal. 2005, 234, 1-7. [CrossRef]

59. Li, Y.; Yunjie, D.; Jia, L.; Hejun, Z.; Liwu, L. Influence of Phosphine Concentration on Propene Hydroformylation over the $\mathrm{PPh}_{3}-\mathrm{Rh} / \mathrm{SiO}_{2}$ Catalyst. Chin. J. Catal. 2011, 32, 31-35.

60. Kim, T.; Celik, F.E.; Hanna, D.G.; Shylesh, S.; Werner, S.; Bell, A.T. Gas-Phase Hydroformylation of Propene over Silica-Supported $\mathrm{PPh}_{3}$-Modified Rhodium Catalysts. Top. Catal. 2011, 54, 299-307. [CrossRef]

61. Shylesh, S.; Hanna, D.; Molinar, A.; Koong, X.-Q.; Reimer, J.A.; Alexis, T. Bell, In Situ Formation of Wilkinson-Type Hydroformylation Catalysts: Insights into the Structure, Stability, and Kinetics of Triphenylphosphine- and Xantphos-Modified $\mathrm{Rh} / \mathrm{SiO}_{2}$. ACS Catalysis 2013, 3, 348-357. [CrossRef]

62. Li, X.; Ding, Y.; Jiao, G.; Li, J.; Lin, R.; Gong, L.; Yan, L.; Zhu, H. A new concept of tethered ligand-modified $\mathrm{Rh} / \mathrm{SiO}_{2}$ catalyst for hydroformylation with high stability. Appl. Catal. A 2009, 353, 266-270. [CrossRef]

63. Liu, J.; Yan, L.; Jiang, M.; Li, C.; Ding, Y. Effect of lengthening alkyl spacer on hydroformylation performance of tethered-phosphine modified $\mathrm{Rh} / \mathrm{SiO}_{2}$ catalyst. Chin. J. Catal. 2016, 37, 268-272. [CrossRef]

64. Liu, J.; Yan, L.; Ding, Y.; Jiang, M.; Dong, W.; Song, X.; Zhu, H. Promoting effect of Al on tethered ligand-modified $\mathrm{Rh} / \mathrm{SiO}_{2}$ catalysts for ethene hydroformylation. Appl. Catal. A 2015, 492, 127-132. [CrossRef]

65. Tana, M.; Ishikuro, Y.; Hosoi, Y.; Yamane, N.; Ai, P.; Zhang, P.; Yanga, G.; Wuc, M.; Yange, R.; Tsubaki, N. PPh functionalized $\mathrm{Rh} / \mathrm{rGO}$ catalyst for heterogeneous hydroformylation: Bifunctional reduction of graphene oxide by organic ligand. Chem. Eng. J. 2017, 330, 863-869. [CrossRef]

66. Trunschke, A.; Bigttcher, H.-C.; Fukuoka, A.; Ichikawa, M.; Miessner, H. Olefin hydroformylation and Selective Hydrogenation of Acetaldehyde on Mo-Promoted $\mathrm{Rh} / \mathrm{SiO}_{2}$ Catalysts Derived from Metal Salt and Heteronuclear Cluster Precursors. Catal. Lett. 1991, 8, 221-228. [CrossRef]

67. Lenarda, M.; Ganzerla, R.; Storaro, L.; Trovarelli, A.; Zanoni, R.; Kaspar, J. Vapour phase hydroformylation of ethene and propene catalyzed by a rhodium-containing aluminum pillared smectite clay. J. Mol. Catal. 1992, 72, 75-84. [CrossRef]

68. Lenarda, M.; Ganzerla, R.; Enzo, S.; Storaro, L.; Zanoni, R. Vapour phase propene hydroformylation catalyzed by the Rh/Al system on silica. J. Mol. Catal. 1993, 80, 105-116. [CrossRef]

69. Lenarda, M.; Ganzerla, R.; Storaro, L.; Zanoni, R. Catalysis by the Rh/B system Part 1. Vapour-phase hydroformylation of ethene at atmospheric pressure on Rh/B on silica. J. Mol. Catal. 1993, 78, 339-350. [CrossRef] 
70. Storaro, L.; Ganzerla, R.; Lenarda, M.; Zanoni, R.; Righini, G. Highly selective vapor phase propene hydroformylation catalyzed by Rh/B and Rh-Co/B systems on silica. J. Mol. Catal. A 1996, 112, 43-54. [CrossRef]

71. Navidi, N.; Thybaut, J.W.; Marin, G.B. Experimental investigation of ethene hydroformylation to propanal on Rh and Co based catalysts. Appl. Catal. A 2014, 469, 357-366. [CrossRef]

72. Hanaoka, T.; Arakawa, H.; Matsuzaki, T.; Sugi, Y.; Kanno, K.; Abe, Y. Ethene Hydroformylation and Carbon Monoxide Hydrogenation over Modified and Unmodified Silica Supported Rhodium Catalysts. Catal. Today 2000, 58, 271-280. [CrossRef]

73. Ni, B.; Wang, X. Face the Edges: Catalytic Active Sites of Nanomaterials. Adv. Sci. 2015, 2, 1-22. [CrossRef]

74. Freund, H.-J.; Libuda, J.; Bäumer, M.; Risse, T.; Carlsson, A. Cluster, Facets, and Edges: Site-Dependent Selective Chemistry on Model Catalysts. Chem. Rec. 2003, 3, 181-200. [CrossRef]

75. Hejral, U.; Franz, D.; Volkov, S.; Francoual, S.; Strempfer, J.; Stierle, A. Identification of a Catalytically Highly Active Surface Phase for CO Oxidation over PtRh Nanoparticles under Operando Reaction Conditions. Phys. Rev. Lett. 2018, 120, 126101-126106. [CrossRef]

76. Murzin, D.Y. Thermodynamic analysis of nanoparticle size effect on catalytic kinetics. Chem. Eng. Sci. 2009, 64, 1046-1052. [CrossRef]

77. Van Santen, R. Complementary Structure Sensitive and Insensitive Catalytic Relationships. Accounts Chem. Res. 2009, 42, 57-66. [CrossRef] [PubMed]

78. Sordelli, L.; Guidotti, M.; Andreatta, D.; Vlaic, G.; Psaro, R. Characterization and catalytic performances of alkali-metal promoted $\mathrm{Rh} / \mathrm{SiO} 2$ catalysts for propene hydroformylation. J. Mol. Catal. A 2003, 204-205, 509-518. [CrossRef]

79. Qiao, B.T.; Wang, A.Q.; Yang, X.F.; Allard, L.F.; Jiang, Z.; Cui, Y.T.; Liu, J.Y.; Li, J.; Zhang, T. Single-atom catalysis of $\mathrm{CO}$ oxidation using $\mathrm{Pt1} / \mathrm{FeO}_{\mathrm{x}}$. Nature Chem. 2011, 3, 634-641. [CrossRef]

80. Liang, J.; Yu, Q.; Yang, X.; Zhang, T.; Li, J. A systematic theoretical study on FeOx-supported single-atom catalysts: M1/FeOx for CO oxidation. Nano Res. 2018, 11, 1599-1611. [CrossRef]

81. Flytzani-Stephanopoulos, M.; Gates, B.C. Atomically Dispersed Supported Metal Catalysts. Annu. Rev. Chem. Biomol. Eng. 2012, 3, 545-574. [CrossRef]

82. Chen, F.; Jiang, X.; Zhang, L.; Lang, R.; Qiao, B. Single-atom catalysis: Bridging the homo- and heterogeneous catalysis. Chin. J. Catal. 2018, 39, 893-898. [CrossRef]

83. Liu, J.Y. Catalysis by Supported Single Metal Atoms. ACS Catal. 2017, 7, 34-59. [CrossRef]

84. Yang, X.-F.; Wang, A.; Qiao, B.; Li, J.; Liu, J.; Zhang, T. Single-Atom Catalysts: A New Frontier in Heterogeneous Catalysis. Acc. Chem. Res. 2013, 46, 1740-1748. [CrossRef]

85. Bayram, E.; Lu, J.; Aydin, C.; Browning, N.D.; Özkar, S.; Finney, E.; Gates, B.C.; Finke, R.G. Agglomerative Sintering of an Atomically Dispersed Ir1/Zeolite Y Catalyst: Compelling Evidence Against Ostwald Ripening but for Bimolecular and Autocatalytic Agglomeration Catalyst Sintering Steps. ACS Catal. 2015, 5, 3514-3527. [CrossRef]

86. Qin, R.; Liu, P.; Fu, G.; Zheng, N. Single-Atom Catalysts: Synthetic Strategies and Electrochemical Applications. Small Methods 2018, 2, 1-21.

87. Choi, C.H.; Kim, M.; Kwon, H.C.; Cho, S.J.; Yun, S.; Kim, H.-T.; Mayrhofer, K.J.J.; Kim, H.; Choi, M. Tuning selectivity of electrochemical reactions by atomically dispersed platinum catalyst. Nature Commun. 2016, 7, 1-9. [CrossRef] [PubMed]

88. Yang, W.; Zhao, M.; Ding, X.; Ma, K.; Wu, C.; Gates, I.D.; Gao, Z. The effect of coordination environment on the kinetic and thermodynamic stability of single-atom iron catalysts. Phys. Chem. Chem. Phys. 2020, 22, 3983-3989. [CrossRef] [PubMed]

89. Lang, R.; Li, T.; Matsumura, D.; Miao, S.; Ren, Y.; Cui, Y.-T.; Tan, Y.; Qiao, B.; Li, L.; Wang, A.; et al. Hydroformylation of Olefins by a Rhodium Single-Atom Catalyst with Activity Comparable to $\mathrm{RhCl}\left(\mathrm{PPh}_{3}\right)_{3}$. Angew. Chem. Int. Ed. 2016, 55, 16054-16058. [CrossRef] [PubMed]

90. Wang, L.; Zhang, W.; Wang, S.; Gao, Z.; Luo, Z.; Wang, X.; Zeng, R.; Li, A.; Li, H.; Wang, M.; et al. Atomic-level insights in optimizing reaction paths for hydroformylation reaction over $\mathrm{Rh} / \mathrm{CoO}$ single-atom catalyst. Nat. Commun. 2016, 7, 14036. [CrossRef]

91. Oyama, S.T. Novel catalysts for advanced hydroprocessing: Transition metal phosphides. J. Catal. 2003, 216, 343-352. [CrossRef] 
92. Oyama, S.T.; Gott, T.; Zhao, H.; Lee, Y.-K. Transition metal phosphide hydroprocessing catalysts: A review. Catal. Today 2009, 143, 94-107. [CrossRef]

93. Kanda, Y.; Uemichi, Y. Noble Metal Phosphides as New Hydrotreating Catalysts: Highly Active Rhodium Phosphide Catalyst. J. Jpn. Pet. Inst. 2015, 58, 20-32. [CrossRef]

94. Prins, R.; Bussell, M. Metal Phosphides: Preparation, Characterization and Catalytic Reactivity. Catal. Lett. 2012, 142, 1413-1436. [CrossRef]

95. Wang, X.; Clark, P.; Oyama, S.T. Synthesis, Characterization, and Hydrotreating Activity of Several Iron Group Transition Metal Phosphides. J. Catal. 2002, 208, 321-331. [CrossRef]

96. Kanda, Y.; Temma, C.; Nakata, K.; Kobayashi, T.; Sugioka, M.; Uemichi, Y. Preparation and performance of noble metal phosphides supported on silica as new hydrodesulfurization catalysts. Appl. Catal. A 2010, 386, 171-178. [CrossRef]

97. Kanda, Y.; Matsukura, Y.; Sawada, A.; Sugioka, M.; Uemichi, Y. Low-temperature synthesis of rhodium phosphide on alumina and investigation of its catalytic activity toward the hydrodesulfurization of thiophene. Appl. Catal. A 2016, 515, 25-31. [CrossRef]

98. Bowker, R.H.; Smith, M.C.; Carrillo, B.A.; Bussell, M.E. Synthesis and Hydrodesulfurization properties of Noble metal phosphides: Ruthenium and palladium. Top. Catal. 2012, 55, 999-1009. [CrossRef]

99. Hayes, J.R.; Bowker, R.H.; Gaudette, A.F.; Smith, M.C.; Moak, C.E.; Nam, C.Y.; Pratum, T.K.; Bussell, M. Hydrodesulfurization properties of rhodium phosphide: Comparison with rhodium metal and sulfide catalysts. J. Catal. 2010, 276, 249-258. [CrossRef]

100. Habas, S.; Baddour, F.; Ruddy, D.; Nash, C.P.; Wang, J.; Pan, M.; Hensley, J.E.; A Schaidle, J. A Facile Molecular Precursor Route to Metal Phosphide Nanoparticles and Their Evaluation as Hydrodeoxygenation Catalysts. Chem. Mat. 2015, 27.22, 7580-7592. [CrossRef]

101. Stinner, C.; Prins, R.; Weber, T. Binary and Ternary Transition-Metal Phosphides as HDN Catalysts. J. Catal. 2001, 202, 187-194. [CrossRef]

102. Rupflin, L.A.; Boscagli, C.; Schunk, S.A. Platinum Group Metal Phosphides as Efficient Catalysts in Hydroprocessing and Syngas-Related Catalysis. Catalysts 2018, 8, 122. [CrossRef]

103. Rupflin, L.A.; Mormul, J.; Lejkowski, M.; Titlbach, S.; Papp, R.; Gläser, R.; Dimitrakopoulou, M.; Huang, X.; Trunschke, A.; Willinger, M.G.; et al. Platinum Group Metal Phosphides as Heterogeneous Catalysts for the Gas-Phase Hydroformylation of Small Olefins. ACS Catal. 2017, 7, 3584-3590. [CrossRef]

104. Schunk, S.A.; Alvarado Rupflin, L.; Mormul, J.; Lejkowski, M.; Titlbach, S.; Papp, R.; Gläser, R.; Dimitrakopoulou, M.; Huang, X.; Trunschke, A.; et al. New horizons for heterogeneously catalyzed $\mathrm{CO}$ insertion reactions: From molecular sieves to extended complex solids. DGMK Tagungsbericht 2007, 125-128.

105. Duan, H.; Li, D.; Tang, Y.; He, Y.; Ji, S.; Wang, R.; Lv, H.; Lopes, P.P.; Paulikas, A.P.; Li, H.; et al. High Performance $\mathrm{Rh}_{2} \mathrm{P}$ Electrocatalyst for Efficient Water Splitting. J. Am. Chem. Soc. 2017, 139, 5494-5502. [CrossRef]

106. Zumbusch, M. Über die Strukturen des Uransubsulfids und der Subphosphide des Iridiums und Rhodiums. Zeitschrift Für Anorganische Und Allgemeine Chemie 1940, 243, 322-329. [CrossRef]

107. El Ghadraoui, E.; Guerin, R.; Sergent, M. Diphosphure de Trirhodium $\mathrm{Rh}_{3} \mathrm{P}_{2}$ : Premier Exemple d'une Structure Lacunaire Ordonnee de Type anti-PbFCl. Acta Cryst. C 1983, 39, 1493-1494. [CrossRef]

108. Rundqvist, S.; Hede, A.; Varde, E.; Westin, G. X-Ray Investigation on Rhodium Phosphides. The Crystal Structure of Rh4P3. Acta Chem. Scand. 1960, 14, 893-902. [CrossRef]

109. Kjekshus, A.; Nolander, B.; Klæboe, P.; Cyvin, S.J.; Lagerlund, I.; Ehrenberg, L. On the Properties of Binary Compounds with the CoSb2 Type Crystal Structure. Acta Chem. Scan. 1971, 25, 411-422. [CrossRef]

110. Rundqvist, S.; Ersson, N. Structure and bonding in skutterudite-type phosphides. Arkiv foer Kemi 1969, 30, 103.

111. Okamoto, H. The P-Rh (phosphorus-rhodium) system. Bull. Alloy Phase Diagr. 1990, 11, 415-417. [CrossRef]

112. Persson, K. Materials Data on $\mathrm{PRh}_{2}$ (SG:225) by Materials Project. Data Explor. 2014. [CrossRef]

113. Muetterties, E.L.; Sauer, J.C. Catalytic Properties of Metal Phosphides. I. Qualitative Assay of Catalytic Properties. J. Am. Chem. Soc. 1974, 96, 3410-3415. [CrossRef]

114. Alvarado Rupflin, L. Rhodiumphosphid $\mathrm{Rh}_{2} \mathrm{P}$ als neues Katalysatormaterial für die Aktivierung von Kohlenstoffmonoxid. Ph.D. Thesis, Universität Leipzig, Leipzig, Germany, 2016. 
115. Dyson, P.J.; Jessop, P.G. Solvent effects in catalysis: Rational improvements of catalysts via manipulation of solvent interactions. Catal. Sci. Technol. 2016, 6, 3302-3316. [CrossRef]

116. Kulyaev, P.O.; Pidko, E.A. Operando Modeling of Multicomponent Reactive Solutions in Homogeneous Catalysis: From Non-standard Free Energies to Reaction Network Control. ChemCatChem 2020, 12, 795-802. [CrossRef]

117. Bazhenov, A.S.; Lefferts, L.; Honkala, K. Adsorption and Activation of Water on Cuboctahedral Rhodium and Platinum Nanoparticles. J. Phys. Chem. C 2017, 121, 4324-4331. [CrossRef]

118. Welton, T. Room-Temperature Ionic Liquids. Solvents for Synthesis and Catalysis. Chem. Rev. 1999, 99, 2071-2084. [CrossRef] [PubMed]

119. Riisager, R.; Fehrmann, M.; Haumann, P. Wasserscheid, Supported ionic liquids: Versatile reaction and separation media. Top. Catal. 2006, 40, 91-102. [CrossRef]

120. Riisager, A.; Fehrmann, R.; Haumann, M.; Wasserscheid, P. Supported Ionic Liquid Phase (SILP) Catalysis: An Innovative Concept for Homogeneous Catalysis in Continuous Fixed-Bed Reactors. Eur. J. Inorg. Chem. 2006, 695-706. [CrossRef]

121. Haumann, M.; Riisager, A. Hydroformylation in Room Temperature Ionic Liquids (RTILs): Catalyst and Process Developments. Chem. Rev. 2008, 108, 1474-1497. [CrossRef]

122. Van Doorslaer, C.; Wahlen, J.; Mertens, P.; Binnemans, K.; De Vos, D. Immobilization of molecular catalysts in supported ionic liquid phases. Dalton Trans. 2010, 39, 8377-8390. [CrossRef]

123. Steinrück, H.-P.; Libuda, J.; Wasserscheid, P.; Cremer, T.; Kolbeck, C.; Laurin, M.; Maier, F.; Sobota, M.; Schulz, P.; Stark, M. Surface Science and Model Catalysis with Ionic Liquid-Modified Materials. Adv. Mater. 2011, 23, 2571-2587. [CrossRef]

124. Riisager, A.; Wasserscheid, P.; Van Hal, R.; Fehrmann, R. Continuous fixed-bed gas-phase hydroformylation using supported ionic liquid-phase (SILP) Rh catalysts. J. Catal. 2003, 219, 452-455. [CrossRef]

125. Riisager, A.; Fehrmann, R.; Flicker, S.; Van Hal, R.; Haumann, M.; Wasserscheid, P. Very Stable and Highly Regioselective Supported Ionic-Liquid-Phase (SILP) Catalysis: Continuous-Flow Fixed-Bed Hydroformylation of Propene. Angew. Chem. Int. Ed. 2005, 44, 815-819. [CrossRef]

126. Riisager, A.; Fehrmann, R.; Haumann, M.; Gorle, B.S.K.; Wasserscheid, P. Stability and Kinetic Studies of Supported Ionic Liquid Phase Catalysts for Hydroformylation of Propene. Ind. Eng. Chem. Res. 2005, 44, 9853-9859. [CrossRef]

127. Hanna, D.G.; Shylesh, S.; Werner, S.; Bell, A.T. The kinetics of gas-phase propene hydroformylation over a supported ionic liquid-phase (SILP) rhodium catalyst. J. Catal. 2012, 292, 166-172. [CrossRef]

128. Shylesh, S.; Hanna, D.; Werner, S.; Bell, A.T. Factors Influencing the Activity, Selectivity, and Stability of Rh-Based Supported Ionic Liquid Phase (SILP) Catalysts for Hydroformylation of Propene. ACS Catal. 2012, 2, 487-493. [CrossRef]

129. Haumann, M.; Dentler, K.; Joni, J.; Riisager, A.; Wasserscheid, P. Continuous Gas-Phase Hydroformylation of 1-Butene using Supported Ionic Liquid Phase (SILP) Catalysts. Adv. Synth. Catal. 2007, 349, 425-431. [CrossRef]

130. Haumann, M.; Jakuttis, M.; Werner, S.; Wasserscheid, P. Supported ionic liquid phase (SILP) catalyzed hydroformylation of 1-butene in a gradient-free loop reactor. J. Catal. 2009, 263, 321-327. [CrossRef]

131. Jakuttis, M.; Schönweiz, A.; Werner, S.; Franke, R.; Wiese, K.-D.; Haumann, M.; Wasserscheid, P. Rhodium-Phosphite SILP Catalysis for the Highly Selective Hydroformylation of Mixed C4 Feedstocks. Angew. Chem. Int. Ed. 2011, 50, 4492-4495. [CrossRef]

132. Weiß, A.; Giese, M.; Lijewski, M.; Franke, R.; Wasserscheid, P.; Haumann, M. Modification of nitrogen doped carbon for SILP catalyzed hydroformylation of ethylene. Catal. Sci. Technol. 2017, 7, 5562-5571. [CrossRef]

133. Ha, H.N.T.; Duc, D.T.; Dao, T.V.; Le, T.M.; Riisager, A.; Fehrmann, R. Characterization and parametrical study of Rh-TPPTS supported ionic liquid phase (SILP) catalysts for ethylene hydroformylation. Catal. Commun. 2012, 25, 136-141. [CrossRef]

(C) 2020 by the authors. Licensee MDPI, Basel, Switzerland. This article is an open access article distributed under the terms and conditions of the Creative Commons Attribution (CC BY) license (http://creativecommons.org/licenses/by/4.0/). 